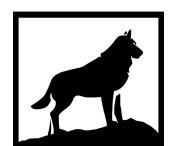

Michigan Technological

18 85 University
Michigan Technological University Digital Commons @ Michigan Tech

\title{
ACUTE CARDIOVASCULAR RESPONSES TO NOVEL COMBINATIONS OF RESISTANCE AND AEROBIC EXERCISE
}

Travis Wakeham

Michigan Technological University, twakeham@mtu.edu

Copyright 2018 Travis Wakeham

\section{Recommended Citation}

Wakeham, Travis, "ACUTE CARDIOVASCULAR RESPONSES TO NOVEL COMBINATIONS OF RESISTANCE AND AEROBIC EXERCISE", Open Access Master's Thesis, Michigan Technological University, 2018.

https://doi.org/10.37099/mtu.dc.etdr/629

Follow this and additional works at: https://digitalcommons.mtu.edu/etdr

Part of the Exercise Physiology Commons 


\title{
ACUTE CARDIOVASCULAR RESPONSES TO NOVEL COMBINATIONS OF RESISTANCE AND AEROBIC EXERCISE
}

\author{
By
}

Travis R. Wakeham

\begin{abstract}
A THESIS
Submitted in partial fulfillment of the requirements for the degree of MASTER OF SCIENCE

In Biological Sciences
\end{abstract}

MICHIGAN TECHNOLOGICAL UNIVERSITY

2018

(C) 2018 Travis R. Wakeham 
This thesis has been approved in partial fulfillment of the requirements for the Degree of MASTER OF SCIENCE in Biological Sciences.

\author{
Department of Biological Sciences
}

\author{
Thesis Advisor: $\quad$ Dr. John J. Durocher \\ Committee Member: Dr. Steven J. Elmer \\ Committee Member: Dr. Min Wang \\ Department Chair: Dr. Chandrashekhar P. Joshi
}




\section{Table of Contents}

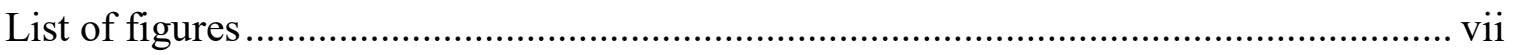

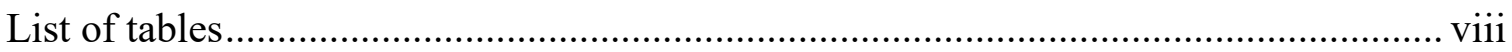

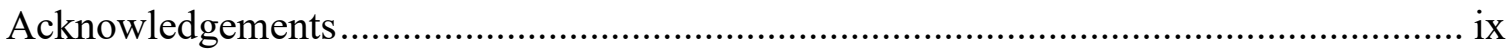

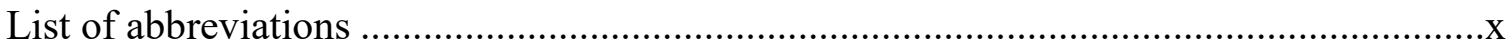

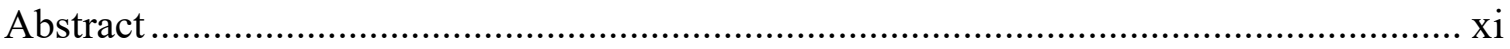

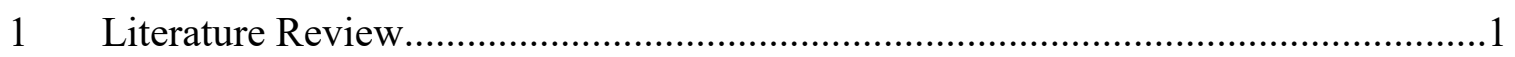

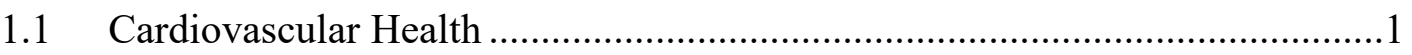

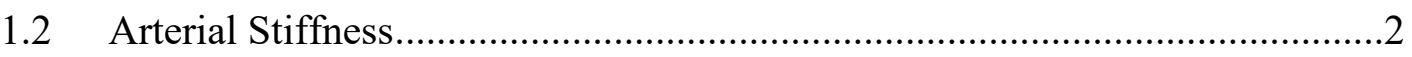

1.2.1 Measurement Techniques .........................................................2

1.3 Cardiovascular Responses to Exercise ………...............................................

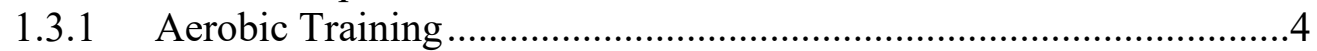

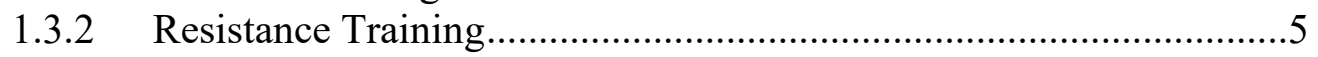

1.3.3 Eccentric v. Concentric Training ....................................................

1.4 Summary and Hypothesis............................................................................

2 Study 1: The Influence of Resistance and Aerobic Exercise Order on Acute Arterial

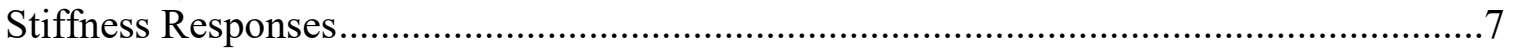

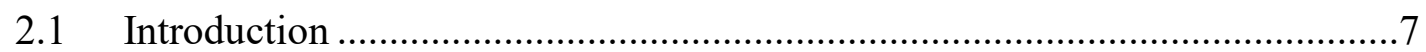

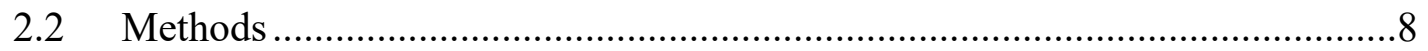

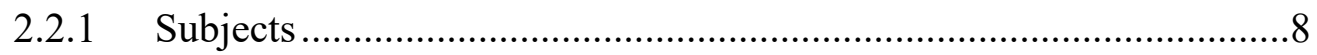

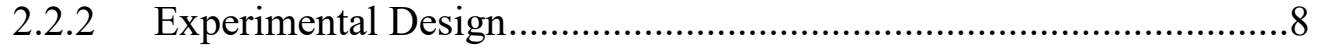

2.2.3 Resistance Training......................................................................

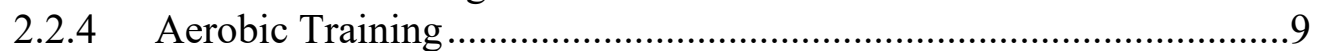

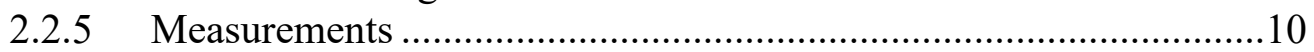

2.2.6 Statistical Analysis.......................................................................

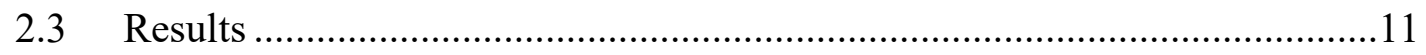

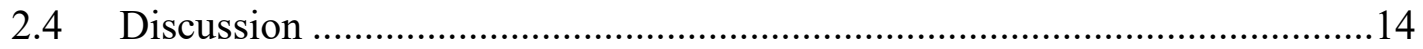

3 Study 2: Post-Exercise Arterial Stiffness Responses Are Similar After Acute

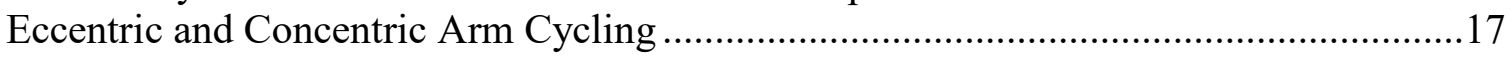

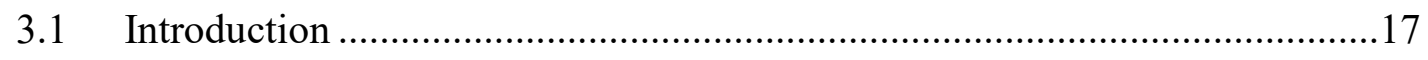

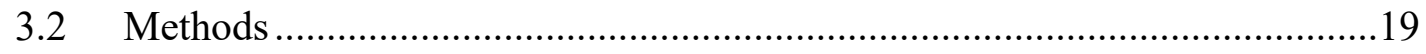

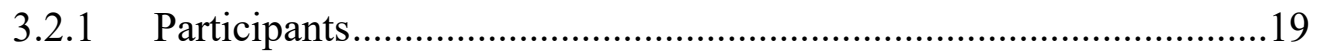

3.2.2 Pre-Experimental Assessments......................................................21 


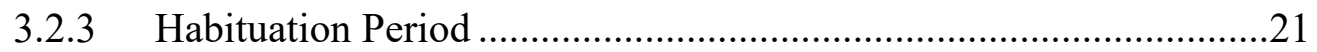

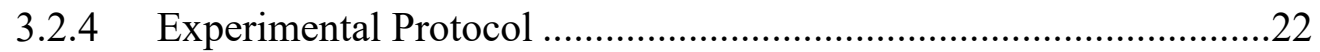

3.2.5 Cardiovascular Parameters...........................................................22

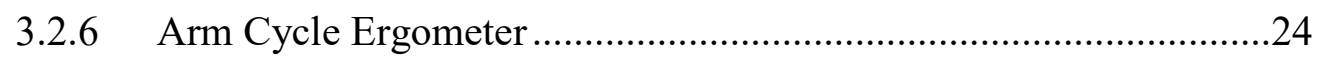

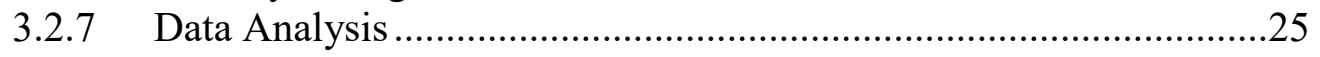

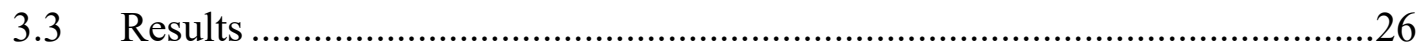

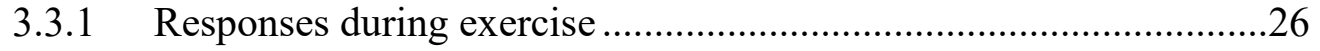

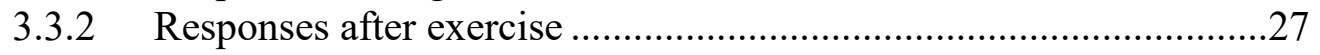

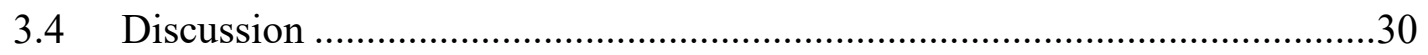

$4 \quad$ Summary, Limitations, and Future Directions ........................................................33

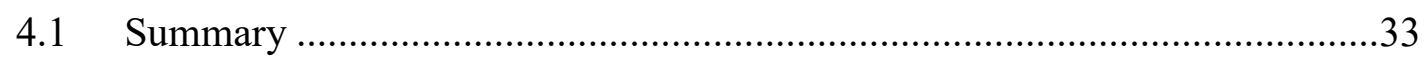

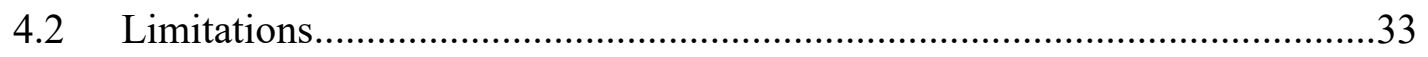

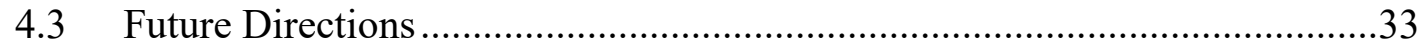

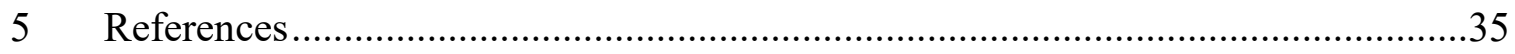

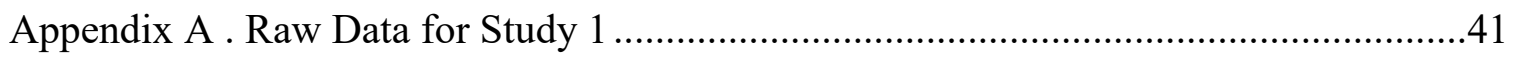

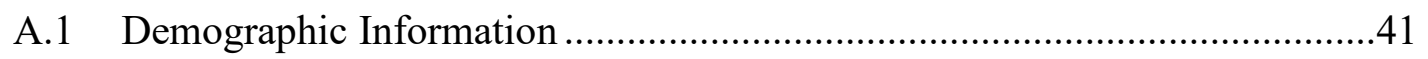

A.2 Target Heart Rate and 10 RM Strength Test ...............................................42

A.3 Brachial Hemodynamics: RA Pre-Exercise ………………...........................43

A.4 Brachial Hemodynamics: AR Pre-Exercise …………………………….......43

A.5 Brachial Hemodynamics: RA Mid-Exercise ...................................................4

A.6 Brachial Hemodynamics: AR Mid-Exercise ..................................................4

A.7 Brachial Hemodynamics: RA 0 Minutes Post-Exercise...................................45

A.8 Brachial Hemodynamics: AR 0 Minutes Post-Exercise....................................45

A.9 Brachial Hemodynamics: RA 30 Minutes Post-Exercise..................................46

A.10 Brachial Hemodynamics: AR 30 Minutes Post-Exercise..................................46

A.11 Pulse Wave Analysis Trial 1: RA Pre-Exercise ..............................................4

A.12 Pulse Wave Analysis Trial 2: RA Pre-Exercise …………………………......4

A.13 Pulse Wave Analysis Trial 1: AR Pre-Exercise ...............................................

A.14 Pulse Wave Analysis Trial 2: AR Pre-Exercise ………………………….....48

A.15 Pulse Wave Analysis Trial 1: RA Mid-Exercise .............................................49

A.16 Pulse Wave Analysis Trial 2: RA Mid-Exercise .............................................49

A.17 Pulse Wave Analysis Trial 1: AR Mid-Exercise .............................................50 
A.18 Pulse Wave Analysis Trial 2: AR Mid-Exercise ..........................................50

A.19 Pulse Wave Analysis Trial 1: RA 0 Minutes Post-Exercise ............................51

A.20 Pulse Wave Analysis Trial 2: RA 0 Minutes Post-Exercise ………………....51

A.21 Pulse Wave Analysis Trial 1: AR 0 Minutes Post-Exercise ............................52

A.22 Pulse Wave Analysis Trial 2: AR 0 Minutes Post-Exercise ...........................52

A.23 Pulse Wave Analysis Trial 1: RA 30 Minutes Post-Exercise …………….....53

A.24 Pulse Wave Analysis Trial 2: RA 30 Minutes Post-Exercise ……………......53

A.25 Pulse Wave Analysis Trial 1: AR 30 Minutes Post-Exercise ……………......54

A.26 Pulse Wave Analysis Trial 2: AR 30 Minutes Post-Exercise …………….....54

A.27 Pulse Wave Velocity: RA Pre-Exercise …………………………………....55

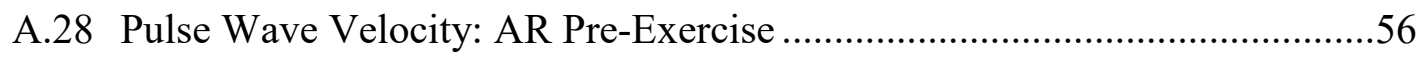

A.29 Pulse Wave Velocity: RA Mid-Exercise.....................................................57

A.30 Pulse Wave Velocity: AR Mid-Exercise .......................................................58

A.31 Pulse Wave Velocity: RA 0 Min Post-Exercise............................................59

A.32 Pulse Wave Velocity: AR 0 Min Post-Exercise................................................60

A.33 Pulse Wave Velocity: RA 30 Min Post-Exercise ...........................................61

A.34 Pulse Wave Velocity: AR 30 Min Post-Exercise ............................................62

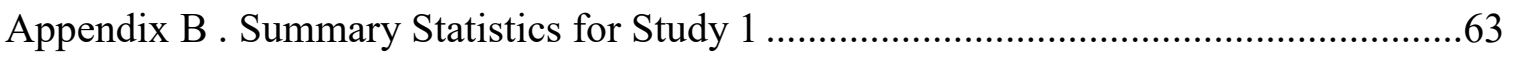

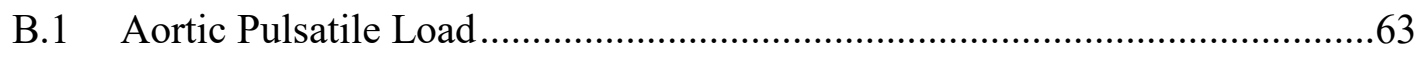

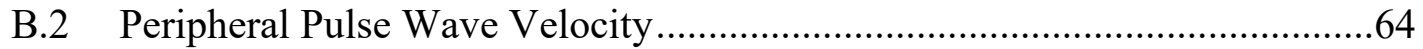

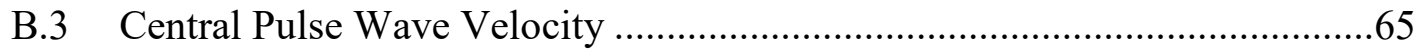

B.4 Normalized Central Pulse Wave Velocity.......................................................66

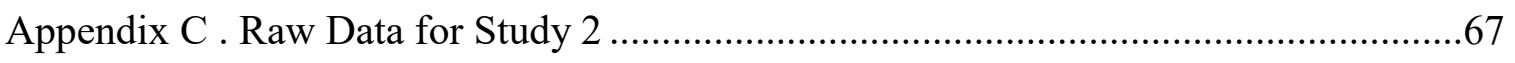

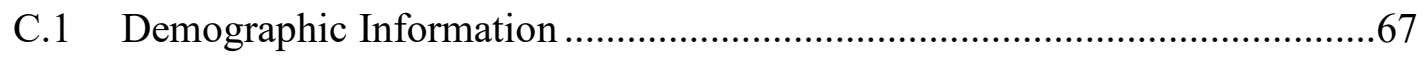

C.2 Brachial Hemodynamics: Pre-Exercise _......................................................68

C.3 Brachial Hemodynamics: 10 min Post-Exercise ............................................69

C.4 Brachial Hemodynamics: 30 min Post-Exercise ............................................70

C.5 Pulse Wave Analysis Trial 1: Pre-Exercise...................................................71

C.6 Pulse Wave Analysis Trial 1: 10 min Post-Exercise ......................................72

C.7 Pulse Wave Analysis Trial 1: 30 min Post-Exercise ........................................73

C.8 Pulse Wave Analysis Trial 2: Pre-Exercise..................................................74 
C.9 Pulse Wave Analysis Trial 2: 10 min Post-Exercise ...................................75

C.10 Pulse Wave Analysis Trial 2: 30 min Post-Exercise .....................................76

C.11 Pulse Wave Velocity: Pre-Exercise.............................................................. 77

C.12 Pulse Wave Velocity: 10 min Post-Exercise ...............................................78

C.13 Pulse Wave Velocity: 30 min Post-Exercise .................................................79

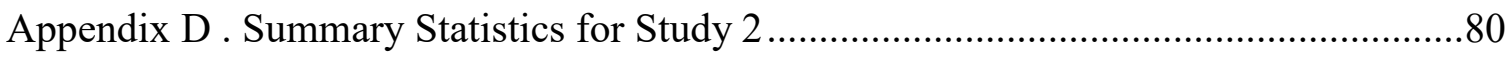

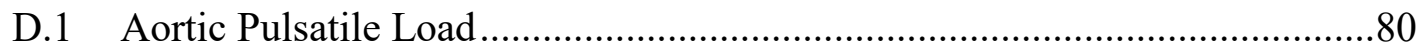

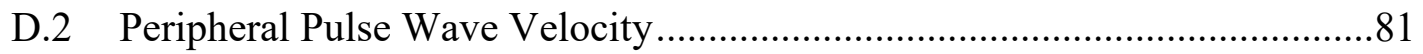

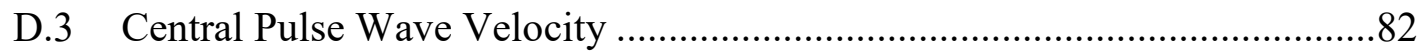




\section{List of figures}

Figure 1: Conceptual diagram describing the protocol for each testing session.

Figure 2: Aortic pulsatile load (aPL) before, between, and after exercise. Time effect: $P<$

0.05 .

Figure 3: Peripheral (Panel A), central (Panel B), and normalized central (Panel C) pulse wave velocity responses $30 \mathrm{~min}$ post-exercise. ${ }^{*} P<0.05$ vs. order.

Figure 4: Motor-driven ergometer for eccentric arm cycling. The handles are driven in a backwards rotation as indicated by the grey arrows, and the participant resists the turning of the handles as indicated by the black arrow

Figure 5: Eccentric arm cycling results in significantly greater production of work and power at a predetermined heart rate (HR) as an absolute value or percentage of the participant's age-predicted maximal value. Ratings of perceived exertion (RPE) were similar. ${ }^{*} \mathrm{p}<0.05$ between groups

Figure 6: Peripheral (i.e. arm) pulse wave velocity (pPWV) was significantly decreased at $10 \mathrm{~min}$ post-exercise in both groups, but returned to baseline at $30 \mathrm{~min}$ post (Panel A). Central (i.e. aortic) pulse wave velocity (cPWV) was not changed from baseline at 10 or 30 min post-exercise for either group (Panel B). ${ }^{*} \mathrm{p}<0.05$ vs.

pre-exercise baseline 


\section{List of tables}

Table 1: Participant demographics, anthropometrics, and resting seated cardiovascular

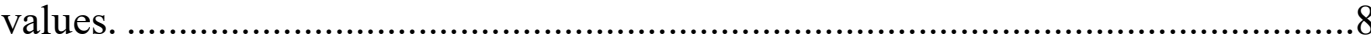

Table 2: Baseline values between two testing sessions...................................................11

Table 3: Participant demographic, anthropometric, and physiological characteristics. ....20

Table 4: Cardiovascular responses to acute exercise session. .........................................29 


\section{Acknowledgements}

First, I would like to thank my advisor, Dr. John. Durocher. You have taught me many lessons throughout the years, but the greatest one is how to be resilient. I sincerely appreciate all the time and energy you have provided me, without your guidance, this work would not have been possible. I feel extremely fortunate to work just a few doors down from you now. I would like to thank Dr. Steven Elmer for his collaboration and expertise in exercise physiology. You helped me to become a better research, teacher, and professional throughout this experience. I would also like to thank Dr. Min Wang for assisting with the statistical design and analysis of this work. You have made me much more comfortable with statistics.

I would like to thank all of the participants for their enthusiastic efforts during the exercise training interventions. I also would like to thank all of the research assistants in the Human Performance, and Clinical and Applied Human Physiology Laboratories for their assistance with the data collection, especially: Morty Harwood, Ryan Dixon, Hannah Marti, and Ian Greenlund.

I would like to thank the Department of Biological Sciences for providing me funding and for their continual support. Finally, I would like to thank my family and friends for always providing me with the support I need to pursue my higher education. I would not be where I am today without all of your encouragement. 


\section{List of abbreviations}

aDAP aortic diastolic arterial pressure

AIx aortic augmentation index

$\begin{array}{ll}\text { AIx@75 } & \text { aortic augmentation index normalized to } 75 \text { beats } / \mathrm{min} \\ \text { aMAP } & \text { aortic mean arterial pressure } \\ \text { aPP } & \text { aortic pulse pressure } \\ \text { aSAP } & \text { aortic systolic arterial pressure } \\ \text { BMI } & \text { body mass index } \\ \text { DAP } & \text { diastolic arterial pressure } \\ \text { HR } & \text { heart rate } \\ \text { MAP } & \text { mean arterial pressure } \\ \text { PL } & \text { pulsatile load } \\ \text { PP } & \text { pulse pressure } \\ \text { PWA } & \text { pulse wave analysis } \\ \text { PWV } & \text { pulse wave velocity } \\ \text { SAP } & \text { systolic arterial pressure }\end{array}$




\section{Abstract}

Cardiovascular disease (CVD) is the leading cause of death globally. One of the most effective forms of prevention and treatment is physical activity. However, recent studies have suggested that resistance exercise can increase arterial stiffness. Maintaining adequate strength is critical for performing activities of daily living, occupational-related tasks, and sport movements. The purpose of this project was to determine if novel combinations of resistance and aerobic exercise could offer musculoskeletal benefits without adverse cardiovascular consequences. In Study 1, we examined the effect of order (i.e. aerobic before resistance, or resistance before aerobic) on arterial stiffness when combining these exercise modes in a single training session. In Study 2, we compared the effects of acute eccentric and concentric arm cycling on central and peripheral arterial stiffness. Eccentric arm cycling is a unique combination of resistance and aerobic exercise. We hypothesized that these novel combinations of resistance and aerobic exercise would not cause arterial stiffening as observed in resistance exercise alone. In Study 1, we concluded performing resistance before aerobic to be the more beneficial exercise order in terms of arterial stiffness. In Study 2, we found that eccentric arm cycling reduces arterial stiffness in the arm, but not centrally. Collectively, our results suggest that the key to reducing the negative effects of resistance exercise on arterial function is to combine it with aerobic exercise, either first within a single session or simultaneously. 


\section{Literature Review}

The literature review of this thesis will provide a general framework to better understand the effects of combined resistance and aerobic exercise on arterial function. First, an overview of cardiovascular health will provide context to the burden of cardiovascular disease and the importance of preventative behaviors. Then, the utility of arterial stiffness an indicator of cardiovascular health will be defined. Additionally, specific measurement techniques used to assess arterial stiffness will be explained. The cardiovascular responses, with an emphasis on arterial stiffness, to different exercise modalities (aerobic, resistance, eccentric, and concentric) will be discussed. Finally, the current literature will be summarized in relation to the two presented research studies.

\subsection{Cardiovascular Health}

Cardiovascular disease (CVD) one of the largest health and economic burdens around the world (Mozaffarian et al., 2015). There are a variety of risk factors that influence the prevalence of CVD, such as: physical inactivity, hypertension, obesity, high blood lipids, diabetes mellitus, and family history (Mozaffarian et al., 2015). Although many agencies are working to reduce the prevalence of CVD, it only reduced modestly between 1999 and 2012 (Booth et al., 2017).

Increased physical activity is one behavioral modification that can be used to prevent CVD. Physical activity is associated with reducing the risk of CVD and all-cause mortality by nearly a third (Nocon et al., 2008). Physical activity and exercise can improve body composition and reduce other risk factors, such as blood pressure. This may be attributed to positive adaptations within the cardiovascular system, specifically changes to the 
vasculature. Improvements in endothelium function and vascular remodeling have been observed following exercise training (Green, Maiorana, O'Driscoll, \& Taylor, 2004), which can reduce stiffening of arteries.

\subsection{Arterial Stiffness}

Arterial stiffness occurs when arteries lose their ability to expand and recoil during the cardiac cycle. Degradation of the elastic fibers occurs naturally through aging, but other factors can either slow or quicken the process. Although there are genetic factors, lifestyle and pathologies (i.e. hypertension, diabetes mellitus, etc.) often contribute to arterial stiffness (Zieman, Melenovsky, \& Kass, 2005). This can cause reflected pressure waveforms from bifurcations in the vasculature to return to the heart early, which then augments aortic blood pressure and potentially induces damage.

\subsubsection{Measurement Techniques}

Arterial stiffness can be assessed noninvasively through applanation tonometry in clinical and research settings. This technique involves placing a small pressure transducer onto a pulse site. The blood vessel is flattened against hard underlying tissue and the pressure waveform at the site is recorded. Pulse wave analysis (PWA) and pulse wave velocities (PWV) can be measured using this technique.

The process of PWA includes estimating aortic pulse pressures based on the measured pressure waveform characteristics and a validated transfer function (Chen et al., 1997). Augmentation index (AIx) can also be calculated by determining the percentage of aortic pulse pressure that is caused by a reflected waveform returning to the heart. AIx has 
been shown to be directly related to arterial stiffness (Laurent et al., 2006). Heart rate can influence the value of AIx, therefore, it is best practice to normalize for the heart rate of 75 beats per minute (AIx@75). Higher values of AIx@75 indicate increased systemic arterial stiffness.

Arterial stiffness can also be assessed regionally using PWV. The process includes measuring two different pulse sites along region of interest (e.g. carotid and radial to assess the arm) and measuring their transit time by gating them to the R-wave of an electrocardiogram. Higher values of pulse wave velocity indicate increased arterial stiffness within that region.

Although AIx and PWV are valuable measures of arterial stiffness, they are not interchangeable. One can be affected independently of the other (Kelly, Millasseau, Ritter,

\& Chowienczyk, 2001). AIx is influenced by integrity of smaller vasculature, whereas PWV is primarily a result of the elasticity of large arteries (Kelly et al., 2001). Measures of AIx and PWV can be taken at rest or pre and post interventions (e.g. exercise) to determine changes in arterial function.

\subsection{Cardiovascular Responses to Exercise}

The cardiovascular system serves a key role in maintaining homeostasis within the human body. Physical activity is one of the most common everyday stressors that stimulate the system to respond. In order to meet the increased metabolic demand to sustain activity, heart rate and blood pressure throughout the vasculature become augmented in order to deliver required oxygen and nutrients to the active tissue. 
The changes within the cardiovascular system are partially regulated by the nervous system. During moderately intense exercise, sympathetic neural activity is increased and parasympathetic neural activity is inhibited. The increase in sympathetic activity, increases cardiac output. In addition, vasoconstriction occurs within the active muscle mass to promote blood flow. Systolic blood pressure increases linearly with dynamic exercise intensity and diastolic tends to decrease (Laughlin, 1999). In contrast, resistance exercise typically causes larger increases in pulse pressure that are oscillatory and dependent on the phase of the exercise (Laughlin, 1999).

Although the changes induced by exercise are well understood, different types of exercise elicit different responses. Therefore, measuring and understanding these physiological differences is important when prescribing exercise, especially in clinical populations.

\subsubsection{Aerobic Training}

Aerobic training involves physical activity activities such as walking, running, cycling, and swimming. It is activity that can be sustained for extended periods of time while consuming oxygen to meet the energy demands. A recent meta-analysis concluded that chronic aerobic exercise training improved both AIx and PWV significantly (Ashor, Lara, Siervo, Celis-Morales, \& Mathers, 2014). Moreover, another meta-analysis found that aerobic exercise had very little acute effects on arterial stiffness (Pierce, Doma, \& Leicht, 2018). However, the results of this meta-analysis did note significant diversity within the aerobic exercise studies. Studies that have examined direct differences between aerobic and resistance exercise suggest that aerobic exercise provides a more beneficial 
stimulus to the cardiovascular system. (Collier et al., 2010; Heffernan, Collier, Kelly, Jae, \& Fernhall, 2007).

\subsubsection{Resistance Training}

In contrast to aerobic training, the effects of resistance exercise on arterial stiffness have been debated. One meta-analysis of 42 randomized, controlled studies found that resistance training had no effect on arterial stiffness (Ashor et al., 2014). Likewise, another review of 17 randomized controlled studies reported that resistance exercise did not augment arterial stiffness (Li, Hanssen, et al., 2015). In contrast, an earlier meta-analysis of eight randomized controlled clinical trials found that resistance training actually increased arterial stiffness (Miyachi, 2013).

Although there have been contrasting findings from studies on the effects of chronic resistance exercise, a recent meta-analysis of 45 acute exercise studies concluded that both carotid-femoral PWV and AIx increases following resistance exercise (Pierce et al., 2018).

\subsubsection{Eccentric v. Concentric Training}

Few studies have examined at the different muscle actions of resistance exercises: concentric (i.e. muscle shortening) and eccentric (i.e. active muscle lengthening). One controlled training study assessed the brachial-ankle pulse wave velocity after 8 weeks of either concentric resistance training, eccentric resistance training, or remaining sedentary (Okamoto, Masuhara, \& Ikuta, 2006b). All three groups had similar pre-training values. However, after training, only the concentric resistance training participants increased their arterial stiffness. Likewise, one of our recent training studies reported no change in radial- 
carotid or carotid-femoral pulse wave velocity after dynamic eccentric arm exercise (Elmer et al., 2017). This suggested that eccentric exercise may be a safe form of resistance exercise in terms of cardiovascular health.

\subsection{Summary and Hypothesis}

Exercise is one the leading methods to prevent and treat CVD (Patnode, Evans, Senger, Redmond, \& Lin, 2017). However, some modalities of exercise can negatively impact the cardiovascular system by eliciting stiffening of the elastic arteries. Although there is some debate, it appears that concentric resistance exercise can have harmful acute cardiovascular consequences (Pierce et al., 2018). However, the negative effects of resistance may be able to be negated by combining aerobic exercise or isolating eccentric muscle contractions within the resistance exercise.

Study 1 examines the effect of order (i.e. aerobic before resistance (AR) or resistance before aerobic (RA)) on arterial stiffness when combining these exercise modes in a single training session. Study 2 compares the effects of acute eccentric and concentric arm cycling on central and peripheral arterial stiffness. We hypothesized that these novel combinations of resistance and aerobic exercise would not cause arterial stiffening as observed in resistance exercise alone. 


\section{Study 1: The Influence of Resistance and Aerobic Exercise Order on Acute Arterial Stiffness Responses}

\subsection{Introduction}

Both aerobic and resistance exercise are frequently used to improve health. Although individuals may focus primarily on one mode or the other, combining both methods has been cited as one of the most effective way to manage body composition and improve overall fitness (Donnelly et al., 2009). Furthermore, in the interest of time and convenience, it is common for individuals to mix these training methods into the same exercise session.

Both aerobic and resistance exercise have been shown to influence arterial stiffness. Chronically, aerobic exercise training is thought to reduce arterial stiffness, while resistance exercise is thought to increase it (Miyachi et al., 2004). Aerobic exercise has been observed to reduce arterial stiffness acutely (Collier et al., 2010; Heffernan, Collier, et al., 2007), while resistance exercise may acutely increase stiffness (DeVan et al., 2005). A single acute session of aerobic exercise is reported to decrease arterial stiffness for up to 60 minutes post-exercise (Heffernan, Collier, et al., 2007).

Although the acute and chronic effects of independent aerobic and resistance exercise on arterial stiffness are known, the acute effects of performing both modes in a single session remain unclear. One study reports that arterial stiffness is reduced after eightweeks of resistance then aerobic training, but not after aerobic then resistance training (Okamoto, Masuhara, \& Ikuta, 2007). However, it is unknown whether the order in which these exercise modes are performed within a session has an effect on post-exercise arterial stiffness. Therefore, we hypothesized that arterial stiffness would be lower following resistance then aerobic (RA), but not after aerobic then resistance (AR) exercise. 


\subsection{Methods}

\subsubsection{Subjects}

Seventeen (12 male, 5 female) healthy, recreationally active individuals participated in the study as shown in Table 1. All participants reported to not smoke, take any heart/blood pressure medications, or have a pacemaker. All participants attended an orientation session before providing written informed consent. A physical activity readiness questionnaire was also completed with each participant before testing. This study was reviewed and approved by the Michigan Technological University Institutional Review Board.

Table 1: Participant demographics, anthropometrics, and resting seated cardiovascular values.

\begin{tabular}{cccccccc}
\hline $\begin{array}{c}\text { Age } \\
(\text { year })\end{array}$ & $\begin{array}{c}\text { Height } \\
(\mathbf{c m})\end{array}$ & $\begin{array}{c}\text { Weight } \\
(\mathbf{k g})\end{array}$ & $\begin{array}{c}\text { BMI } \\
\left(\mathbf{k g} / \mathbf{m}^{2}\right)\end{array}$ & $\begin{array}{c}\text { SAP } \\
(\mathbf{m m H g})\end{array}$ & $\begin{array}{c}\text { DAP } \\
(\mathbf{m m H g})\end{array}$ & $\begin{array}{c}\text { MAP } \\
(\mathbf{m m H g})\end{array}$ & $\begin{array}{c}\text { HR } \\
(\mathbf{b p m})\end{array}$ \\
\hline $24 \pm 2$ & $174 \pm 2$ & $78 \pm 3$ & $25 \pm 1$ & $118 \pm 3$ & $65 \pm 3$ & $83 \pm 2$ & $59 \pm 2$ \\
\hline
\end{tabular}

Values are reported as mean \pm standard error. Body mass index (BMI), systolic arterial pressure (SAP), diastolic arterial pressure (DAP), mean arterial pressure (MAP), and heart rate (HR).

\subsubsection{Experimental Design}

Two testing sessions were performed, one in which participants performed a bout of RA exercise, and one where the opposite order was performed (i.e. AR). Each mode of exercise was performed for 30 minutes, so that the total exercise duration per session was 60 minutes. All participants completed both testing sessions approximately one week apart in a randomized balanced crossover design. Prior to each testing session, participants abstained from alcohol, caffeine, and exercise for a minimum of 12 hours, and fasted for at least 3 hours before. 


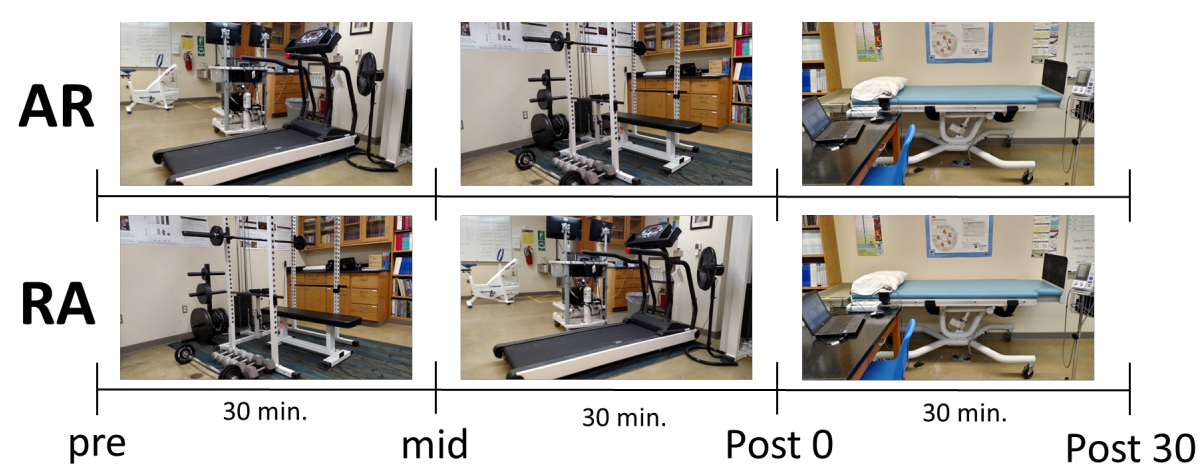

Figure 1: Conceptual diagram describing the protocol for each testing session.

\subsubsection{Resistance Training}

Resistance exercise training consisted of three sets of ten repetitions for six exercises, with each separated by one minute of rest. The exercises were performed in the following order: barbell squat, barbell bench press, seated lat pull down, triceps pushdown, biceps curls, and single leg lunge. The load for the each exercise was set at each participant's tenrepetition max, which was measured during the orientation session. The same load was used for both RA and AR exercise sessions. Resistance training duration averaged 30 minutes, with a range of 28 to 32 minutes.

\subsubsection{Aerobic Training}

Aerobic exercise training was conducted using a treadmill. Participants were able to self-select the speed and grade in order to maintain approximately $70 \%$ of their agepredicted maximum heart rate for 30 minutes to match the intensity and time of the resistance training. The same speed and grade was used for the RA and AR exercise sessions. 


\subsubsection{Measurements}

During each testing session, measurements were taken at pre-exercise, mid-exercise (in between the two modes of exercise), directly after the exercise session, and 30 minutes post-exercise. The pre-exercise brachial blood pressures were taken in triplicate after at least 10 minutes of supine rest with an automated cuff (Omron HEM-907XL, Omron Health Care, Vernon Hills, IL) with one minute between each recording. A single supine blood pressure was taken at mid, post, and 30 minutes post-exercise.

The brachial blood pressures were used to calibrate the SphygmoCor CPVH system (AtCor Medical, West Ryde, Australia) for pulse wave analysis (PWA) measurements. A small pressure transducer (Milar Instruments, Houston, TX) was placed at the radial pulse site to record ten consecutive waveforms to estimate the aortic augmentation index and aortic blood pressure. These PWA measurements were performed in duplicate at each of the time points outlined above.

Peripheral pulse wave velocity (pPWV) was measured from waveforms at the radial and carotid pulses to observe arm arterial stiffness. Central pulse wave velocity (cPWV) was measured from waveforms at the carotid and femoral pulses to observe trunk arterial stiffness. The waveforms were gated to the R-wave of a three-lead electrocardiogram recording, which was also used to obtain heart rate (HR). Distances between the suprasternal notch, carotid pulse, radial pulse, and femoral pulse sites were measured as straight lines with a tape measure. Recordings were completed in duplicate following recommendations from the American Heart Association (Townsend et al., 2015). Aortic pulsatile load was calculated by multiplying aortic pulse pressure by the heart rate derived from the SphygmoCor system. 


\subsubsection{Statistical Analysis}

Paired t-tests were used to test for differences in resting physiological values between to the two trials. A 2 (exercise order) $\mathrm{x} 4$ (time) repeated measures analysis of variance (ANOVA) was used to assess difference in heart rate, mean arterial pressure, aortic pulsatile load, and pulse wave velocities (pPWV and cPWV). Post-hoc paired t-tests were performed when a significant time effect or condition (i.e. exercise order) by time interaction were observed after the ANOVA procedures. Data are presented as mean \pm standard error and the a priori alpha was set to 0.05 .

\subsection{Results}

Heart rate, mean arterial pressure, $\mathrm{pPWV}$, and $\mathrm{cPWV}$ values were similar at rest before both exercise order conditions as shown in Table 2 . Aortic pulsatile load was slightly higher preceding the AR than the RA condition.

Table 2: Baseline values between two testing sessions.

\begin{tabular}{lccc}
\hline Variable & RA Session & AR Session & P value \\
\hline Heart Rate $(\mathrm{bpm})$ & $57 \pm 2$ & $57 \pm 3$ & 0.54 \\
MAP $(\mathrm{mmHg})$ & $81 \pm 2$ & $81 \pm 2$ & 0.97 \\
Peripheral PWV (m/s) & $7.3 \pm 0.3$ & $7.3 \pm 0.3$ & 1.00 \\
Central PWV (m/s) & $5.8 \pm 0.3$ & $5.6 \pm 0.2$ & 0.48 \\
\hline
\end{tabular}

Values are reported as mean \pm standard error. Mean arterial pressure (MAP), pulse wave velocity (PWV).

Heart rate increases were similar (time effect: $P<0.05$ ) for RA and AR. Heart rate increased during exercise and remained elevated afterwards in both conditions. ( $57 \pm 2$ vs. $57 \pm 2,89 \pm 5$ vs. $92 \pm 3,97 \pm 3$ vs. $100 \pm 4$, and $74 \pm 3$ vs. $79 \pm 4$, time effect: $P=0.00$ ). Mean arterial pressure increased significantly during exercise, but returned to baseline 30 
minutes post-exercise during the RA session ( $81 \pm 2$ vs. $79 \pm 2 \mathrm{mmHg}, P=0.38)$ and was reduced after the AR session $(81 \pm 2$ vs. $74 \pm 2 \mathrm{mmHg}, P<0.05)$. Aortic pulsatile load increased during exercise and remained elevated post-exercise after both sessions $(P<0.05$ for both) as depicted in Figure 1.

Arm arterial stiffness (i.e., pPWV) tended to decrease 30 minutes after both RA and AR sessions $(7.4 \pm 0.3$ vs. $6.9 \pm 0.3 ; 7.2 \pm 0.3$ vs. $6.9 \pm 0.3 \mathrm{~m} / \mathrm{s}$, time effect: $P=0.086)$. Aortic arterial stiffness (i.e. cPWV) decreased similarly 30 minutes after both RA and AR sessions $(5.8 \pm 0.3$ vs. $5.5 \pm 0.2 ; 5.6 \pm 0.2$ vs. $5.5 \pm 0.2 \mathrm{~m} / \mathrm{s}$, time effect: $P<0.05)$. When normalized to aortic mean arterial pressure, cPWV values were increased following the AR session $(0.072 \pm 0.002$ vs. $0.078 \pm 0.003 \mathrm{~m} / \mathrm{s} / \mathrm{mmHg}, P<0.05)$.

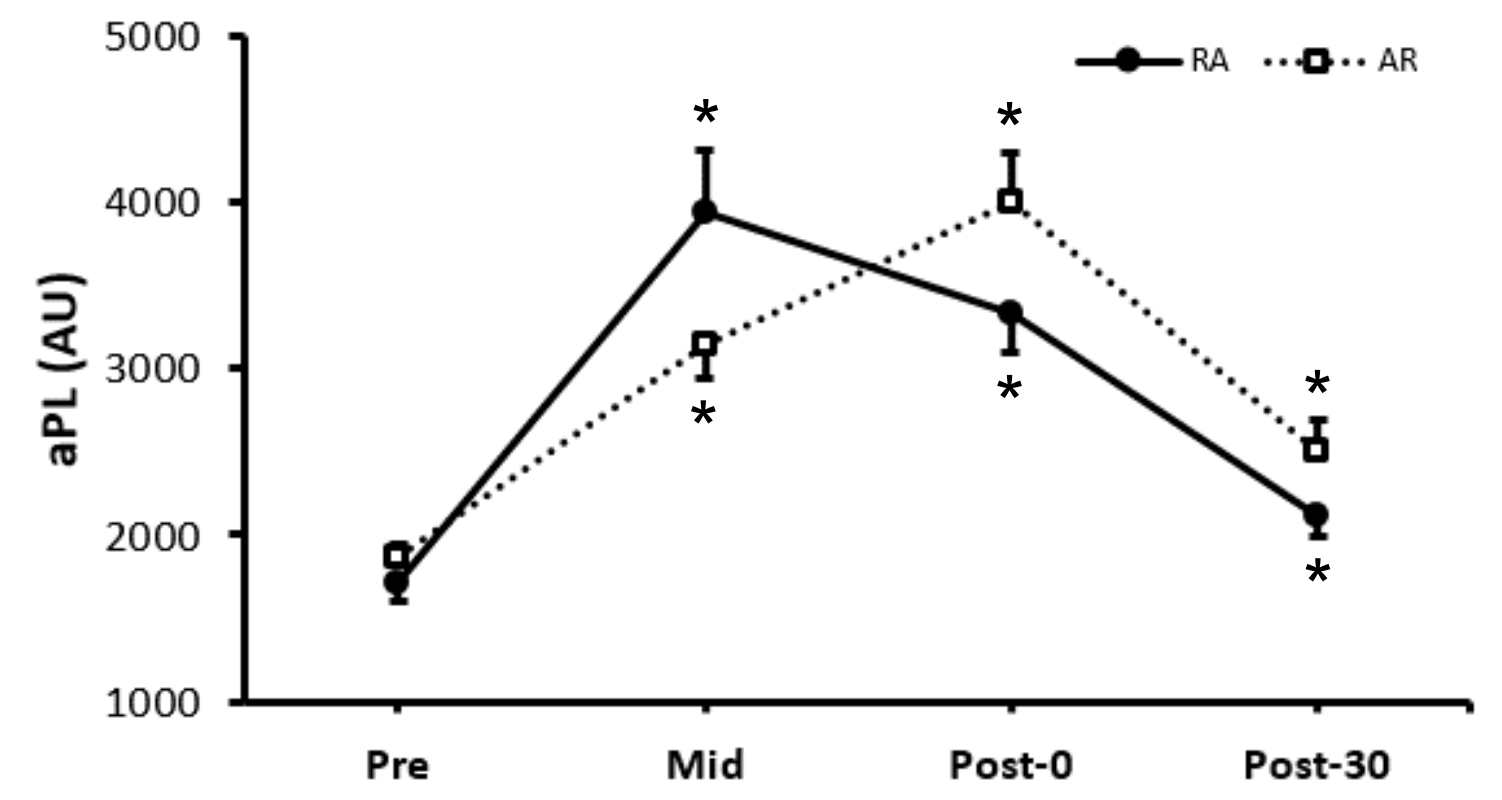

Z

Figure 2: Aortic pulsatile load (aPL) before, between, and after exercise. Time effect: $P<$ 0.05 

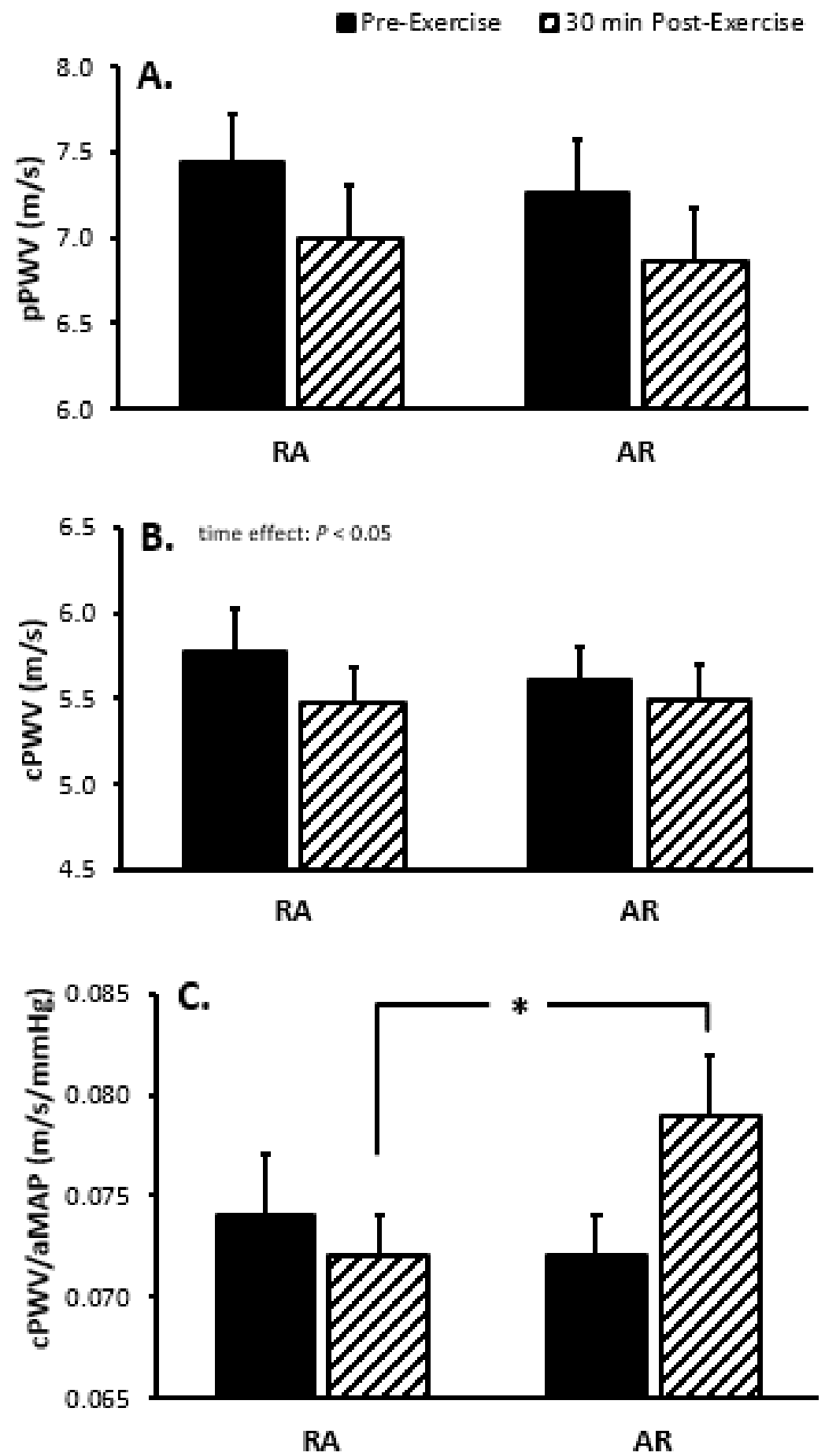

Figure 3: Peripheral (Panel A), central (Panel B), and normalized central (Panel C) pulse wave velocity responses 30 min post-exercise. ${ }^{*} P<0.05$ vs. order 


\subsection{Discussion}

This is the first study to report the effect of the order of aerobic and resistance exercise on acute cardiovascular responses. Heart rate changed and recovered similarly for each exercise order (i.e. RA and AR). Likewise, aortic pulsatile load increased and remained elevated after each session similarly. After both RA and AR, pPWV tended to be reduced 30 minutes post. There was a similar reduction in cPWV after each order. However, when normalized to mean aortic blood pressure, cPWV appears to be elevated following AR.

Prolonged elevated aortic pulse pressure and / or heart rate can increase pulsatility to pressure sensitive end organs, such as the brain and the kidney (Augustine, Yoon, Choo, Heffernan, \& Jae, 2016). In the present study, aortic pulsatile load remained elevated 30 minutes post-exercise for both the RA and AR conditions. Although this elevation is not likely to cause long-term damage, it is important to consider in future chronic training studies and clinical populations. It would be interesting to determine if pulsatile load is reduced to baseline conditions more rapidly following RA or AR.

Peripheral and central arteries are structurally and functionally different, and therefore may respond to exercise differently. The peripheral vasculature can vasodilate in active tissue and vasoconstrict in other areas during resistance exercise, whereas aerobic exercise typically induces whole body vasodilation (Sardeli, Gaspari, \& Chacon-Mikahil, 2015). Vasodilation during exercise can increase shear stress and nitric oxide bioavailability, which in turn can decrease regional arterial stiffness (Beck, Casey, Martin, Emerson, \& Braith, 2013; C. Goto et al., 2003). Arterial stiffness in the arms, as measured by pPWV in our study, tended to decrease after each session. The tendency for reductions 
in pPWV may have been due to vasoactive substances, such as nitric oxide, similar to previous work by Beck, Martin, Casey, and Braith (2013). Moreover, this reduction in pPWV is likely associated with our study protocol, which included four upper-body resistance exercises (Fahs, Heffernan, \& Fernhall, 2009).

Although cPWV is considered the gold standard for measuring arterial stiffness (Laurent et al., 2006), cPWV is a pressure-dependent measure. Therefore, normalizing cPWV to aortic mean pressure, can be useful when interpreting results from an exercise intervention (Sacre, Jennings, \& Kingwell, 2014). Our acute normalized cPWV results suggest that RA may be a better option for combined exercise compared to AR. Results from an 8-week combined training study reported that performing resistance then aerobic exercise can reduce arterial stiffness (Okamoto et al., 2007). Importantly, the above benefits were lost with four weeks of detraining (Okamoto et al., 2007), signifying the importance of consistence acute bouts of combined exercise. Furthermore, early studies noted improved growth hormone (K. Goto, Higashiyama, Ishii, \& Takamatsu, 2005) and greater lipolysis (K. Goto, Ishii, Sugihara, Yoshioka, \& Takamatsu, 2007) when resistance exercise is performed before aerobic exercise. More recently, this order of combined training has also been shown to be beneficial in diabetics by improving glycemic stability (Yardley et al., 2012) and increasing growth hormone secretion (Yardley, Sigal, Riddell, Perkins, \& Kenny, 2014) throughout the exercise session.

One limitation to this study is that the sample size did not allow us to adequately examine potential sex differences. Our sample had a larger percentage of male participants (12 male, 5 female). It has been previously reported that there can be differences in arterial stiffness at rest and after acute bouts of exercise between males and females (Doonan, 
Mutter, Egiziano, Gomez, \& Daskalopoulou, 2013). Understanding these potential differences is important for future exercise prescription recommendations.

In conclusion, although there is much debate of the effects of resistance exercise on arterial stiffness, and a recent meta-analysis concluded that acute resistance exercise is likely to have adverse effects on arterial stiffness (Pierce et al., 2018). Conversely, aerobic exercise was reported to reduce pulse wave velocity (Pierce et al., 2018). However, it has been demonstrated in a cross-sectional study that simultaneous resistance and aerobic exercise (i.e. rowing) can be used to reduce stiffening (Cook et al., 2006). Our results in the present study also suggest that by combining both forms of exercise within a single exercise session can also reduce stiffening independent of exercise order. However, our results regarding $\mathrm{cPWV}$ normalized to aMAP, in conjunction with previous work on arterial stiffness (Okamoto et al., 2007) and metabolic function (K. Goto et al., 2005; K. Goto et al., 2007; Yardley et al., 2012; Yardley et al., 2014), may suggest that RA would be the most beneficial combined exercise order. 


\section{Study 2: Post-Exercise Arterial Stiffness Responses Are Similar After Acute Eccentric and Concentric Arm Cycling}

\subsection{Introduction}

Many activities of daily living, work-related manual labor, and locomotor tasks such as wheelchair propulsion rely on arm, shoulder, and trunk musculature. Adequate upperbody strength is critical for maintaining health, functioning independently, and preventing lifestyle related diseases (P. LaStayo, Marcus, Dibble, Frajacomo, \& Lindstedt, 2014). However, both acute (Pierce et al., 2018) and chronic (Miyachi et al., 2004) resistance exercise can increase arterial stiffness. Additionally, upper-body resistance exercise has been observed to increase arterial stiffness both acutely (Li, Bopp, et al., 2015) and chronically (Okamoto, Masuhara, \& Ikuta, 2009) to a greater extent than lower-body resistance exercise. Increased stiffness (inability to expand and recoil during the cardiac cycle) of arteries contributes to hypertension (Carthy, 2014), and increases the risk for cardiovascular disease (Vlachopoulos, Aznaouridis, \& Stefanadis, 2010). In contrast to upper-body resistance exercise, upper-body aerobic exercise provides cardiorespiratory benefits and can acutely decrease regional (i.e. arm) arterial stiffness (Ranadive et al., 2012).

Resistance exercise typically includes both concentric (active muscle shortening) and eccentric (active muscle lengthening) phases. Forces produced during eccentric muscle actions can be substantially greater than those produced during concentric muscle actions (P. C. LaStayo, Pierotti, Pifer, Hoppeler, \& Lindstedt, 2000). In addition to this increased capacity for force production, eccentric exercise is performed with a lower metabolic cost 
and thus lower perceived exertion (Elmer, Danvind, \& Holmberg, 2013; Elmer \& LaStayo, 2014; Elmer, Marshall, McGinnis, Van Haitsma, \& LaStayo, 2013). To date, it is well established that eccentric exercise is more effective than traditional concentric-based exercise at improving neuromuscular function (Elmer et al., 2017), balance, and mobility in populations ranging from cardiopulmonary patients to competitive athletes (IsnerHorobeti et al., 2013; P. LaStayo et al., 2014).

During eccentric exercise sympathetic activation and blood pressure are lower compared to similarly matched concentric exercise (Carrasco, Delp, \& Ray, 1999). These attributes would possibly favor lower post-exercise arterial stiffness outcomes. In related work, Okamoto and colleagues reported that eight weeks of eccentric elbow flexor actions increased strength without changing arterial stiffness, whereas concentric elbow flexor actions increased strength and arterial stiffness (Okamoto, Masuhara, \& Ikuta, 2006a). These results are promising and imply that attenuated circulatory adjustments to eccentric muscle action might help to offset the effects of arterial stiffening associated with resistance exercise. With this in mind, we sought to determine whether a novel form of upper-body resistance cycling exercise could be performed without compromising arterial function.

We recently developed a novel eccentric arm cycle ergometer in which the user resists the reverse moving motor-driven handles (Figure 3). This modality can be used to safely perform repetitive, high-force, multi-joint eccentric actions with the upper-body while minimizing metabolic and cardiorespiratory strain. Assessment of arterial stiffness following acute eccentric and concentric arm cycling performed at the same heart rate would offer a model for evaluating the impact of aerobically-based upper-body resistance 
exercise on arterial function. Accordingly, the purpose of this study was to compare the effects of acute eccentric and concentric arm cycling on central and peripheral arterial stiffness. We anticipated that power output during eccentric arm cycling would be $\sim 2 \mathrm{x}$ greater than that during concentric arm cycling (Elmer, Danvind, et al., 2013). Previous work has shown that regional arterial stiffness is reduced after acute arm and leg cycle ergometry, but that central arterial stiffness remains unchanged (Ranadive et al., 2012). Therefore, we hypothesized that peripheral arterial stiffness would be reduced following both eccentric and concentric arm cycling, but that that central arterial stiffness would remain unchanged.

\subsection{Methods}

\subsubsection{Participants}

Twenty-two healthy individuals volunteered to participate in this study. Seventeen of these participants were part of a previously published training study (Elmer et al., 2017). Participants were recreationally active, but did not regularly participate in upper-body aerobic or resistance exercise. Experimental procedures used in this investigation were reviewed and approved by the Michigan Technological University Institutional Review Board. The protocol and procedures were explained verbally and all participants provided

written informed consent prior to testing. Participants were clustered together in such a way as to create two exercise groups of 11 participants with similar body composition, upper-body cardiorespiratory capacity, and maximum upper-body muscular power as shown in Table 1. 
Table 3: Participant demographic, anthropometric, and physiological characteristics.

\begin{tabular}{|c|c|c|c|}
\hline Variable & $\begin{array}{l}\text { Eccentric } \\
(n=11)\end{array}$ & $\begin{array}{l}\text { Concentric } \\
(n=11)\end{array}$ & $P$ value \\
\hline Age (yr) & $23 \pm 1$ & $24 \pm 1$ & 0.53 \\
\hline Height (m) & $1.74 \pm 0.03$ & $1.77 \pm 0.03$ & 0.60 \\
\hline Body mass (kg) & $74 \pm 4$ & $79 \pm 5$ & 0.40 \\
\hline $\operatorname{BMI}\left(\mathrm{kg} \cdot \mathrm{m}^{-2}\right)$ & $24 \pm 1$ & $25 \pm 1$ & 0.58 \\
\hline Body Fat (\%) & $22 \pm 4$ & $25 \pm 4$ & 0.62 \\
\hline $\begin{array}{l}\text { Systolic Arterial } \\
\text { Pressure (mmHg) }\end{array}$ & $110 \pm 4$ & $111 \pm 3$ & 0.86 \\
\hline $\begin{array}{l}\text { Diastolic Arterial } \\
\text { Pressure (mmHg) }\end{array}$ & $60 \pm 3$ & $61 \pm 2$ & 0.86 \\
\hline $\begin{array}{l}\text { Resting Heart Rate } \\
\left(b \cdot \min ^{-1}\right)\end{array}$ & $64 \pm 3$ & $60 \pm 3$ & 0.33 \\
\hline$\dot{\mathrm{VO}}_{2 \text { peak }}\left(\mathrm{L} \cdot \mathrm{min}^{-1}\right)$ & $2.2 \pm 0.2$ & $2.3 \pm 0.2$ & 0.74 \\
\hline$\dot{\mathrm{VO}}{ }_{2 \text { peak }}\left(\mathrm{ml} \cdot \mathrm{kg}^{-1} \cdot \mathrm{min}^{-1}\right)$ & $29 \pm 3$ & $29 \pm 2$ & 0.82 \\
\hline $\mathrm{HR}_{\text {peak }}\left(\mathrm{b} \cdot \mathrm{min}^{-1}\right)$ & $185 \pm 3$ & $181 \pm 3$ & 0.37 \\
\hline $\mathrm{W}_{\text {peak }}(\mathrm{W})$ & $134 \pm 12$ & $134 \pm 12$ & 1.00 \\
\hline $\mathrm{P}_{\max }(\mathrm{W})$ & $599 \pm 59$ & $591 \pm 60$ & 0.94 \\
\hline
\end{tabular}

Values are reported as Mean \pm SE. Body mass index (BMI), peak oxygen consumption $\left(\mathrm{VO}_{2 \text { peak }}\right)$, peak heart rate $\left(\mathrm{HR}_{\text {peak }}\right)$, peak power reached at the end of $\mathrm{VO}_{2 \text { peak }}$ test $\left(\mathrm{W}_{\text {peak }}\right)$, and maximal upper-body concentric power $\left(\mathrm{P}_{\text {max }}\right)$. 


\subsubsection{Pre-Experimental Assessments}

Body composition was assessed using dual energy x-ray absorptiometry (DEXA; Lunar Prodigy, General Electric Company, Fairfield, CT, USA). Upper-body cardiorespiratory capacity was evaluated during an incremental concentric arm cycling test $\left(15+15 \mathrm{~W} \cdot \mathrm{min}^{-1}\right)$ using an expired air analysis system (ParvoMedics TrueOne 2400, Salt Lake City, UT, USA) for determination of peak oxygen consumption ( $\left.\dot{\mathrm{V}}_{2 \text { peak }}\right)$, peak heart rate $\left(\mathrm{HR}_{\text {peak }}\right)$, and peak power output reached $\left(\mathrm{W}_{\max }\right)$. Maximum upper-body power was determined during maximal concentric arm cycling trials ( $3 \mathrm{~s}, 120 \mathrm{rpm})$. Exercise groups were then assigned to one of the following exercise conditions: 1) eccentric arm cycling, or 2) concentric arm cycling.

\subsubsection{Habituation Period}

During the weeks preceding the experimental visit, participants in the eccentric group performed several habituation trials of eccentric arm cycling in order become familiar with the cycle ergometer, acquire the specific coordination required for eccentric arm cycling, and minimize the occurrence of muscle soreness that can be associated with unaccustomed eccentric exercise (P. C. LaStayo et al., 2000). Participants in the concentric group also performed similar habituation sessions of concentric arm cycling. Muscle soreness associated with eccentric arm cycling or concentric arm cycling was monitored using a visual analog scale $(0-10 \mathrm{~cm} ; 10 \mathrm{~cm}$ representing the most soreness possible (Elmer, Marshall, et al., 2013; P. C. LaStayo et al., 2000)). Specifically, 24 to 48 hours after each habituation trial, participants performed a standardized bilateral elbow extension movement ("bench dip") during which they indicated the level of perceived muscle 
soreness in their arms by placing a mark on the visual analog scale. Perceived muscle soreness was quantified by measuring the distance to the mark on the line to the nearest 0.1 $\mathrm{cm}$. Both groups tolerated the habituation sessions well as muscle soreness was minimal $(<1.0 \mathrm{~cm})$, and thus were reasonably trained with their respective modality.

\subsubsection{Experimental Protocol}

For the experimental visit, participants were instructed to avoid exercise and caffeine for $12 \mathrm{~h}$ preceding the experiment which was performed at least $3 \mathrm{~h}$ post-prandial. Baseline measures of heart rate, blood pressure, and pulse wave velocity were recorded before exercise (described below). Subsequently, participants performed either eccentric arm cycling or concentric arm cycling on an isokinetic arm cycle ergometer (described below) at $\sim 70 \%$ of $\mathrm{HR}_{\text {peak }}$ for $20 \mathrm{~min}$ at a pedaling rate of $\sim 60 \mathrm{rpm}$. Arm cycling power output and heart rate (Polar Electro OY, Kempele, Finland) were recorded and averaged over the 20

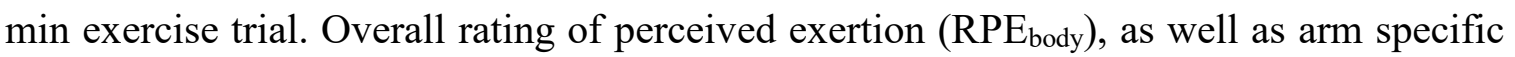
RPE (RPEarm), were assessed during the final min of exercise using a Borg 6-20 scale (Borg, 1982). Heart rate, blood pressure, and pulse wave velocity were reassessed at 10 min and 30 post exercise. These time points were selected because previous studies have shown that arterial stiffness can be altered from 10 to 30 min post-exercise (Heffernan, Jae, Echols, Lepine, \& Fernhall, 2007; Ranadive et al., 2012).

\subsubsection{Cardiovascular Parameters}

All measurements were completed following the guidelines from the American Heart Association for standardizing vascular research (Townsend et al., 2015). At baseline, 
brachial blood pressures were taken in triplicate after at least 10 minutes of supine rest with an automated cuff (Omron HEM-907XL, Omron Health Care, Vernon Hills, IL) with one minute between each recording. Average systolic arterial pressure (SAP) and diastolic arterial pressure (DAP) were used to calibrate the SphygmoCor CPVH system (AtCor Medical, West Ryde, Australia) for pulse wave analysis measurements. A single supine blood pressure was taken to calibrate directly before recordings at 10 and $30 \mathrm{~min}$ post exercise.

A small pressure transducer (Millar Instruments, Houston, TX) was placed at the radial pulse site to record consecutive waveforms during pulse wave analysis. The SphygmoCor system was used to estimate aortic blood pressures and aortic augmentation index (AIx) from the radial site. Recordings were completed in duplicate with an operator index of $\geq 80$ for all readings as recommended by the manufacturer. Values are reported as an average of the two recordings. Aortic pulsatile load was calculated by multiplying the average aortic pulse pressure by the heart rate from the SphygmoCor system.

Peripheral pulse wave velocity (pPWV) was measured from waveforms at the radial and carotid pulses to indicate arm arterial stiffness. Central pulse wave velocity (cPWV) was measured from waveforms at the carotid and femoral pulses to indicate aortic arterial stiffness. The pressure waveforms were gated to the R-waves of a three-lead electrocardiogram recording, which was also used to obtain heart rate (HR). Distances between the suprasternal notch to the carotid, radial, and femoral pulse sites were measured as straight lines with a tape measure. Pulse wave velocity recordings were taken in duplicate with $\leq 10 \%$ standard error and a HR difference of $\leq 5 \mathrm{~b} \cdot \mathrm{min}^{-1}$ between the consecutive measurements sites. Values are reported as an average of the two recordings. 


\subsubsection{Arm Cycle Ergometer}

The isokinetic arm cycle ergometer (Figure 1) used in this investigation has been previously described in detail (Elmer, Marshall, et al., 2013). Briefly, the flywheel of the ergometer was driven in reverse for eccentric arm cycling group by a $560 \mathrm{~W}$ three-phase electric motor (Leeson, C4T17PT2C; Santa Fe Springs, CA, USA) via pulleys and a belt, or driven forward by the participants in the concentric arm cycling group. The motor was controlled by a variable frequency drive equipped with regenerative braking capability (Leeson, SM2 Series, Sante Fe Springs, CA, USA). Power delivered to the ergometer crank was quantified using a power meter (Schoberer Rad Messtechnik, SRM, Jülich, Germany), which serves as an accurate method to quantify cycling power (Abbiss, Quod, Levin, Martin, \& Laursen, 2009). Pedaling rate was set to $\sim 60 \mathrm{rpm}$ and the SRM power meter (sampled at $2 \mathrm{~Hz}$ ) displayed the power that the participant was absorbing (eccentric arm cycling trials) or producing (concentric arm cycling trials). The SRM power meter was calibrated using static calibration procedures (Elmer, Danvind, et al., 2013) and a zero offset ( $\left.f_{\text {unloaded }}\right)$ was obtained before all arm cycling trials. The cranks $(170 \mathrm{~mm})$ were positioned in the asynchronous fashion and custom made wider surface area handles were used to allow for a comfortable pronated hand position. Ergometer seat position was carefully standardized such that the: 1) crank axle was set just below the level of the heart, 2) elbow was positioned at a comfortable angle when the cranks were horizontal $\left(\sim 20^{\circ}\right.$ ulnar notch to humeral head), and 3) legs were positioned to help stabilize the torso ( $\sim 90^{\circ}$ lateral malleolus to greater trochanter). Finally, for the eccentric arm cycling trials, participants were instructed to "resist" the motor-driven handles of the ergometer at the 
specified target heart rate whereas for the concentric arm cycling trials, participants were instructed to propel the handles of the ergometer at the specified target heart rate.

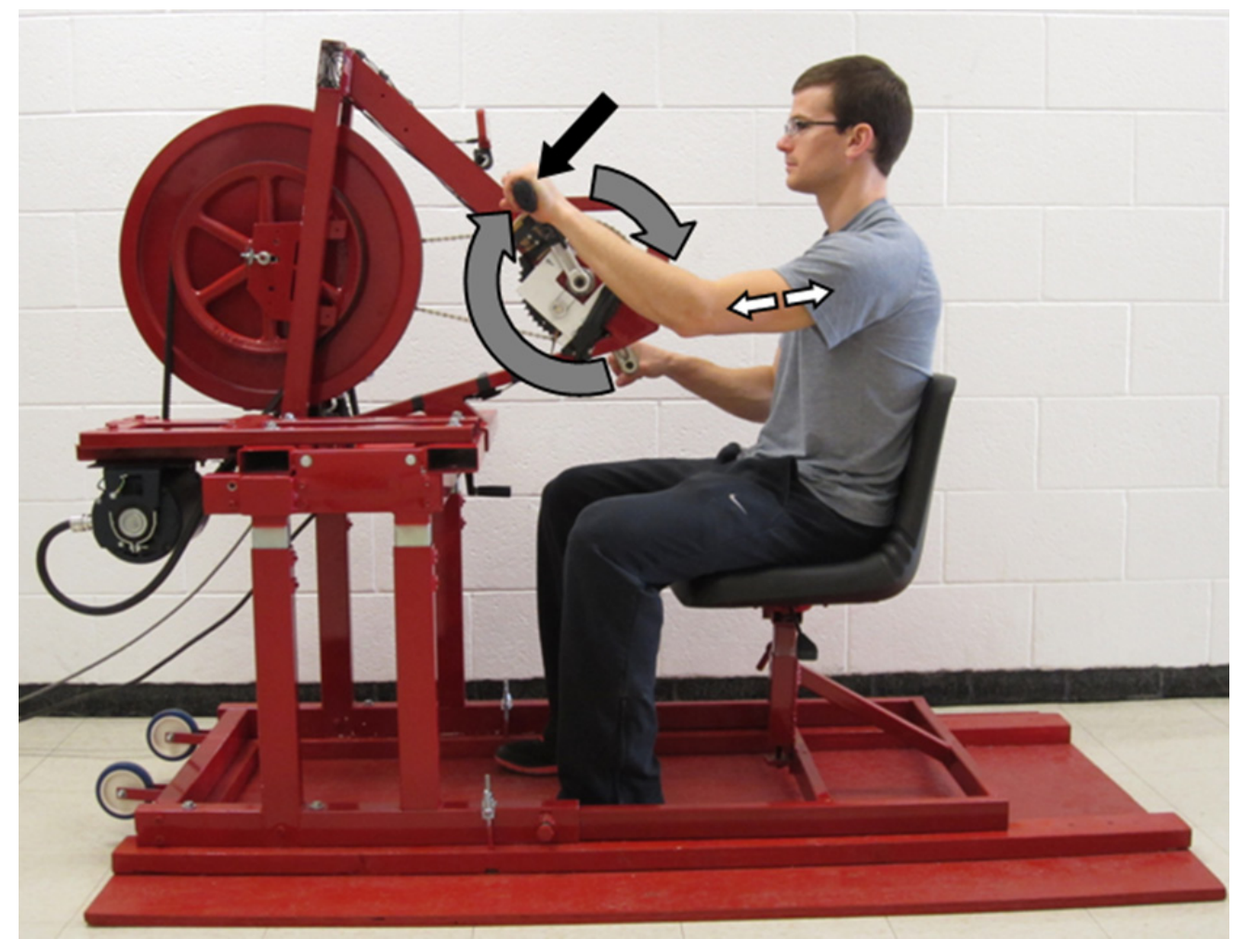

Figure 4: Motor-driven ergometer for eccentric arm cycling. The handles are driven in a backwards rotation as indicated by the grey arrows, and the participant resists the turning of the handles as indicated by the black arrow.

\subsubsection{Data Analysis}

Independent t-tests were used to test for differences in participant demographic data, power output, heart rate, and RPE values between eccentric arm cycling and concentric arm cycling. A 2 (exercise group) x 3 (time) repeated measures analysis of variance (ANOVA) was used to assess differences in heart rate, brachial blood pressures, aortic blood pressures, aortic augmentation index normalized to 75 b·min $\operatorname{mix}^{-1}$ (AIx@75), and pulse wave velocity (cPWV, pPWV). If any of the ANOVA procedures revealed a significant time effect, and/or group $\mathrm{x}$ time interaction, then subsequent post-hoc tests were 
performed to determine where those differences occurred. Data are presented as mean \pm standard error and the a priori alpha was set to 0.05 .

\subsection{Results}

\subsubsection{Responses during exercise}

Mechanical, cardiorespiratory, and perceptual responses to the 20 min exercise trial are reported in Figure 4. Power absorbed during eccentric arm cycling was $\sim 2 \mathrm{x}$ that produced during concentric arm cycling $(125 \pm 13$ vs. $67 \pm 7 \mathrm{~W}, \mathrm{p}<0.01)$. These powers corresponded to $94 \pm 5$ and $50 \pm 2 \%$ of the peak power reached during the concentric arm cycling $\mathrm{VO}_{2 \text { peak }}$ test $\left(\mathrm{W}_{\text {peak }}\right)$ and to $22 \pm 2$ and $12 \pm 1 \%$ of maximal concentric arm cycling power $\left(\mathrm{P}_{\max }\right)$, respectively. Mean absolute and relative heart rates during eccentric arm cycling (122 $\pm 4 \mathrm{~b} \cdot \mathrm{min}^{-1}, 66 \pm 2 \%$ of $\left.\mathrm{HR}_{\text {peak }}\right)$ and concentric arm cycling (122 $\pm 2 \mathrm{~b} \cdot \mathrm{min}^{-1}$, $67 \pm 1 \%$ of $\left.\mathrm{HR}_{\text {peak }}\right)$ did not differ ( $\mathrm{p}=0.87$ and $\mathrm{p}=0.68$, respectively) and were close to the prescribed target of target of $70 \%$ of $\mathrm{HR}_{\text {peak. }}$. Rating of perceived exertion for the wholebody during eccentric and concentric arm cycling was between a "light" and "somewhat hard" effort and did not differ between groups $(12.6 \pm 0.4$ vs. $11.8 \pm 0.5, p=0.20)$. Rating of perceived exertion for the arms during eccentric and concentric arm cycling was between a "somewhat hard" and "hard" effort and did not differ between groups (14.0 \pm 0.3 vs. 13.4 $\pm 0.6, \mathrm{p}=0.38)$ 

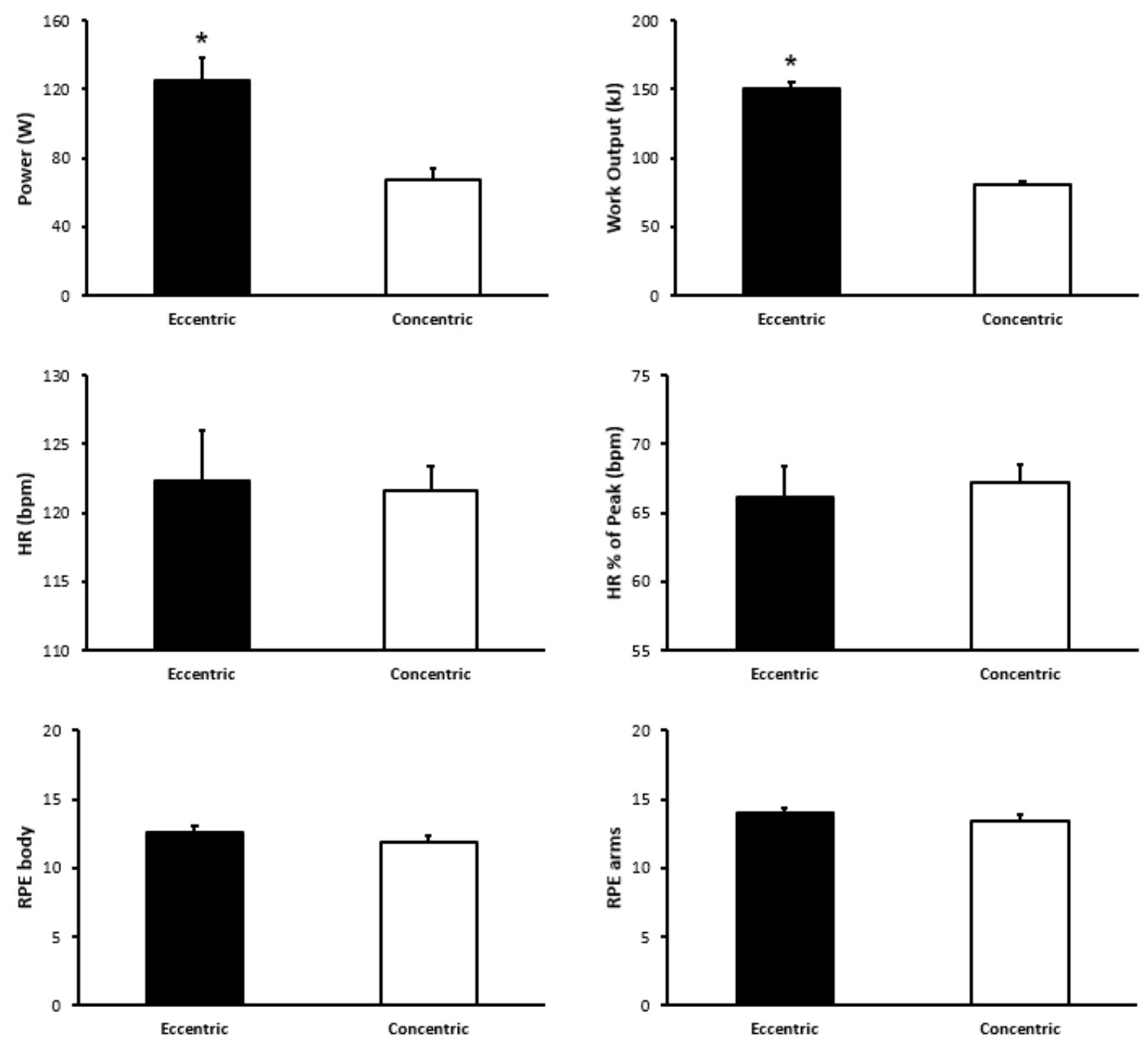

Figure 5: Eccentric arm cycling results in significantly greater production of work and power at a predetermined heart rate $(\mathrm{HR})$ as an absolute value or percentage of the participant's age-predicted maximal value. Ratings of perceived exertion (RPE) were similar. $* \mathrm{p}<0.05$ between groups

\subsubsection{Responses after exercise}

Heart rate tended to be elevated at 10 min post $\mathrm{ECC}_{\mathrm{arm}}(\mathrm{p}=0.08)$ and was elevated at 10 min post $\mathrm{CON}_{\mathrm{arm}}(\mathrm{p}<0.01)$, but returned to baseline levels at 30 min post-exercise in both groups. Mean arterial pressure was not significantly changed from baseline at 10 or 30 min post-exercise in either group. Aortic pulsatile load remained elevated 10 and 30 min post exercise in both groups ( $<<0.01$ for both). AIx@75 was elevated in both groups 
at $10 \mathrm{~min}$ post-exercise ( $\mathrm{p}<0.03$ for both), but returned to baseline values at $30 \mathrm{~min}$ post (see Table 4). As shown in Figure 5, pPWV was decreased at 10 min post-exercise for both $\mathrm{ECC}_{\text {arm }}$ and $\mathrm{CON}_{\mathrm{arm}}(\mathrm{p}<0.05)$, while both groups returned to baseline values by $30 \mathrm{~min}$ post. cPWV did not change in either group.
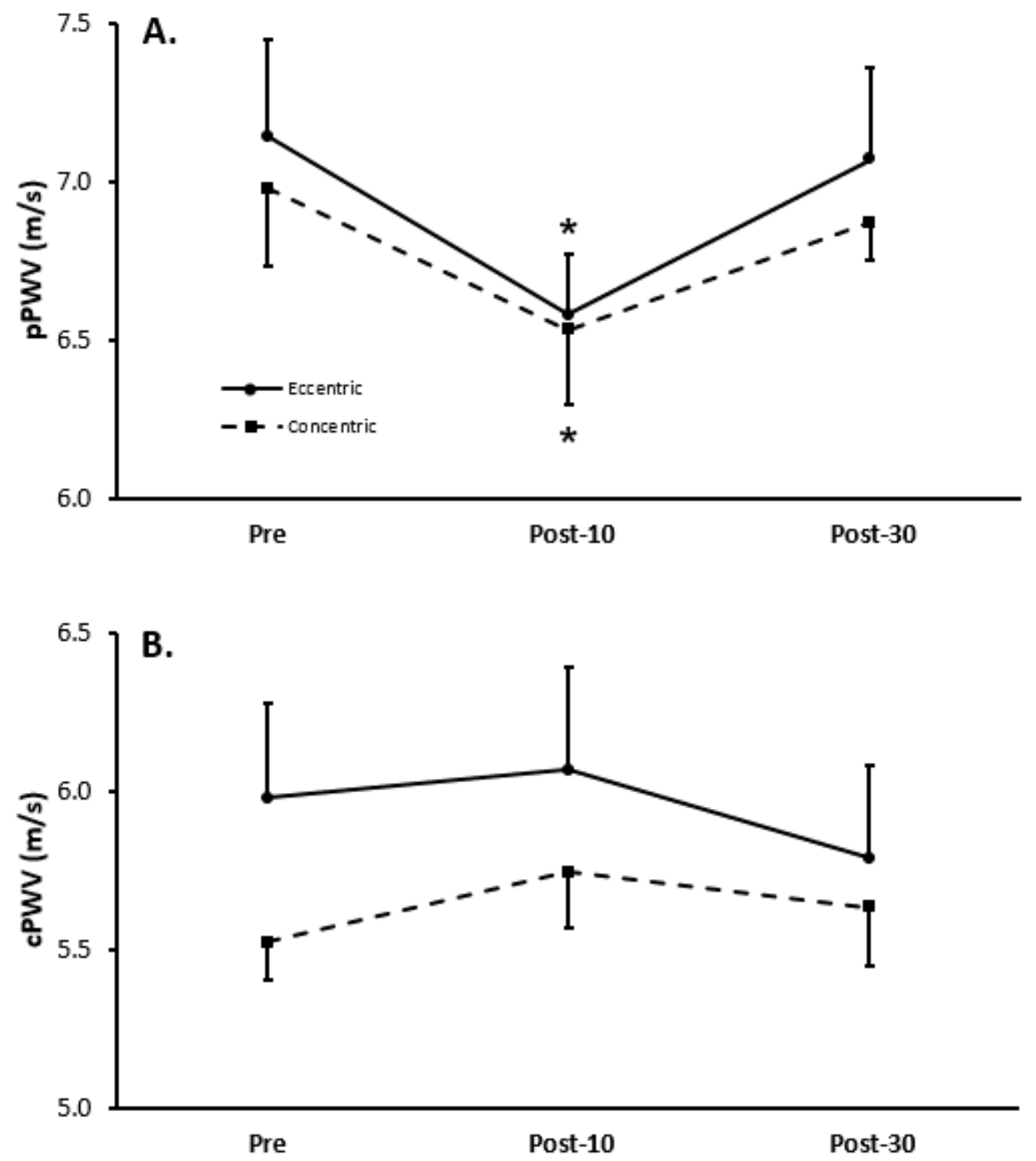

Figure 6: Peripheral (i.e. arm) pulse wave velocity (pPWV) was significantly decreased at 10 min post-exercise in both groups, but returned to baseline at $30 \mathrm{~min}$ post (Panel A). Central (i.e. aortic) pulse wave velocity (cPWV) was not changed from baseline at 10 or 30 min post-exercise for either group (Panel B). ${ }^{*} \mathrm{p}<0.05$ vs. pre-exercise baseline. 
Table 4: Cardiovascular responses to acute exercise session.

\begin{tabular}{|c|c|c|c|c|c|c|}
\hline \multirow[b]{2}{*}{ Variable } & \multicolumn{3}{|c|}{ Eccentric $(n=11)$} & \multicolumn{3}{|c|}{ Concentric $(n=11)$} \\
\hline & $\begin{array}{l}\text { Pre- } \\
\text { Exercise }\end{array}$ & $\begin{array}{l}10 \text { min } \\
\text { Post- } \\
\text { Exercise }\end{array}$ & $\begin{array}{l}30 \text { min } \\
\text { Post- } \\
\text { Exercise }\end{array}$ & $\begin{array}{l}\text { Pre- } \\
\text { Exercise }\end{array}$ & $\begin{array}{l}10 \text { min } \\
\text { Post- } \\
\text { Exercise }\end{array}$ & $\begin{array}{l}30 \text { min } \\
\text { Post- } \\
\text { Exercise }\end{array}$ \\
\hline HR (bpm) & $64 \pm 3$ & $68 \pm 3$ & $61 \pm 2$ & $60 \pm 3$ & $71 \pm 4^{*}$ & $66 \pm 3$ \\
\hline $\begin{array}{l}\text { bMAP } \\
(\mathrm{mmHg})\end{array}$ & $76 \pm 3$ & $79 \pm 2$ & $75 \pm 2$ & $77 \pm 2$ & $72 \pm 2$ & $74 \pm 2$ \\
\hline AIx@75 & $-9 \pm 3$ & $0 \pm 3^{*}$ & $-4 \pm 3$ & $-14 \pm 4$ & $-4 \pm 3 *$ & $-12 \pm 3$ \\
\hline aSAP (mmHg) & $91 \pm 3$ & $96 \pm 2$ & $93 \pm 2$ & $92 \pm 2$ & $89 \pm 2$ & $87 \pm 3$ \\
\hline aDAP (mmHg) & $61 \pm 3$ & $59 \pm 2$ & $59 \pm 2$ & $63 \pm 2$ & $52 \pm 2$ & $54 \pm 2$ \\
\hline $\begin{array}{l}\text { aMAP } \\
(\mathrm{mmHg})\end{array}$ & $74 \pm 3$ & $76 \pm 2$ & $74 \pm 2$ & $74 \pm 2$ & $69 \pm 2$ & $69 \pm 2$ \\
\hline aPP (mmHg) & $31 \pm 1$ & $38 \pm 1^{*}$ & $35 \pm 1$ & $31 \pm 2$ & $37 \pm 2^{*}$ & $35 \pm 2$ \\
\hline aPL (aU) & $1907 \pm 136$ & $2607 \pm 184^{*}$ & $2074 \pm 130 *$ & $1800 \pm 107$ & $2440 \pm 121 *$ & $2179 \pm 172 *$ \\
\hline
\end{tabular}

Values are reported as Mean \pm SE. Heart rate (HR), brachial mean atrial pressure (bMAP), aortic augmentation index normalized to 75 beats per minute (Aix@75), aortic systolic blood pressure (aSAP), aortic diastolic blood pressure (aDAP), aortic mean blood pressure (aMAP), aortic pulse pressure (aPP), aortic pulsatile load (aPL). * $\mathrm{p}<0.05$ vs. pre-exercise baseline 


\subsection{Discussion}

This study compared arterial stiffness responses to acute steady-state eccentric and concentric upper body cycling. The main finding of our study was that both eccentric and concentric upper body cycling elicit similar acute arterial stiffness responses. This is supported by three novel findings. First, pPWV measured in the arm was reduced at 10 min post-exercise after both eccentric and concentric arm ergometry, but returned to preexercise values by 30 min post-exercise. Second, cPWV was similar to pre-exercise baseline values at 10 and 30 min post-eccentric and post-concentric arm ergometry. Third, AIx@75 was elevated at 10 min post-exercise, but returned to baseline values at 30 min post-exercise in both groups.

Our pPWV results (top panel of Figure 5) are in agreement with findings from Ranadive et al. (2012), who reported that maximal concentric upper body cycling can acutely decrease arterial stiffness in the arm. Acute decreases in pPWV are thought to be largely due to increases in nitric oxide which can contribute to vasodilation (C. Goto et al., 2003). Additionally, our observation that cPWV did not change through concentric arm cycling agrees with previous findings from Ranadive et al. (2012). However, it was not previously known if eccentric arm cycling would elicit similar responses.

Arm cycling recruits a smaller muscle mass compared to many other forms of aerobic exercise, such as running or biking. Therefore, arm blood flow is higher during arm cycling compared to whole body exercise (Volianitis \& Secher, 2002). Hence, it is plausible that the vasculature in the arms would be primarily effected during our protocol and not the descending aorta. Furthermore, changes in the stiffness of muscular peripheral arteries are 
due to changes in endothelial function, whereas the central arteries change more so due to structural changes associated with aging (Choi et al., 2010).

AIx has been demonstrated to be influenced independently from pulse wave velocity and is affected by heart rate to a greater extent (Kelly et al., 2001). Heart rate returned to baseline values by $30 \mathrm{~min}$ post-eccentric arm cycling, but was still elevated at $30 \mathrm{~min}$ postconcentric arm cycling. This may partially explain the disparity between AIx and PWV responses. Increases in aortic pulse pressure were similar at $30 \mathrm{~min}$ post-exercise for the eccentric and concentric groups ( $\sim \mathrm{mmHg}$ ). Elevated aortic pulse pressure, and / or heart rate, can increase the pulsatility to end organs such as the brain and kidney and lead to long-term damage (Augustine et al., 2016). Increased aortic pulsatility is also noted to increase the risk for coronary heart disease (Nishijima et al., 2001). Aortic pulsatile load increased after exercise and remained elevated 30 minutes after in each group.

It would be beneficial to include more female participants in future studies to allow for potential sex differences to be examined. Measurements of PWV were taken at 10 and 30 minutes to measure acute changes following exercise and after a brief recovery. However, it would be beneficial to add additional time points, as the cardiovascular system can rapidly change following exercise.

Our findings have potential implications for clinicians who prescribe exercise to improve upper body strength to patient populations, especially those with cardiovascular impairments. Specifically, our results demonstrate that eccentric arm cycling can be used to provide significant mechanical stress at moderate levels of perceived exertion while not increasing arterial stiffness. This exercise modality could also be useful in athletic 
populations to increase performance in which upper-body strength and endurance is important, such as rowing or cross-country skiing.

These acute findings, in conjunction with our recent longitudinal training study that indicated no change in pPWV or cPWV (Elmer et al., 2017), demonstrate that eccentric arm cycling does not appear to negatively influence arterial stiffness. These results are promising, considering that participants increased their upper body strength and power in our longitudinal eccentric exercise study (Elmer et al., 2017), whereas traditional longitudinal upper body resistance training has been reported to increase pulse wave velocity (Okamoto et al., 2009). These findings indicate that eccentric arm cycling appears to be safe for healthy individuals in regard to arterial function. It is currently unknown if these findings will extend to those with pre-clinical, or clinical, conditions such as hypertension or coronary artery disease. 


\section{Summary, Limitations, and Future Directions}

\subsection{Summary}

Our results suggest that a key to reducing the negative effects of resistance exercise on arterial function is to combine it with aerobic exercise, either within a single session or simultaneously. Eccentric arm cycling is a novel form of resistance exercise at aerobic capacities that prevents adverse arterial responses.

\subsection{Limitations}

Both studies have a pool of young, healthy individuals. Although this is an important first step to determine the effects of combined resistance and aerobic exercise, it limits our ability to prescribe exercise to clinical populations. Additionally, our sample is not large enough to adequately examine potential sex differences - something that continues to be absent in much of the literature.

Peripheral stiffness measurements were focused only in the arm (carotid-radial). Recently, there has been a focus on differential response in the upper and lower arterial segments (Mutter, Cooke, Saleh, Gomez, \& Daskalopoulou, 2017). Additional recordings of femoral-pedal pulse wave velocities could further our understanding of cardiovascular responses to combined resistance and aerobic exercise.

\subsection{Future Directions}

Future studies could use more invasive measures to determine the mechanisms that are responsible for the observed cardiovascular responses. This might include measurements of nitric oxide, endothelin-1, and other vasoactive substances. Another 
regulatory mechanism that could be further studied is muscle sympathetic nerve activity, which is associated with arterial stiffness (Swierblewska et al., 2010). Ultrasonography and the flow-mediated dilation technique could also offer further insight into the changes in arterial diameter and stiffness after eccentric exercise. 


\section{References}

Abbiss, C. R., Quod, M. J., Levin, G., Martin, D. T., \& Laursen, P. B. (2009). Accuracy of the Velotron ergometer and SRM power meter. Int J Sports Med, 30(2), 107112. doi: $10.1055 / \mathrm{s}-0028-1103285$

Ashor, A. W., Lara, J., Siervo, M., Celis-Morales, C., \& Mathers, J. C. (2014). Effects of exercise modalities on arterial stiffness and wave reflection: a systematic review and meta-analysis of randomized controlled trials. PLoS One, 9(10), e1 10034. doi:10.1371/journal.pone.0110034

Augustine, J. A., Yoon, E. S., Choo, J., Heffernan, K. S., \& Jae, S. Y. (2016). The Relationship Between Cardiorespiratory Fitness and Aortic Stiffness in Women with Central Obesity. J Womens Health (Larchmt), 25(7), 680-686. doi:10.1089/jwh.2015.5314

Beck, D. T., Casey, D. P., Martin, J. S., Emerson, B. D., \& Braith, R. W. (2013). Exercise training improves endothelial function in young prehypertensives. Exp Biol Med (Maywood), 238(4), 433-441. doi:10.1177/1535370213477600

Beck, D. T., Martin, J. S., Casey, D. P., \& Braith, R. W. (2013). Exercise training reduces peripheral arterial stiffness and myocardial oxygen demand in young prehypertensive subjects. Am J Hypertens, 26(9), 1093-1102. doi:10.1093/ajh/hpt080

Booth, J. N., 3rd, Li, J., Zhang, L., Chen, L., Muntner, P., \& Egan, B. (2017). Trends in Prehypertension and Hypertension Risk Factors in US Adults: 1999-2012. Hypertension, 70(2), 275-284. doi:10.1161/HYPERTENSIONAHA.116.09004

Borg, G. A. (1982). Psychophysical bases of perceived exertion. Med Sci Sports Exerc, 14(5), 377-381.

Carrasco, D. I., Delp, M. D., \& Ray, C. A. (1999). Effect of concentric and eccentric muscle actions on muscle sympathetic nerve activity. $J$ Appl Physiol (1985), 86(2), 558-563.

Carthy, E. R. (2014). Autonomic dysfunction in essential hypertension: A systematic review. Ann Med Surg (Lond), 3(1), 2-7. doi:10.1016/j.amsu.2013.11.002

Chen, C. H., Nevo, E., Fetics, B., Pak, P. H., Yin, F. C., Maughan, W. L., \& Kass, D. A. (1997). Estimation of central aortic pressure waveform by mathematical transformation of radial tonometry pressure. Validation of generalized transfer function. Circulation, 95(7), 1827-1836.

Choi, C. U., Kim, E. J., Kim, S. H., Shin, S. Y., Choi, U. J., Kim, J. W., . . Oh, D. J. (2010). Differing effects of aging on central and peripheral blood pressures and 
pulse wave velocity: a direct intraarterial study. J Hypertens, 28(6), 1252-1260. doi:10.1097/HJH.0b013e328337dad6

Collier, S. R., Diggle, M. D., Heffernan, K. S., Kelly, E. E., Tobin, M. M., \& Fernhall, B. (2010). Changes in arterial distensibility and flow-mediated dilation after acute resistance vs. aerobic exercise. J Strength Cond Res, 24(10), 2846-2852. doi:10.1519/JSC.0b013e3181e $840 \mathrm{e} 0$

Cook, J. N., DeVan, A. E., Schleifer, J. L., Anton, M. M., Cortez-Cooper, M. Y., \& Tanaka, H. (2006). Arterial compliance of rowers: implications for combined aerobic and strength training on arterial elasticity. Am J Physiol Heart Circ Physiol, 290(4), H1596-1600. doi:10.1152/ajpheart.01054.2005

DeVan, A. E., Anton, M. M., Cook, J. N., Neidre, D. B., Cortez-Cooper, M. Y., \& Tanaka, H. (2005). Acute effects of resistance exercise on arterial compliance. $J$ Appl Physiol (1985), 98(6), 2287-2291. doi:10.1152/japplphysiol.00002.2005

Donnelly, J. E., Blair, S. N., Jakicic, J. M., Manore, M. M., Rankin, J. W., Smith, B. K., \& American College of Sports, M. (2009). American College of Sports Medicine Position Stand. Appropriate physical activity intervention strategies for weight loss and prevention of weight regain for adults. Med Sci Sports Exerc, 41(2), 459471. doi:10.1249/MSS.0b013e3181949333

Doonan, R. J., Mutter, A., Egiziano, G., Gomez, Y. H., \& Daskalopoulou, S. S. (2013). Differences in arterial stiffness at rest and after acute exercise between young men and women. Hypertens Res, 36(3), 226-231. doi:10.1038/hr.2012.158

Elmer, S. J., Anderson, D. J., Wakeham, T. R., Kilgas, M. A., Durocher, J. J., Lindstedt, S. L., \& LaStayo, P. C. (2017). Chronic eccentric arm cycling improves maximum upper-body strength and power. Eur J Appl Physiol, 117(7), 14731483. doi:10.1007/s00421-017-3642-9

Elmer, S. J., Danvind, J., \& Holmberg, H. C. (2013). Development of a novel eccentric arm cycle ergometer for training the upper body. Med Sci Sports Exerc, 45(1), 206-211. doi:10.1249/MSS.0b013e318269c79c

Elmer, S. J., \& LaStayo, P. C. (2014). Revisiting the positive aspects of negative work. $J$ Exp Biol, 217(Pt 14), 2434-2436. doi:10.1242/jeb.092247

Elmer, S. J., Marshall, C. S., McGinnis, K. R., Van Haitsma, T. A., \& LaStayo, P. C. (2013). Eccentric arm cycling: physiological characteristics and potential applications with healthy populations. Eur J Appl Physiol, 113(10), 2541-2552. doi: $10.1007 / \mathrm{s} 00421-013-2687-7$ 
Fahs, C. A., Heffernan, K. S., \& Fernhall, B. (2009). Hemodynamic and vascular response to resistance exercise with L-arginine. Med Sci Sports Exerc, 41(4), 773779. doi:10.1249/MSS.0b013e3181909d9d

Goto, C., Higashi, Y., Kimura, M., Noma, K., Hara, K., Nakagawa, K., . . Nara, I. (2003). Effect of different intensities of exercise on endothelium-dependent vasodilation in humans: role of endothelium-dependent nitric oxide and oxidative stress. Circulation, 108(5), 530-535. doi:10.1161/01.CIR.0000080893.55729.28

Goto, K., Higashiyama, M., Ishii, N., \& Takamatsu, K. (2005). Prior endurance exercise attenuates growth hormone response to subsequent resistance exercise. Eur J Appl Physiol, 94(3), 333-338. doi:10.1007/s00421-004-1296-x

Goto, K., Ishii, N., Sugihara, S., Yoshioka, T., \& Takamatsu, K. (2007). Effects of resistance exercise on lipolysis during subsequent submaximal exercise. Med Sci Sports Exerc, 39(2), 308-315. doi:10.1249/01.mss.0000246992.33482.cb

Green, D. J., Maiorana, A., O'Driscoll, G., \& Taylor, R. (2004). Effect of exercise training on endothelium-derived nitric oxide function in humans. J Physiol, 561(Pt 1), 1-25. doi:10.1113/jphysiol.2004.068197

Heffernan, K. S., Collier, S. R., Kelly, E. E., Jae, S. Y., \& Fernhall, B. (2007). Arterial stiffness and baroreflex sensitivity following bouts of aerobic and resistance exercise. Int J Sports Med, 28(3), 197-203. doi:10.1055/s-2006-924290

Heffernan, K. S., Jae, S. Y., Echols, G. H., Lepine, N. R., \& Fernhall, B. (2007). Arterial stiffness and wave reflection following exercise in resistance-trained men. Med Sci Sports Exerc, 39(5), 842-848. doi:10.1249/mss.0b013e318031b03c

Isner-Horobeti, M. E., Dufour, S. P., Vautravers, P., Geny, B., Coudeyre, E., \& Richard, R. (2013). Eccentric exercise training: modalities, applications and perspectives. Sports Med, 43(6), 483-512. doi:10.1007/s40279-013-0052-y

Kelly, R. P., Millasseau, S. C., Ritter, J. M., \& Chowienczyk, P. J. (2001). Vasoactive drugs influence aortic augmentation index independently of pulse-wave velocity in healthy men. Hypertension, 37(6), 1429-1433.

LaStayo, P., Marcus, R., Dibble, L., Frajacomo, F., \& Lindstedt, S. (2014). Eccentric exercise in rehabilitation: safety, feasibility, and application. $J$ Appl Physiol (1985), 116(11), 1426-1434. doi:10.1152/japplphysiol.00008.2013

LaStayo, P. C., Pierotti, D. J., Pifer, J., Hoppeler, H., \& Lindstedt, S. L. (2000). Eccentric ergometry: increases in locomotor muscle size and strength at low training intensities. Am J Physiol Regul Integr Comp Physiol, 278(5), R1282-1288. 
Laughlin, M. H. (1999). Cardiovascular response to exercise. Am J Physiol, 277(6 Pt 2), S244-259. doi:10.1152/advances.1999.277.6.S244

Laurent, S., Cockcroft, J., Van Bortel, L., Boutouyrie, P., Giannattasio, C., Hayoz, D., . . . European Network for Non-invasive Investigation of Large, A. (2006). Expert consensus document on arterial stiffness: methodological issues and clinical applications. Eur Heart J, 27(21), 2588-2605. doi:10.1093/eurheartj/eh1254

Li, Y., Bopp, M., Botta, F., Nussbaumer, M., Schafer, J., Roth, R., . . Hanssen, H. (2015). Lower Body vs. Upper Body Resistance Training and Arterial Stiffness in Young Men. Int J Sports Med, 36(12), 960-967. doi:10.1055/s-0035-1549921

Li, Y., Hanssen, H., Cordes, M., Rossmeissl, A., Endes, S., \& Schmidt-Trucksass, A. (2015). Aerobic, resistance and combined exercise training on arterial stiffness in normotensive and hypertensive adults: A review. Eur J Sport Sci, 15(5), 443-457. doi:10.1080/17461391.2014.955129

Miyachi, M. (2013). Effects of resistance training on arterial stiffness: a meta-analysis. $\mathrm{Br}$ J Sports Med, 47(6), 393-396. doi:10.1136/bjsports-2012-090488

Miyachi, M., Kawano, H., Sugawara, J., Takahashi, K., Hayashi, K., Yamazaki, K., . . . Tanaka, H. (2004). Unfavorable effects of resistance training on central arterial compliance: a randomized intervention study. Circulation, 110(18), 2858-2863. doi:10.1161/01.CIR.0000146380.08401.99

Mozaffarian, D., Benjamin, E. J., Go, A. S., Arnett, D. K., Blaha, M. J., Cushman, M., , . . Stroke Statistics, S. (2015). Heart disease and stroke statistics--2015 update: a report from the American Heart Association. Circulation, 131(4), e29-322. doi:10.1161/CIR.0000000000000152

Mutter, A. F., Cooke, A. B., Saleh, O., Gomez, Y. H., \& Daskalopoulou, S. S. (2017). A systematic review on the effect of acute aerobic exercise on arterial stiffness reveals a differential response in the upper and lower arterial segments. Hypertens Res, 40(2), 146-172. doi:10.1038/hr.2016.111

Nishijima, T., Nakayama, Y., Tsumura, K., Yamashita, N., Yoshimaru, K., Ueda, H., . . . Yoshikawa, J. (2001). Pulsatility of ascending aortic blood pressure waveform is associated with an increased risk of coronary heart disease. Am J Hypertens, 14(5 Pt 1), 469-473.

Nocon, M., Hiemann, T., Muller-Riemenschneider, F., Thalau, F., Roll, S., \& Willich, S. N. (2008). Association of physical activity with all-cause and cardiovascular mortality: a systematic review and meta-analysis. Eur J Cardiovasc Prev Rehabil, 15(3), 239-246. doi:10.1097/HJR.0b013e3282f55e09 
Okamoto, T., Masuhara, M., \& Ikuta, K. (2006a). Cardiovascular responses induced during high-intensity eccentric and concentric isokinetic muscle contraction in healthy young adults. Clin Physiol Funct Imaging, 26(1), 39-44.

doi:10.1111/j.1475-097X.2005.00651.x

Okamoto, T., Masuhara, M., \& Ikuta, K. (2006b). Effects of eccentric and concentric resistance training on arterial stiffness. J Hum Hypertens, 20(5), 348-354. doi:10.1038/sj.jhh.1001979

Okamoto, T., Masuhara, M., \& Ikuta, K. (2007). Combined aerobic and resistance training and vascular function: effect of aerobic exercise before and after resistance training. J Appl Physiol (1985), 103(5), 1655-1661.

doi:10.1152/japplphysiol.00327.2007

Okamoto, T., Masuhara, M., \& Ikuta, K. (2009). Upper but not lower limb resistance training increases arterial stiffness in humans. Eur J Appl Physiol, 107(2), 127134. doi:10.1007/s00421-009-1110-x

Patnode, C. D., Evans, C. V., Senger, C. A., Redmond, N., \& Lin, J. S. (2017). Behavioral Counseling to Promote a Healthful Diet and Physical Activity for Cardiovascular Disease Prevention in Adults Without Known Cardiovascular Disease Risk Factors: Updated Evidence Report and Systematic Review for the US Preventive Services Task Force. JAMA, 318(2), 175-193. doi:10.1001/jama.2017.3303

Pierce, D. R., Doma, K., \& Leicht, A. S. (2018). Acute Effects of Exercise Mode on Arterial Stiffness and Wave Reflection in Healthy Young Adults: A Systematic Review and Meta-Analysis. Front Physiol, 9, 73. doi:10.3389/fphys.2018.00073

Ranadive, S. M., Fahs, C. A., Yan, H., Rossow, L. M., Agiovlasitis, S., \& Fernhall, B. (2012). Comparison of the acute impact of maximal arm and leg aerobic exercise on arterial stiffness. Eur J Appl Physiol, 112(7), 2631-2635. doi:10.1007/s00421$011-2238-z$

Sacre, J. W., Jennings, G. L., \& Kingwell, B. A. (2014). Exercise and dietary influences on arterial stiffness in cardiometabolic disease. Hypertension, 63(5), 888-893. doi:10.1161/HYPERTENSIONAHA.113.02277

Sardeli, A. V., Gaspari, A. F., \& Chacon-Mikahil, M. P. (2015). About the article: Effect of combined aerobic and resistance training versus aerobic training on arterial stiffness. Int J Cardiol, 184, 519-520. doi:10.1016/j.ijcard.2015.03.019

Swierblewska, E., Hering, D., Kara, T., Kunicka, K., Kruszewski, P., Bieniaszewski, L., . . . Narkiewicz, K. (2010). An independent relationship between muscle sympathetic nerve activity and pulse wave velocity in normal humans. $J$ Hypertens, 28(5), 979-984. 
Townsend, R. R., Wilkinson, I. B., Schiffrin, E. L., Avolio, A. P., Chirinos, J. A., Cockcroft, J. R., . . A American Heart Association Council on, H. (2015). Recommendations for Improving and Standardizing Vascular Research on Arterial Stiffness: A Scientific Statement From the American Heart Association. Hypertension, 66(3), 698-722. doi:10.1161/HYP.0000000000000033

Vlachopoulos, C., Aznaouridis, K., \& Stefanadis, C. (2010). Prediction of cardiovascular events and all-cause mortality with arterial stiffness: a systematic review and meta-analysis. J Am Coll Cardiol, 55(13), 1318-1327. doi:10.1016/j.jacc.2009.10.061

Volianitis, S., \& Secher, N. H. (2002). Arm blood flow and metabolism during arm and combined arm and leg exercise in humans. J Physiol, 544(Pt 3), 977-984.

Yardley, J. E., Kenny, G. P., Perkins, B. A., Riddell, M. C., Malcolm, J., Boulay, P., .. . Sigal, R. J. (2012). Effects of performing resistance exercise before versus after aerobic exercise on glycemia in type 1 diabetes. Diabetes Care, 35(4), 669-675. doi: $10.2337 / \mathrm{dc} 11-1844$

Yardley, J. E., Sigal, R. J., Riddell, M. C., Perkins, B. A., \& Kenny, G. P. (2014). Performing resistance exercise before versus after aerobic exercise influences growth hormone secretion in type 1 diabetes. Appl Physiol Nutr Metab, 39(2), 262-265. doi:10.1139/apnm-2013-0329

Zieman, S. J., Melenovsky, V., \& Kass, D. A. (2005). Mechanisms, pathophysiology, and therapy of arterial stiffness. Arterioscler Thromb Vasc Biol, 25(5), 932-943. doi:10.1161/01.ATV.0000160548.78317.29 


\section{Appendix A. Raw Data for Study 1}

\section{A.1 Demographic Information}

\begin{tabular}{cccccccccc}
$\begin{array}{c}\text { SUBECT } \\
\#\end{array}$ & SEX & $\begin{array}{c}\text { AGE } \\
(\mathbf{y e a r})\end{array}$ & $\begin{array}{c}\text { HEIGHT } \\
(\mathbf{c m})\end{array}$ & $\begin{array}{c}\text { WEIGHT } \\
(\mathbf{k g})\end{array}$ & $\begin{array}{c}\text { BMI } \\
\left(\mathbf{k g} / \mathbf{m}^{2}\right)\end{array}$ & $\begin{array}{c}\text { SAP } \\
(\mathbf{m m H g})\end{array}$ & $\begin{array}{c}\text { DAP } \\
(\mathbf{m m H})\end{array}$ & $\begin{array}{c}\text { MAP } \\
(\mathbf{m m H g})\end{array}$ & $\begin{array}{c}\text { HR } \\
(\mathbf{b p m})\end{array}$ \\
\hline 1 & $\mathrm{M}$ & 33 & 181 & 95.6 & 29.2 & 137 & 79 & 98 & 59 \\
2 & $\mathrm{~F}$ & 22 & 170 & 61.8 & 21.4 & 93 & 58 & 70 & 45 \\
3 & $\mathrm{~F}$ & 20 & 168 & 59.8 & 21.2 & 107 & 57 & 74 & 56 \\
4 & $\mathrm{M}$ & 41 & 173 & 96.0 & 32.1 & 115 & 62 & 80 & 56 \\
5 & $\mathrm{M}$ & 21 & 180 & 84.0 & 25.9 & 128 & 70 & 89 & 66 \\
6 & $\mathrm{M}$ & 19 & 184 & 81.4 & 24.0 & 125 & 44 & 71 & 52 \\
7 & $\mathrm{M}$ & 21 & 176 & 72.2 & 23.3 & 120 & 73 & 89 & 61 \\
8 & $\mathrm{~F}$ & 32 & 165 & 56.9 & 20.9 & 118 & 77 & 91 & 50 \\
9 & $\mathrm{M}$ & 29 & 186 & 101.4 & 29.3 & 142 & 83 & 103 & 72 \\
10 & $\mathrm{M}$ & 21 & 173 & 80.2 & 26.8 & 125 & 76 & 92 & 66 \\
11 & $\mathrm{M}$ & 21 & 166 & 85.5 & 31.0 & 117 & 61 & 80 & 67 \\
12 & $\mathrm{M}$ & 21 & 179 & 80.8 & 25.2 & 110 & 53 & 72 & 61 \\
13 & $\mathrm{M}$ & 19 & 170 & 73.3 & 25.4 & 123 & 67 & 86 & 77 \\
14 & $\mathrm{M}$ & 19 & 166 & 61.9 & 22.5 & 115 & 66 & 82 & 56 \\
15 & $\mathrm{M}$ & 19 & 178 & 81.5 & 25.7 & 101 & 50 & 67 & 50 \\
16 & $\mathrm{~F}$ & 19 & 178 & 81.0 & 25.6 & 114 & 61 & 79 & 57 \\
17 & $\mathrm{~F}$ & 36 & 173 & 70.9 & 23.7 & 108 & 71 & 83 & 50
\end{tabular}


A.2 Target Heart Rate and 10 RM Strength Test

\begin{tabular}{cccccccc} 
Subject & $\begin{array}{c}\text { Target } \\
\text { HR } \\
\text { (bpm) }\end{array}$ & $\begin{array}{c}\text { Barbell } \\
\text { Squat } \\
\text { (lbs) }\end{array}$ & $\begin{array}{c}\text { Barbell } \\
\text { Bench } \\
\text { Press } \\
\text { (lbs) }\end{array}$ & $\begin{array}{c}\text { Seated } \\
\text { Lat Pull } \\
\text { Down } \\
\text { (lbs) }\end{array}$ & $\begin{array}{c}\text { Triceps } \\
\text { Pushdown } \\
\text { (lbs) }\end{array}$ & $\begin{array}{c}\text { Siceps } \\
\text { Curl } \\
\text { (lbs) }\end{array}$ & $\begin{array}{c}\text { Single } \\
\text { Leg } \\
\text { Lunge } \\
\text { (lbs) }\end{array}$ \\
\hline 1 & 149 & 185 & 165 & 130 & 60 & 55 & 65 \\
2 & 152 & 115 & 95 & 60 & 40 & 40 & 65 \\
3 & 157 & 115 & 55 & 60 & 30 & 30 & 65 \\
4 & 142 & 80 & 155 & 90 & 60 & 55 & 30 \\
5 & 159 & 155 & 115 & 70 & 40 & 50 & 25 \\
6 & 156 & 225 & 105 & 100 & 50 & 50 & 95 \\
7 & 158 & 135 & 145 & 110 & 50 & 55 & 55 \\
8 & 146 & 85 & 75 & 60 & 30 & 30 & 15 \\
9 & 155 & 135 & 115 & 100 & 50 & 45 & 45 \\
10 & 159 & 95 & 155 & 100 & 60 & 70 & 25 \\
11 & 159 & 175 & 125 & 70 & 50 & 65 & 75 \\
12 & 158 & 205 & 155 & 90 & 40 & 45 & 110 \\
13 & 164 & 155 & 125 & 70 & 40 & 50 & 25 \\
14 & 157 & 205 & 125 & 60 & 40 & 35 & 105 \\
15 & 156 & 155 & 105 & 90 & 40 & 45 & 0 \\
16 & 158 & 155 & 75 & 80 & 40 & 45 & 50 \\
17 & 143 & 65 & 60 & 50 & 30 & 30 & 25
\end{tabular}


A.3 Brachial Hemodynamics: RA Pre-Exercise

\begin{tabular}{ccccc} 
Subject \# & SAP & DAP & MAP & HR \\
\hline 1 & 144 & 65 & 91 & 96 \\
2 & 112 & 54 & 73 & 62 \\
3 & 145 & 63 & 90 & 99 \\
4 & 145 & 78 & 100 & 77 \\
5 & 135 & 60 & 85 & 97 \\
6 & 135 & 47 & 76 & 57 \\
7 & 140 & 66 & 91 & 106 \\
8 & 123 & 67 & 86 & 67 \\
9 & 182 & 63 & 103 & 117 \\
10 & 115 & 53 & 74 & 101 \\
11 & 149 & 49 & 82 & 51 \\
12 & 148 & 47 & 81 & 111 \\
13 & 133 & 75 & 94 & 109 \\
14 & 137 & 59 & 85 & 121 \\
15 & 109 & 40 & 63 & 99 \\
16 & 120.0 & 57 & 78 & 64 \\
17 & 120.0 & 68 & 85 & 80
\end{tabular}

\section{A.4 Brachial Hemodynamics: AR Pre-Exercise}

\begin{tabular}{ccccc} 
Subject \# & SAP & DAP & MAP & HR \\
\hline 1 & 119 & 68 & 85 & 53 \\
2 & 103 & 58 & 73 & 45 \\
3 & 104 & 52 & 69 & 52 \\
4 & 115 & 62 & 80 & 56 \\
5 & 127 & 67 & 87 & 66 \\
6 & 113 & 52 & 72 & 54 \\
7 & 119 & 70 & 86 & 70 \\
8 & 118 & 77 & 91 & 50 \\
9 & 141 & 72 & 95 & 71 \\
10 & 120 & 68 & 85 & 78 \\
11 & 111 & 56 & 74 & 48 \\
12 & 115 & 64 & 81 & 52 \\
13 & 120 & 64 & 83 & 72 \\
14 & 121 & 68 & 86 & 51 \\
15 & 103 & 52 & 69 & 54 \\
16 & 116 & 59 & 78 & 55 \\
17 & 110 & 66 & 81 & 48
\end{tabular}


A.5 Brachial Hemodynamics: RA Mid-Exercise

\begin{tabular}{ccccc} 
Subject \# & SAP & DAP & MAP & HR \\
\hline 1 & 144 & 65 & 91 & 96 \\
2 & 112 & 54 & 73 & 62 \\
3 & 145 & 63 & 90 & 99 \\
4 & 145 & 78 & 100 & 77 \\
5 & 135 & 60 & 85 & 97 \\
6 & 135 & 47 & 76 & 57 \\
7 & 140 & 66 & 91 & 106 \\
8 & 123 & 67 & 86 & 67 \\
9 & 182 & 63 & 103 & 117 \\
10 & 115 & 53 & 74 & 101 \\
11 & 149 & 49 & 82 & 51 \\
12 & 148 & 47 & 81 & 111 \\
13 & 133 & 75 & 94 & 109 \\
14 & 137 & 59 & 85 & 121 \\
15 & 109 & 40 & 63 & 99 \\
16 & 120 & 57 & 78 & 64 \\
17 & 120 & 68 & 85 & 80
\end{tabular}

\section{A.6 Brachial Hemodynamics: AR Mid-Exercise}

\begin{tabular}{ccccc} 
Subject \# & SAP & DAP & MAP & HR \\
\hline 1 & 137 & 66 & 90 & 122 \\
2 & 137 & 67 & 90 & 86 \\
3 & 127 & 66 & 86 & 99 \\
4 & 137 & 58 & 84 & 106 \\
5 & 140 & 62 & 88 & 119 \\
6 & 134 & 56 & 82 & 69 \\
7 & 114 & 70 & 85 & 112 \\
8 & 120 & 72 & 88 & 65 \\
9 & 151 & 53 & 86 & 105 \\
10 & 125 & 62 & 83 & 107 \\
11 & 133 & 50 & 78 & 97 \\
12 & 125 & 38 & 67 & 106 \\
13 & 136 & 61 & 86 & 108 \\
14 & 143 & 64 & 90 & 118 \\
15 & 137 & 52 & 80 & 100 \\
16 & 123 & 67 & 86 & 83 \\
17 & 141 & 72 & 95 & 100
\end{tabular}


A.7 Brachial Hemodynamics: RA 0 Minutes Post-Exercise

\begin{tabular}{ccccc} 
Subject \# & SAP & DAP & MAP & HR \\
\hline 1 & 147 & 73 & 98 & 94 \\
2 & 121 & 67 & 85 & 76 \\
3 & 122 & 73 & 89 & 98 \\
4 & 121 & 87 & 98 & 88 \\
5 & 133 & 71 & 92 & 102 \\
6 & 138 & 60 & 86 & 80 \\
7 & 143 & 79 & 100 & 114 \\
8 & 143 & 73 & 96 & 87 \\
9 & 160 & 79 & 106 & 106 \\
10 & 111 & 57 & 75 & 102 \\
11 & 132 & 55 & 81 & 103 \\
12 & 125 & 67 & 86 & 85 \\
13 & 132 & 56 & 81 & 109 \\
14 & 132 & 51 & 78 & 114 \\
15 & 143 & 58 & 86 & 103 \\
16 & 129 & 72 & 91 & 99 \\
17 & 121 & 73 & 89 & 89
\end{tabular}

A.8 Brachial Hemodynamics: AR 0 Minutes Post-Exercise

\begin{tabular}{ccccc} 
Subject \# & SAP & DAP & MAP & HR \\
\hline 1 & 137 & 66 & 90 & 122 \\
2 & 137 & 67 & 90 & 86 \\
3 & 127 & 66 & 86 & 99 \\
4 & 137 & 58 & 84 & 106 \\
5 & 140 & 62 & 88 & 119 \\
6 & 134 & 56 & 82 & 69 \\
7 & 114 & 70 & 85 & 112 \\
8 & 120 & 72 & 88 & 65 \\
9 & 151 & 53 & 86 & 105 \\
10 & 125 & 62 & 83 & 107 \\
11 & 133 & 50 & 78 & 97 \\
12 & 125 & 38 & 67 & 106 \\
13 & 136 & 61 & 86 & 108 \\
14 & 143 & 64 & 90 & 118 \\
15 & 137 & 52 & 80 & 100 \\
16 & 123 & 67 & 86 & 83 \\
17 & 141 & 72 & 95 & 100
\end{tabular}


A.9 Brachial Hemodynamics: RA 30 Minutes Post-Exercise

\begin{tabular}{ccccc} 
Subject \# & SAP & DAP & MAP & HR \\
\hline 1 & 122 & 69 & 87 & 60 \\
2 & 106 & 72 & 83 & 59 \\
3 & 104 & 60 & 75 & 70 \\
4 & 120 & 72 & 88 & 77 \\
5 & 121 & 68 & 86 & 75 \\
6 & 112 & 50 & 71 & 55 \\
7 & 110 & 67 & 81 & 85 \\
8 & 113 & 71 & 85 & 66 \\
9 & 126 & 74 & 91 & 82 \\
10 & 106 & 48 & 67 & 95 \\
11 & 116 & 53 & 74 & 82 \\
12 & 110 & 54 & 73 & 66 \\
13 & 124 & 81 & 95 & 87 \\
14 & 111 & 48 & 69 & 84 \\
15 & 97 & 49 & 65 & 85 \\
16 & 110 & 59 & 76 & 67 \\
17 & 109 & 71 & 84 & 55
\end{tabular}

A.10 Brachial Hemodynamics: AR 30 Minutes Post-Exercise

\begin{tabular}{ccccc} 
Subject \# & SAP & DAP & MAP & HR \\
\hline 1 & 117 & 57 & 77 & 79 \\
2 & 107 & 61 & 76 & 57 \\
3 & 107 & 55 & 72 & 69 \\
4 & 120 & 69 & 86 & 81 \\
5 & 115 & 56 & 76 & 95 \\
6 & 120 & 52 & 75 & 53 \\
7 & 101 & 56 & 71 & 90 \\
8 & 116 & 73 & 87 & 58 \\
9 & 114 & 54 & 74 & 75 \\
10 & 122 & 64 & 83 & 89 \\
11 & 102 & 44 & 63 & 79 \\
12 & 110 & 44 & 66 & 87 \\
13 & 110 & 53 & 72 & 98 \\
14 & 120 & 35 & 63 & 117 \\
15 & 99 & 39 & 59 & 78 \\
16 & 115 & 58 & 77 & 69 \\
17 & 110 & 68 & 82 & 64
\end{tabular}




\section{A.11 Pulse Wave Analysis Trial 1: RA Pre-Exercise}

\begin{tabular}{ccccc} 
Subject \# & aSAP & aDAP & aMAP & aPP \\
\hline 1 & 104 & 77 & 89 & 27 \\
2 & 87 & 60 & 72 & 27 \\
3 & 90 & 57 & 73 & 33 \\
4 & 100 & 69 & 82 & 31 \\
5 & 104 & 76 & 89 & 28 \\
6 & 86 & 51 & 64 & 35 \\
7 & 90 & 62 & 75 & 28 \\
8 & 102 & 73 & 86 & 29 \\
9 & 123 & 84 & 102 & 39 \\
10 & 86 & 61 & 73 & 25 \\
11 & 92 & 57 & 74 & 35 \\
12 & 91 & 58 & 71 & 33 \\
13 & 102 & 70 & 84 & 32 \\
14 & 95 & 68 & 80 & 27 \\
15 & 79 & 50 & 62 & 29 \\
16 & 83 & 57 & 67 & 26 \\
17 & 99 & 71 & 82 & 28
\end{tabular}

\section{A.12 Pulse Wave Analysis Trial 2: RA Pre-Exercise}

\begin{tabular}{ccccc} 
Subject \# & aSAP & aDAP & aMAP & aPP \\
\hline 1 & 104 & 77 & 88 & 27 \\
2 & 87 & 61 & 73 & 26 \\
3 & 89 & 57 & 72 & 32 \\
4 & 100 & 69 & 83 & 31 \\
5 & 104 & 76 & 90 & 28 \\
6 & 86 & 51 & 63 & 35 \\
7 & 90 & 62 & 74 & 28 \\
8 & 104 & 73 & 87 & 31 \\
9 & 124 & 84 & 102 & 40 \\
10 & 85 & 61 & 72 & 24 \\
11 & 92 & 57 & 73 & 35 \\
12 & 94 & 59 & 72 & 35 \\
13 & 101 & 70 & 84 & 31 \\
14 & 92 & 67 & 79 & 25 \\
15 & 78 & 50 & 61 & 28 \\
16 & 83 & 57 & 68 & 26 \\
17 & 98 & 71 & 81 & 27
\end{tabular}




\section{A.13 Pulse Wave Analysis Trial 1: AR Pre-Exercise}

\begin{tabular}{ccccc} 
Subject \# & aSAP & aDAP & aMAP & aPP \\
\hline 1 & 99 & 69 & 81 & 30 \\
2 & 84 & 58 & 68 & 26 \\
3 & 87 & 53 & 70 & 34 \\
4 & 95 & 62 & 76 & 33 \\
5 & 101 & 67 & 79 & 34 \\
6 & 88 & 52 & 66 & 36 \\
7 & 98 & 71 & 83 & 27 \\
8 & 111 & 77 & 93 & 34 \\
9 & 113 & 73 & 91 & 40 \\
10 & 101 & 69 & 85 & 32 \\
11 & 91 & 57 & 71 & 34 \\
12 & 97 & 64 & 78 & 33 \\
13 & 96 & 65 & 78 & 31 \\
14 & 104 & 69 & 85 & 35 \\
15 & 82 & 52 & 65 & 30 \\
16 & 97 & 60 & 77 & 37 \\
17 & 96 & 66 & 78 & 30
\end{tabular}

\section{A.14 Pulse Wave Analysis Trial 2: AR Pre-Exercise}

\begin{tabular}{ccccc} 
Subject \# & aSAP & aDAP & aMAP & aPP \\
\hline 1 & 100 & 68 & 80 & 32 \\
2 & 84 & 58 & 70 & 26 \\
3 & 86 & 53 & 69 & 33 \\
4 & 96 & 63 & 77 & 33 \\
5 & 101 & 67 & 79 & 34 \\
6 & 88 & 52 & 66 & 36 \\
7 & 98 & 71 & 85 & 27 \\
8 & 111 & 77 & 92 & 34 \\
9 & 112 & 73 & 91 & 39 \\
10 & 98 & 69 & 82 & 29 \\
11 & 91 & 57 & 71 & 35 \\
12 & 97 & 65 & 78 & 32 \\
13 & 96 & 64 & 78 & 32 \\
14 & 104 & 69 & 85 & 35 \\
15 & 83 & 52 & 64 & 31 \\
16 & 96 & 60 & 75 & 36 \\
17 & 97 & 66 & 79 & 31
\end{tabular}




\section{A.15 Pulse Wave Analysis Trial 1: RA Mid-Exercise}

\begin{tabular}{ccccc} 
Subject \# & aSAP & aDAP & aMAP & aPP \\
\hline 1 & $\cdot$ &. & $\cdot$ & $\cdot$ \\
2 & 93 & 55 & 72 & 38 \\
3 & 109 & 64 & 79 & 45 \\
4 & 120 & 80 & 97 & 40 \\
5 & 105 & 64 & 81 & 41 \\
6 & 99 & 47 & 65 & 52 \\
7 & 112 & 69 & 87 & 43 \\
8 & 105 & 68 & 85 & 37 \\
9 & 131 & 66 & 89 & 65 \\
10 & 94 & 54 & 73 & 40 \\
11 & 114 & 55 & 80 & 59 \\
12 & 105 & 50 & 69 & 55 \\
13 & 105 & 59 & 79 & 46 \\
14 & 106 & 63 & 83 & 43 \\
15 & 89 & 41 & 62 & 48 \\
16 & 84 & 58 & 70 & 26 \\
17 & 99 & 69 & 84 & 30
\end{tabular}

\section{A.16 Pulse Wave Analysis Trial 2: RA Mid-Exercise}

\begin{tabular}{ccccc} 
Subject \# & aSAP & aDAP & aMAP & aPP \\
\hline 1 & $\cdot$ &. &. & $\cdot$ \\
2 & 93 & 55 & 73 & 38 \\
3 &. &. &. &. \\
4 & 120 & 80 & 98 & 40 \\
5 & 105 & 64 & 81 & 41 \\
6 & 100 & 48 & 68 & 52 \\
7 & 112 & 69 & 87 & 43 \\
8 & 104 & 68 & 85 & 36 \\
9 & 131 & 67 & 91 & 64 \\
10 & 92 & 54 & 71 & 38 \\
11 & 114 & 54 & 79 & 60 \\
12 & 107 & 48 & 73 & 59 \\
13 & 104 & 59 & 79 & 45 \\
14 & 106 & 62 & 83 & 44 \\
15 & 88 & 42 & 62 & 46 \\
16 & 83 & 57 & 69 & 26 \\
17 & 100 & 69 & 85 & 31
\end{tabular}




\section{A.17 Pulse Wave Analysis Trial 1: AR Mid-Exercise}

\begin{tabular}{ccccc} 
Subject \# & aSAP & aDAP & aMAP & aPP \\
\hline 1 & 113 & 76 & 90 & 37 \\
2 & 93 & 59 & 68 & 34 \\
3 & 106 & 75 & 90 & 31 \\
4 & 119 & 77 & 97 & 42 \\
5 & 119 & 78 & 95 & 41 \\
6 & 110 & 60 & 81 & 50 \\
7 & 106 & 79 & 91 & 27 \\
8 & 112 & 82 & 97 & 30 \\
9 & 118 & 76 & 94 & 42 \\
10 & 93 & 65 & 78 & 28 \\
11 & 102 & 57 & 80 & 45 \\
12 & 111 & 74 & 89 & 37 \\
13 & 106 & 65 & 83 & 41 \\
14 & 102 & 72 & 87 & 30 \\
15 & 104 & 69 & 84 & 35 \\
16 & 103 & 71 & 86 & 32 \\
17 & 106 & 80 & 93 & 26
\end{tabular}

\section{A.18 Pulse Wave Analysis Trial 2: AR Mid-Exercise}

\begin{tabular}{ccccc} 
Subject \# & aSAP & aDAP & aMAP & aPP \\
\hline 1 & 113 & 76 & 88 & 37 \\
2 & 92 & 58 & 68 & 34 \\
3 & 105 & 75 & 89 & 33 \\
4 & 119 & 77 & 97 & 42 \\
5 & 119 & 77 & 95 & 42 \\
6 & 109 & 60 & 81 & 49 \\
7 & 106 & 79 & 91 & 27 \\
8 & 112 & 82 & 97 & 30 \\
9 & 119 & 76 & 94 & 43 \\
10 & 94 & 65 & 77 & 29 \\
11 & 101 & 57 & 77 & 44 \\
12 & 110 & 74 & 89 & 36 \\
13 & 107 & 68 & 84 & 39 \\
14 & 102 & 72 & 87 & 30 \\
15 & 109 & 70 & 87 & 39 \\
16 & 103 & 71 & 86 & 32 \\
17 & 106 & 80 & 93 & 26
\end{tabular}


A.19 Pulse Wave Analysis Trial 1: RA 0 Minutes Post-Exercise

\begin{tabular}{ccccc} 
Subject \# & aSAP & aDAP & aMAP & aPP \\
\hline 1 & 118 & 78 & 96 & 40 \\
2 & 100 & 68 & 84 & 32 \\
3 & 102 & 76 & 89 & 26 \\
4 & 108 & 89 & 98 & 19 \\
5 & 108 & 75 & 89 & 33 \\
6 & 108 & 62 & 83 & 46 \\
7 & 118 & 83 & 100 & 35 \\
8 & 119 & 76 & 98 & 43 \\
9 & 127 & 85 & 102 & 42 \\
10 & 92 & 59 & 73 & 33 \\
11 & 101 & 59 & 76 & 42 \\
12 & 105 & 71 & 84 & 34 \\
13 & 110 & 80 & 94 & 30 \\
14 & 99 & 55 & 76 & 44 \\
15 & 112 & 61 & 84 & 51 \\
16 & 105 & 75 & 89 & 30 \\
17 & 103 & 75 & 90 & 28
\end{tabular}

A.20 Pulse Wave Analysis Trial 2: RA 0 Minutes Post-Exercise

\begin{tabular}{ccccc} 
Subject \# & aSAP & aDAP & aMAP & aPP \\
\hline 1 & 120 & 76 & 94 & 44 \\
2 & 104 & 69 & 87 & 35 \\
3 & 102 & 76 & 88 & 26 \\
4 & 108 & 89 & 98 & 19 \\
5 & 108 & 75 & 90 & 33 \\
6 & 109 & 62 & 83 & 47 \\
7 & 118 & 83 & 98 & 35 \\
8 & 120 & 75 & 98 & 45 \\
9 & 126 & 83 & 100 & 43 \\
10 & 92 & 59 & 74 & 33 \\
11 & 101 & 59 & 76 & 42 \\
12 & 104 & 72 & 84 & 32 \\
13 & 110 & 80 & 94 & 30 \\
14 & 99 & 55 & 76 & 44 \\
15 & 107 & 59 & 80 & 48 \\
16 & 106 & 74 & 90 & 32 \\
17 & 104 & 75 & 90 & 29
\end{tabular}


A.21 Pulse Wave Analysis Trial 1: AR 0 Minutes Post-Exercise

\begin{tabular}{ccccc} 
Subject \# & aSAP & aDAP & aMAP & aPP \\
\hline 1 & 109 & 73 & 85 & 36 \\
2 & 107 & 68 & 86 & 39 \\
3 & 106 & 68 & 85 & 38 \\
4 & 110 & 70 & 84 & 40 \\
5 & 108 & 65 & 83 & 43 \\
6 & 103 & 57 & 75 & 46 \\
7 & 97 & 72 & 82 & 25 \\
8 & 107 & 73 & 90 & 34 \\
9 & 112 & 60 & 79 & 52 \\
10 & 103 & 62 & 80 & 41 \\
11 & 101 & 56 & 76 & 45 \\
12 & 89 & 41 & 60 & 48 \\
13 & 103 & 51 & 75 & 52 \\
14 & 110 & 68 & 89 & 42 \\
15 & 111 & 56 & 77 & 55 \\
16 & 100 & 68 & 83 & 32 \\
17 & 115 & 75 & 93 & 40
\end{tabular}

A.22 Pulse Wave Analysis Trial 2: AR 0 Minutes Post-Exercise

\begin{tabular}{ccccc} 
Subject \# & aSAP & aDAP & aMAP & aPP \\
\hline 1 & 109 & 72 & 85 & 37 \\
2 & 107 & 68 & 83 & 39 \\
3 & 104 & 68 & 84 & 36 \\
4 & 108 & 67 & 82 & 41 \\
5 & 108 & 64 & 82 & 44 \\
6 & 104 & 57 & 76 & 47 \\
7 & 97 & 72 & 82 & 25 \\
8 & 105 & 73 & 88 & 32 \\
9 & 114 & 58 & 79 & 56 \\
10 & 104 & 64 & 81 & 40 \\
11 & 103 & 58 & 76 & 45 \\
12 & 91 & 40 & 61 & 51 \\
13 & 102 & 51 & 74 & 51 \\
14 & 110 & 68 & 89 & 42 \\
15 & 112 & 54 & 77 & 58 \\
16 & 102 & 69 & 85 & 33 \\
17 & 114 & 74 & 94 & 40
\end{tabular}


A.23 Pulse Wave Analysis Trial 1: RA 30 Minutes Post-Exercise

\begin{tabular}{ccccc} 
Subject \# & aSAP & aDAP & aMAP & aPP \\
\hline 1 & 100 & 70 & 83 & 30 \\
2 & 93 & 72 & 81 & 21 \\
3 &. &. &. &. \\
4 & 102 & 74 & 86 & 28 \\
5 & 99 & 69 & 81 & 30 \\
6 & 86 & 50 & 65 & 36 \\
7 & 94 & 69 & 80 & 25 \\
8 & 98 & 72 & 85 & 26 \\
9 & 103 & 75 & 87 & 28 \\
10 & 87 & 53 & 66 & 34 \\
11 & 91 & 55 & 72 & 36 \\
12 & 87 & 55 & 69 & 32 \\
13 & 105 & 82 & 92 & 23 \\
14 & 87 & 49 & 65 & 38 \\
15 & 82 & 55 & 64 & 27 \\
16 & 92 & 60 & 74 & 32 \\
17 & 96 & 72 & 83 & 24
\end{tabular}

A.24 Pulse Wave Analysis Trial 2: RA 30 Minutes Post-Exercise

\begin{tabular}{ccccc} 
Subject \# & aSAP & aDAP & aMAP & aPP \\
\hline 1 & 100 & 70 & 83 & 30 \\
2 & 93 & 73 & 82 & 20 \\
3 &. &. &. &. \\
4 & 102 & 73 & 86 & 29 \\
5 & 99 & 69 & 82 & 30 \\
6 & 86 & 50 & 61 & 36 \\
7 & 92 & 68 & 77 & 24 \\
8 & 100 & 72 & 86 & 28 \\
9 & 103 & 75 & 87 & 28 \\
10 & 86 & 52 & 65 & 34 \\
11 & 90 & 55 & 71 & 35 \\
12 & 88 & 55 & 70 & 33 \\
13 & 105 & 83 & 93 & 22 \\
14 & 86 & 50 & 67 & 36 \\
15 & 81 & 54 & 63 & 27 \\
16 & 91 & 60 & 74 & 31 \\
17 & 97 & 72 & 83 & 25
\end{tabular}


A.25 Pulse Wave Analysis Trial 1: AR 30 Minutes Post-Exercise

\begin{tabular}{ccccc} 
Subject \# & aSAP & aDAP & aMAP & aPP \\
\hline 1 & 92 & 61 & 73 & 31 \\
2 & 87 & 61 & 73 & 26 \\
3 & 85 & 56 & 67 & 29 \\
4 & 101 & 71 & 84 & 30 \\
5 & 92 & 61 & 73 & 31 \\
6 & 91 & 53 & 67 & 38 \\
7 & 85 & 60 & 69 & 25 \\
8 & 102 & 74 & 87 & 28 \\
9 & 89 & 54 & 66 & 35 \\
10 & 99 & 66 & 79 & 33 \\
11 & 79 & 46 & 61 & 33 \\
12 & 88 & 52 & 66 & 36 \\
13 & 89 & 60 & 70 & 29 \\
14 & 85 & 41 & 59 & 44 \\
15 & 77 & 44 & 55 & 33 \\
16 & 91 & 59 & 74 & 32 \\
17 & 95 & 69 & 82 & 26
\end{tabular}

A.26 Pulse Wave Analysis Trial 2: AR 30 Minutes Post-Exercise

\begin{tabular}{ccccc} 
Subject \# & aSAP & aDAP & aMAP & aPP \\
\hline 1 & 91 & 59 & 71 & 32 \\
2 & 87 & 62 & 73 & 25 \\
3 & 86 & 56 & 72 & 30 \\
4 & 101 & 71 & 84 & 30 \\
5 & 93 & 64 & 75 & 29 \\
6 & 91 & 52 & 65 & 39 \\
7 & 85 & 62 & 70 & 23 \\
8 & 102 & 74 & 88 & 28 \\
9 & 90 & 55 & 68 & 35 \\
10 & 99 & 67 & 80 & 32 \\
11 & 78 & 45 & 59 & 33 \\
12 & 88 & 52 & 66 & 36 \\
13 & 88 & 59 & 71 & 29 \\
14 & 87 & 41 & 60 & 46 \\
15 & 74 & 41 & 53 & 33 \\
16 & 91 & 58 & 73 & 33 \\
17 & 94 & 69 & 81 & 25
\end{tabular}


A.27 Pulse Wave Velocity: RA Pre-Exercise

Peripheral PWV (m/s)

Trial 1

Trial 2

\begin{tabular}{ccccccccc} 
Subject \# & Value & SD & Value & SD & Value & SD & Value & SD \\
\hline 1 & 8.6 & 0.2 & 9.9 & 0.5 & 8.5 & 0.4 & 6.5 & 0.3 \\
2 & 4.1 & 0.2 & 6.9 & 0.3 & 5.3 & 0.2 & 6.2 & 0.4 \\
3 & 7.7 & 0.7 & 6.2 & 0.5 & 5.0 & 0.3 &. &. \\
4 & 8.2 & 0.6 & 7.2 & 0.5 & 6.1 & 0.3 & 6.5 & 0.6 \\
5 & 7.2 & 4.4 & 7.9 & 0.4 & 5.8 & 0.3 & 5.4 & 0.3 \\
6 & 5.6 & 0.3 & 6.3 & 0.5 & 4.7 & 0.4 & 5.3 & 0.3 \\
7 & 8.2 & 0.8 & 6.9 & 0.4 & 8.5 & 0.8 & 7.8 & 0.5 \\
8 & 8.5 & 0.8 & 8.0 & 0.6 & 5.8 & 0.4 & 5.3 & 0.4 \\
9 & 7.8 & 0.4 & 7.9 & 0.5 & 7.1 & 0.6 & 7.2 & 0.6 \\
10 & 7.1 & 0.6 & 6.2 & 0.4 & 5.3 & 0.5 & 4.8 & 0.3 \\
11 & 6.6 & 0.6 & 7.1 & 0.6 & 5.4 & 0.5 & 6.4 & 0.3 \\
12 & 7.7 & 0.7 & 7.1 & 0.6 & 4.1 & 0.2 & 5.0 & 0.4 \\
13 & 6.1 & 0.4 & 6.8 & 0.5 & 5.0 & 0.2 & 5.6 & 0.3 \\
14 & 7.6 & 0.8 & 11.3 & 1.2 & 4.8 & 0.3 & 5.8 & 0.4 \\
15 & 6.3 & 0.4 & 7.0 & 0.5 & 4.3 & 0.2 & 4.8 & 0.2 \\
16 & 5.5 & 0.6 & 5.1 & 0.3 & 4.8 & 0.4 & 4.7 & 0.3 \\
17 & 8.9 & 0.5 & 8.2 & 0.7 & 6.5 & 0.2 & 6.0 & 0.3
\end{tabular}

Central PWV (m/s)

Trial $1 \quad$ Trial 2 
A.28 Pulse Wave Velocity: AR Pre-Exercise

Peripheral PWV (m/s)

Trial 1

Trial 2

Central PWV (m/s)

Trial 1

Trial 2

\begin{tabular}{ccccccccc} 
Subject \# & Value & SD & Value & SD & Value & SD & Value & SD \\
\hline 1 & 6.6 & 0.6 & 9.6 & 0.6 & 5.9 & 0.3 & 6.0 & 0.4 \\
2 & 7.3 & 0.7 & 9.1 & 0.4 & 4.8 & 0.3 & 5.6 & 0.5 \\
3 & 6.0 & 0.4 & 7.2 & 0.4 & 5.0 & 0.4 & 4.4 & 0.2 \\
4 & 8.9 & 0.7 & 7.4 & 0.5 & 7.6 & 0.6 & 6.0 & 0.3 \\
5 & 7.6 & 0.5 & 7.0 & 0.5 & 6.2 & 0.3 & 6.5 & 0.5 \\
6 & 6.5 & 0.4 & 6.8 & 0.3 & 4.7 & 0.2 & 6.0 & 0.4 \\
7 & 7.3 & 0.7 & 7.3 & 0.4 & 5.7 & 0.4 & 5.7 & 0.5 \\
8 & 8.4 & 0.8 & 8.5 & 0.7 & 7.3 & 0.7 & 6.5 & 0.5 \\
9 & 7.1 & 0.5 & 7.4 & 0.5 & 6.4 & 0.6 & 6.9 & 0.5 \\
10 & 5.3 & 0.2 & 4.8 & 0.2 & 5.4 & 0.3 & 5.6 & 0.3 \\
11 & 6.5 & 0.4 & 6.2 & 0.6 & 6.0 & 0.5 & 5.7 & 0.5 \\
12 & 6.1 & 0.3 & 7.0 & 0.5 & 4.4 & 0.2 & 5.2 & 0.5 \\
13 & 6.9 & 0.5 & 7.1 & 0.4 & 5.9 & 0.5 & 5.2 & 0.5 \\
14 & 8.9 & 0.8 & 8.0 & 0.5 & 5.3 & 0.4 & 5.5 & 0.3 \\
15 & 6.1 & 0.5 & 7.0 & 0.6 & 3.8 & 0.2 & 3.9 & 0.2 \\
16 & 5.8 & 0.5 & 5.9 & 0.5 & 4.6 & 0.3 & 5.3 & 0.5 \\
17 & 11.3 & 0.9 & 9.2 & 0.6 & 5.5 & 0.3 & 5.4 & 0.2
\end{tabular}




\section{A.29 Pulse Wave Velocity: RA Mid-Exercise}

Peripheral PWV (m/s)

Trial 1

\begin{tabular}{ccccccccc} 
Subject \# & Value & SD & Value & SD & Value & SD & Value & SD \\
\hline 1 & 10.6 & 0.6 & 7.9 & 0.4 & 7.4 & 0.4 & 7.2 & 10.6 \\
2 & 7.2 & 0.6 & 7.5 & 0.4 & 6.9 & 0.4 & 6.3 & 7.2 \\
3 & 5.7 & 0.2 & 6.3 & 0.3 & 5.0 & 0.2 & 5.1 & 5.7 \\
4 & 7.5 & 0.4 & 7.4 & 0.5 & 7.1 & 0.4 & 7.3 & 7.5 \\
5 & 6.9 & 0.2 & 6.4 & 0.2 & 6.9 & 0.5 & 6.6 & 6.9 \\
6 & 6.2 & 0.4 & 7.0 & 0.3 & 5.1 & 0.3 & 5.4 & 6.2 \\
7 & 5.3 & 0.3 & 5.7 & 0.5 & 7.0 & 0.4 & 6.8 & 5.3 \\
8 & 9.3 & 0.8 & 7.0 & 0.3 & 5.6 & 0.3 & 6.0 & 9.3 \\
9 & 7.6 & 0.4 & 7.5 & 0.3 & 6.1 & 0.3 & 8.2 & 7.6 \\
10 & 5.4 & 0.2 & 4.9 & 0.2 & 5.1 & 0.2 & 5.2 & 5.4 \\
11 & 6.4 & 0.3 & 5.8 & 0.3 & 7.6 & 0.4 & 5.9 & 6.4 \\
12 & 6.3 & 0.3 & 6.4 & 0.3 & 4.8 & 0.2 & 4.4 & 6.3 \\
13 & 7.6 & 0.4 & 6.7 & 0.4 & 5.2 & 0.2 & 6.0 & 7.6 \\
14 & 6.3 & 0.3 & 6.7 & 0.3 & 5.8 & 0.4 & 5.4 & 6.3 \\
15 & 4.5 & 0.2 & 5.1 & 0.3 & 4.6 & 0.3 & 4.0 & 4.5 \\
16 & 5.5 & 0.2 & 5.8 & 0.3 & 5.6 & 0.6 & 5.6 & 5.5 \\
17 & 8.3 & 0.3 & 7.9 & 0.3 & 5.9 & 0.3 & 5.8 & 8.3
\end{tabular}

Central PWV (m/s)

Trial $1 \quad$ Trial 2

Trial 2 
A.30 Pulse Wave Velocity: AR Mid-Exercise

Peripheral PWV (m/s)

Trial 1

Trial 2

Central PWV (m/s)

Trial $1 \quad$ Trial 2

\begin{tabular}{ccccccccc} 
Subject \# & Value & SD & Value & SD & Value & SD & Value & SD \\
\hline 1 & 10.6 & 1.0 & 9.5 & 0.5 & 7.3 & 0.5 & 6.2 & 0.3 \\
2 & 6.8 & 0.4 & 6.7 & 0.4 & 4.4 & 0.3 & 4.5 & 0.3 \\
3 & 8.0 & 0.5 & 5.8 & 0.3 & 5.2 & 0.2 & 4.8 & 0.3 \\
4 & 8.7 & 0.6 & 8.5 & 0.6 & 7.7 & 0.4 & 8.7 & 0.4 \\
5 & 5.3 & 0.1 & 6.1 & 0.2 & 6.0 & 0.2 & 6.6 & 0.3 \\
6 & 6.4 & 0.5 & 6.3 & 0.3 & 4.5 & 0.2 & 6.0 & 0.5 \\
7 & 8.1 & 0.4 & 6.5 & 0.3 & 6.2 & 0.3 & 6.0 & 0.4 \\
8 & 7.8 & 0.5 & 8.9 & 0.7 & 6.1 & 0.5 & 6.9 & 0.6 \\
9 & 9 & 0.7 & 7.7 & 0.5 & 6.0 & 0.4 & 7.8 & 0.7 \\
10 & 7.2 & 0.2 & 6.2 & 0.2 & 5.5 & 0.1 & 5.9 & 0.2 \\
11 & 6.0 & 0.3 & 6.3 & 0.2 & 5.9 & 0.3 & 6.6 & 0.4 \\
12 & 8.0 & 0.4 & 7.4 & 0.4 & 5.1 & 0.2 &. &. \\
13 & 6.1 & 0.3 & 6.1 & 0.3 & 4.8 & 0.2 & 5.3 & 0.3 \\
14 & 9.1 & 0.6 & 7.5 & 0.7 & 4.8 & 0.3 & 6.0 & 0.4 \\
15 & 7.1 & 0.4 & 6.0 & 0.5 & 4.3 & 0.2 & 4.1 & 0.2 \\
16 & 7.7 & 0.5 & 7.1 & 0.6 & 5.3 & 0.5 & 5.8 & 0.6 \\
17 & 10.4 & 0.9 & 8.0 & 0.5 & 5.5 & 0.1 & 5.9 & 0.2
\end{tabular}




\section{A.31 Pulse Wave Velocity: RA 0 Min Post-Exercise}

Peripheral PWV (m/s)

Trial 1
Trial 2
Central PWV (m/s)

Trial 2

\begin{tabular}{ccccccccc} 
Subject \# & Value & SD & Value & SD & Value & SD & Value & SD \\
\hline 1 & 9.9 & 0.7 & 10.5 & 0.6 & 7.7 & 0.5 & 6.6 & 0.4 \\
2 & 6.9 & 0.3 & 7.8 & 0.3 & 6.1 & 0.5 & 6.6 & 0.3 \\
3 & 6.7 & 0.5 & 6.6 & 0.2 & 4.3 & 0.2 & 4.6 & 0.2 \\
4 & 7.8 & 0.3 & 8.5 & 0.3 & 6.9 & 0.4 & 7.3 & 0.4 \\
5 & 6.8 & 0.3 & 8.0 & 0.5 & 5.9 & 0.3 & 5.1 & 0.3 \\
6 & 6.4 & 0.4 & 6.0 & 0.3 & 5.8 & 0.4 & 5.7 & 0.4 \\
7 & 6.1 & 0.2 & 7.4 & 0.4 & 5.5 & 0.3 & 5.1 & 0.4 \\
8 & 9.1 & 0.6 & 7.8 & 0.4 & 4.7 & 0.2 & 5.7 & 0.4 \\
9 & 9.5 & 0.5 & 8.1 & 0.7 & 7.7 & 0.6 & 8.2 & 0.7 \\
10 & 6.0 & 0.2 & 6.8 & 0.2 & 4.7 & 0.2 & 4.8 & 0.2 \\
11 & 6.4 & 0.2 & 7.1 & 0.2 & 7.0 & 0.3 & 8.8 & 0.5 \\
12 & 6.9 & 0.4 & 7.0 & 0.3 & 5.3 & 0.3 & 4.6 & 0.3 \\
13 & 7.2 & 0.5 & 6.4 & 0.3 & 5.9 & 0.3 & 5.0 & 0.2 \\
14 & 7.1 & 0.4 & 6.7 & 0.4 & 5.1 & 0.3 & 5.4 & 0.2 \\
15 & 5.0 & 0.2 & 5.3 & 0.3 & 3.8 & 0.1 & 4.0 & 0.2 \\
16 & 6.7 & 0.4 & 5.8 & 0.4 & 5.0 & 0.4 & 5.3 & 0.5 \\
17 & 9.9 & 0.8 & 8.9 & 0.6 & 5.4 & 0.2 & 5.6 & 0.3
\end{tabular}




\section{A.32 Pulse Wave Velocity: AR 0 Min Post-Exercise}

Peripheral PWV (m/s)

Trial 1

\begin{tabular}{ccccccccc} 
Subject \# & Value & SD & Value & SD & Value & SD & Value & SD \\
\hline 1 & 7.8 & 0.4 & 7.8 & 0.3 & 7.6 & 0.5 & 7.7 & 0.5 \\
2 & 6.7 & 0.4 & 6.0 & 0.2 & 4.9 & 0.3 & 5.1 & 0.2 \\
3 & 6.5 & 0.3 & 6.0 & 0.4 & 5.7 & 0.3 & 5.8 & 0.2 \\
4 & 7.5 & 0.4 & 7.9 & 0.5 & 6.8 & 0.4 & 8.7 & 0.5 \\
5 & 6.5 & 0.3 & 5.3 & 0.2 & 7.3 & 0.5 & 6.0 & 0.2 \\
6 & 7.0 & 0.7 & 6.3 & 0.4 & 5.1 & 0.2 & 4.6 & 0.2 \\
7 & 5.8 & 0.2 & 6.3 & 0.3 & 5.5 & 0.4 & 5.4 & 0.3 \\
8 & 7.7 & 0.4 & 8.4 & 0.3 & 6.9 & 0.5 & 7.5 & 0.4 \\
9 & 7.0 & 0.3 & 6.1 & 0.2 & 6.4 & 0.4 & 6.9 & 0.5 \\
10 & 5.3 & 0.2 & 5.1 & 0.3 & 5.8 & 0.4 & 6.2 & 0.3 \\
11 & 6.1 & 0.3 & 5.5 & 0.1 & 6.7 & 0.5 & 6.9 & 0.3 \\
12 & 5.7 & 0.2 & 5.3 & 0.3 & 4.7 & 0.3 & 4.4 & 0.2 \\
13 & 7.0 & 0.3 & 6.7 & 0.4 & 4.8 & 0.2 & 5.1 & 0.2 \\
14 & 6.3 & 0.4 & 7.1 & 0.4 & 5.0 & 0.3 & 5.9 & 0.3 \\
15 & 5.1 & 0.2 & 5.3 & 0.3 & 4.2 & 0.2 & 4.0 & 0.2 \\
16 & 7.9 & 0.6 & 7.5 & 0.8 & 5.6 & 0.4 & 5.7 & 0.5 \\
17 & 7.5 & 0.4 & 8.1 & 0.4 & 5.9 & 0.3 & 6.6 & 0.4
\end{tabular}




\section{A.33 Pulse Wave Velocity: RA 30 Min Post-Exercise}

Peripheral PWV (m/s)

Trial 1

\begin{tabular}{ccccccccc} 
Subject \# & Value & SD & Value & SD & Value & SD & Value & SD \\
\hline 1 & 8.8 & 0.3 & 9.1 & 0.4 & 6.3 & 0.3 & 7.5 & 0.6 \\
2 & 7.4 & 0.5 &. &. & 6.3 & 0.5 & 7.0 & 0.6 \\
3 & 6.6 & 0.4 & 7.7 & 0.4 & 4.4 & 0.1 & 4.4 & 0.3 \\
4 & 7.3 & 0.8 & 8.3 & 0.5 & 5.8 & 0.4 & 6.1 & 0.4 \\
5 & 6.6 & 0.2 & 5.9 & 0.3 & 5.2 & 0.2 & 6.6 & 0.3 \\
6 & 6.5 & 0.5 & 5.7 & 0.4 & 4.9 & 0.3 & 4.3 & 0.2 \\
7 & 8.2 & 0.6 & 8.4 & 0.5 & 6.4 & 0.5 & 5.6 & 0.5 \\
8 & 9.8 & 1.0 & 9.2 & 0.7 & 5.8 & 0.4 & 5.5 & 0.2 \\
9 & 7.6 & 0.5 & 7.4 & 0.3 & 6.6 & 0.3 & 6.1 & 0.3 \\
10 & 5.7 & 0.2 & 5.7 & 0.2 & 5.0 & 0.3 & 4.6 & 0.2 \\
11 & 5.7 & 0.3 & 6.1 & 0.5 & 6.2 & 0.6 & 5.4 & 0.4 \\
12 & 7.3 & 0.3 & 6.4 & 0.2 & 4.4 & 0.2 & 4.6 & 0.3 \\
13 & 6.6 & 0.3 & 7.2 & 0.6 & 4.9 & 0.3 & 6.2 & 0.3 \\
14 & 5.4 & 0.2 & 6.6 & 0.4 & 4.7 & 0.3 & 4.4 & 0.4 \\
15 & 4.6 & 0.2 & 5.5 & 0.5 & 4.2 & 0.2 & 4.5 & 0.3 \\
16 & 5.8 & 0.4 & 5.6 & 0.3 & 4.3 & 0.3 & 4.9 & 0.3 \\
17 & 8.0 & 0.5 & 7.7 & 0.5 & 6.7 & 0.4 & 5.7 & 0.4
\end{tabular}


A.34 Pulse Wave Velocity: AR 30 Min Post-Exercise

Peripheral PWV (m/s)

Trial 1

\begin{tabular}{ccccccccc} 
Subject \# & Value & SD & Value & SD & Value & SD & Value & SD \\
\hline 1 & 10.5 & 0.9 & 10.1 & 0.7 & 6.3 & 0.4 & 5.9 & 0.3 \\
2 &. &. &. &. & 4.5 & 0.3 & 6.0 & 0.3 \\
3 & 6.1 & 0.2 & 6.1 & 0.4 & 3.9 & 0.1 & 4.2 & 0.2 \\
4 & 7.8 & 0.4 & 7.7 & 0.4 & 5.6 & 0.2 & 6.3 & 0.3 \\
5 & 4.8 & 0.2 & 6.6 & 0.3 & 5.4 & 0.2 & 5.2 & 0.2 \\
6 & 6.7 & 0.2 & 6.4 & 0.4 & 5.7 & 0.5 & 5.3 & 0.4 \\
7 & 6.7 & 0.5 & 6.6 & 0.4 & 5.5 & 0.3 & 6.3 & 0.4 \\
8 & 7.0 & 0.4 & 6.2 & 0.5 & 6.2 & 0.5 & 7.1 & 0.4 \\
9 & 7.1 & 0.5 & 7.1 & 0.4 & 7.5 & 0.5 & 6.9 & 0.4 \\
10 & 6.2 & 0.3 & 5.2 & 0.2 & 4.8 & 0.2 & 5.8 & 0.3 \\
11 & 6.4 & 0.3 & 6.2 & 0.2 & 5.1 & 0.2 & 4.9 & 0.4 \\
12 & 6.9 & 0.4 & 5.6 & 0.1 & 5.0 & 0.2 & 5.1 & 0.2 \\
13 & 6.5 & 0.3 & 6.6 & 0.3 & 4.9 & 0.2 & 5.4 & 0.2 \\
14 & 7.1 & 0.5 & 6.2 & 0.3 & 6.0 & 0.4 & 5.0 & 0.2 \\
15 & 4.8 & 0.2 & 5.1 & 0.4 & 3.6 & 0.2 & 3.4 & 0.1 \\
16 & 7.2 & 0.6 & 8.2 & 0.9 & 6.0 & 0.4 & 5.5 & 0.4 \\
17 & 8.0 & 0.4 & 9.2 & 4.0 & 6.0 & 0.3 & 5.5 & 0.3
\end{tabular}




\section{Appendix B. Summary Statistics for Study 1}

\section{B.1 Aortic Pulsatile Load}

\section{Repeated Measures ANOVA}

\begin{tabular}{llllll}
$\begin{array}{l}\text { Within Subjects } \\
\text { Effect }\end{array}$ & $\begin{array}{l}\text { Mauchy's } \\
\text { W }\end{array}$ & $\begin{array}{l}\text { Approx. Chi- } \\
\text { Squate }\end{array}$ & df & Sig. & $\begin{array}{l}\text { Greenhouse- } \\
\text { Geisser }\end{array}$ \\
\hline Condition & 1.000 & 0.000 & 0 &. & 1.000 \\
Time & 0.607 & 6.346 & 5 & 0.275 & 0.760 \\
Condition * Time & 0.151 & 24.086 & 5 & 0.000 & 0.617
\end{tabular}

\begin{tabular}{|c|c|c|c|c|c|c|}
\hline Source & & $\begin{array}{l}\text { Type III Sum } \\
\text { of Squares }\end{array}$ & df & Mean Square & $\mathbf{F}$ & Sig \\
\hline \multirow[t]{2}{*}{ Time } & $\begin{array}{l}\text { Sphericity } \\
\text { Assumed }\end{array}$ & 77125740.90 & 3 & 25708580.30 & 54.080 & 0.000 \\
\hline & $\begin{array}{l}\text { Greenhouse- } \\
\text { Geisser }\end{array}$ & 77125740.90 & 2.279 & 33847235.59 & 54.080 & 0.000 \\
\hline \multirow[t]{2}{*}{$\begin{array}{l}\text { Time } x \\
\text { Condition }\end{array}$} & $\begin{array}{l}\text { Sphericity } \\
\text { Assumed }\end{array}$ & 9093383.067 & 3 & 3031127.689 & 6.914 & 0.001 \\
\hline & $\begin{array}{l}\text { Greenhouse- } \\
\text { Geisser }\end{array}$ & 9093383.067 & 1.850 & 4916622.719 & 6.914 & 0.005 \\
\hline
\end{tabular}

\section{$\underline{\text { Paired T-Tests }}$}

\section{5\% Confidence Interval}

\begin{tabular}{lllllll} 
& Mean & Lower & Upper & T & df & $\begin{array}{l}\text { Sig. } \\
(\mathbf{2} \text {-tailed) }\end{array}$ \\
\hline Pre-RA - Mid-RA & -2229.188 & -2883.141 & -1575.234 & -7.266 & 15 & 0.000 \\
Pre-RA - P10-RA & -1605.941 & -2065.932 & -1145.950 & -7.401 & 16 & 0.000 \\
Pre-RA - P30-RA & -426.375 & -714.553 & -138.197 & -3.154 & 15 & 0.007 \\
Pre-AR - Mid-AR & -1286.118 & -1581.767 & -990.468 & -9.222 & 16 & 0.000 \\
Pre-AR - P10-AR & -2086.824 & -2599.207 & -1574.440 & -8.634 & 16 & 0.000 \\
Pre-AR - P30-AR & -632.765 & -963.091 & -302.439 & -4.061 & 16 & 0.001
\end{tabular}




\section{B.2 Peripheral Pulse Wave Velocity}

\section{Repeated Measures ANOVA}

\begin{tabular}{llllll}
$\begin{array}{l}\text { Within Subjects } \\
\text { Effect }\end{array}$ & $\begin{array}{l}\text { Mauchy's } \\
\text { W }\end{array}$ & $\begin{array}{l}\text { Approx. Chi- } \\
\text { Squate }\end{array}$ & df & Sig. & $\begin{array}{l}\text { Greenhouse- } \\
\text { Geisser }\end{array}$ \\
\hline Condition & 1.000 & 0.000 & 0 &. & 1.000 \\
Time & 0.288 & 17.076 & 5 & 0.004 & 0.550 \\
Condition * Time & 0.819 & 2.735 & 5 & 0.741 & 0.898
\end{tabular}

\begin{tabular}{|c|c|c|c|c|c|c|}
\hline Source & & $\begin{array}{l}\text { Type III Sum } \\
\text { of Squares }\end{array}$ & df & $\begin{array}{l}\text { Mean } \\
\text { Square }\end{array}$ & $\mathbf{F}$ & Sig \\
\hline \multirow[t]{2}{*}{ Time } & $\begin{array}{l}\text { Sphericity } \\
\text { Assumed }\end{array}$ & 3.426 & 3 & 1.142 & 2.609 & 0.063 \\
\hline & $\begin{array}{l}\text { Greenhouse- } \\
\text { Geisser }\end{array}$ & 3.426 & 1.649 & 2.077 & 2.609 & 0.102 \\
\hline \multirow[t]{2}{*}{$\begin{array}{l}\text { Time } x \\
\text { Condition }\end{array}$} & $\begin{array}{l}\text { Sphericity } \\
\text { Assumed }\end{array}$ & 9.244 & 3 & 3.081 & 7.134 & 0.001 \\
\hline & $\begin{array}{l}\text { Greenhouse- } \\
\text { Geisser }\end{array}$ & 9.244 & 2.694 & 3.432 & 7.134 & 0.001 \\
\hline
\end{tabular}

\section{$\underline{\text { Paired T-Tests }}$}

\begin{tabular}{lllllll} 
& \multicolumn{9}{c}{$95 \%$ Confidence Interval } \\
& Mean & Lower & Upper & T & df & Sig. (2-tailed) \\
\hline Pre-RA - Pre-AR & 0.000 & -0.547 & 0.457 & 0.000 & 16 & 1.000 \\
Mid-RA - Mid-AR & -0.694 & -1.196 & -0.192 & -2.932 & 16 & 0.010 \\
P10-RA - P10-AR & 0.741 & 0.242 & 1.240 & 3.148 & 16 & 0.006 \\
P30-RA - P30-AR & 0.125 & 0.289 & 0.740 & 0.433 & 15 & 0.671
\end{tabular}




\section{B.3 Central Pulse Wave Velocity}

\section{Repeated Measures ANOVA}

\begin{tabular}{llllll}
$\begin{array}{l}\text { Within Subjects } \\
\text { Effect }\end{array}$ & $\begin{array}{l}\text { Mauchy's } \\
\text { W }\end{array}$ & $\begin{array}{l}\text { Approx. Chi- } \\
\text { Squate }\end{array}$ & df & Sig. & $\begin{array}{l}\text { Greenhouse- } \\
\text { Geisser }\end{array}$ \\
\hline Condition & 1.00 & 0.000 & 0 &. & 1.000 \\
Time & 0.292 & 18.114 & 5 & 0.003 & 0.619 \\
Condition * Time & 0.543 & 8.985 & 5 & 0.110 & 0.765
\end{tabular}

\begin{tabular}{|c|c|c|c|c|c|c|}
\hline Source & & $\begin{array}{l}\text { Type III Sum } \\
\text { of Squares }\end{array}$ & df & $\begin{array}{l}\text { Mean } \\
\text { Square }\end{array}$ & $\mathbf{F}$ & Sig \\
\hline \multirow[t]{2}{*}{ Time } & $\begin{array}{l}\text { Sphericity } \\
\text { Assumed }\end{array}$ & 3.700 & 3 & 1.233 & 4.975 & 0.061 \\
\hline & $\begin{array}{l}\text { Greenhouse- } \\
\text { Geisser }\end{array}$ & 3.700 & 1.858 & 1.991 & 4.975 & 0.061 \\
\hline \multirow[t]{2}{*}{$\begin{array}{l}\text { Time } x \\
\text { Condition }\end{array}$} & $\begin{array}{l}\text { Sphericity } \\
\text { Assumed }\end{array}$ & 0.757 & 3 & 0.252 & 1.123 & 0.237 \\
\hline & $\begin{array}{l}\text { Greenhouse- } \\
\text { Geisser }\end{array}$ & 0.757 & 2.294 & 0.330 & 1.123 & 0.237 \\
\hline
\end{tabular}




\section{B.4 Normalized Central Pulse Wave Velocity}

\section{Repeated Measures ANOVA}

\begin{tabular}{llllll}
$\begin{array}{l}\text { Within Subjects } \\
\text { Effect }\end{array}$ & $\begin{array}{l}\text { Mauchy's } \\
\text { W }\end{array}$ & $\begin{array}{l}\text { Approx. Chi- } \\
\text { Squate }\end{array}$ & df & Sig. & $\begin{array}{l}\text { Greenhouse- } \\
\text { Geisser }\end{array}$ \\
\hline Condition & 1.00 & 1.000 & 0 &. & 1.000 \\
Time & 0.292 & 0.450 & 5 & 0.072 & 0.714 \\
Condition * Time & 0.543 & 0.770 & 5 & 0.651 & 0.883
\end{tabular}

\begin{tabular}{lllllll} 
Source & & $\begin{array}{l}\text { Type III Sum } \\
\text { of Squares }\end{array}$ & df & $\begin{array}{l}\text { Mean } \\
\text { Square }\end{array}$ & F & Sig \\
\hline Time & $\begin{array}{l}\text { Sphericity } \\
\text { Assumed } \\
\text { Greenhouse- }\end{array}$ & 0.001 & 3 & 0.000 & 2.617 & 0.063 \\
& $\begin{array}{l}\text { Geisser } \\
\text { Sphericity }\end{array}$ & 0.001 & 2.143 & 0.000 & 2.617 & 0.083 \\
$\begin{array}{l}\text { Time } \mathrm{x} \\
\text { Condition }\end{array}$ & $\begin{array}{l}\text { Spsumed } \\
\text { Assumen } \\
\text { Greenhouse- }\end{array}$ & 0.001 & 3 & 0.000 & 7.424 & 0.000 \\
& Geisser & 0.001 & 2.649 & 0.000 & 7.424 & 0.001
\end{tabular}

\section{$\underline{\text { Paired T-Tests }}$}

\begin{tabular}{lllllll} 
& \multicolumn{2}{c}{$95 \%$ Confidence Interval } \\
& Mean & Lower & Upper & T & df & Sig. (2-tailed) \\
\hline Pre-RA - Pre-AR & 0.002 & -0.005 & 0.009 & 0.688 & 16 & 0.502 \\
Mid-RA - Mid-AR & 0.009 & 0.004 & 0.014 & 4.099 & 15 & 0.001 \\
P10-RA - P10-AR & -0.008 & -0.014 & -0.001 & -2.616 & 15 & 0.019 \\
P30-RA - P30-AR & -0.007 & -0.013 & -0.001 & -2.322 & 15 & 0.035
\end{tabular}




\section{Appendix C. Raw Data for Study 2}

\section{C.1 Demographic Information}

\begin{tabular}{|c|c|c|c|c|c|c|c|}
\hline Group & Subject \# & Sex & Age & $\begin{array}{c}\text { Height } \\
\text { (cm) }\end{array}$ & $\begin{array}{l}\text { Mass } \\
(\mathrm{kg})\end{array}$ & BMI & $\begin{array}{c}\text { Body Fat } \\
(\%)\end{array}$ \\
\hline \multirow{11}{*}{ 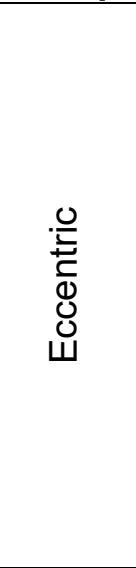 } & 1 & $M$ & 31 & 169 & 69.6 & 24.4 & 17.0 \\
\hline & 2 & $M$ & 22 & 174 & 76.8 & 25.4 & 15.6 \\
\hline & 3 & $\mathrm{~F}$ & 21 & 164 & 60.9 & 22.6 & 29.6 \\
\hline & 4 & $F$ & 21 & 159.5 & 73.2 & 28.8 & 48.4 \\
\hline & 5 & $M$ & 25 & 179.5 & 69.2 & 21.5 & 8.2 \\
\hline & 6 & $\mathrm{~F}$ & 22 & 165.1 & 60.3 & 22.1 & 33.2 \\
\hline & 7 & $M$ & 20 & 183 & 75.6 & 22.6 & 18.6 \\
\hline & 8 & $M$ & 20 & 182 & 106.9 & 32.3 & 37.6 \\
\hline & 9 & $M$ & 20 & 191.5 & 70.3 & 19.2 & 16.5 \\
\hline & 10 & $M$ & 26 & 177 & 79.8 & 25.5 & 8.9 \\
\hline & 11 & $M$ & 24 & 172.2 & 71.1 & 24.0 & 8.0 \\
\hline \multirow{11}{*}{ 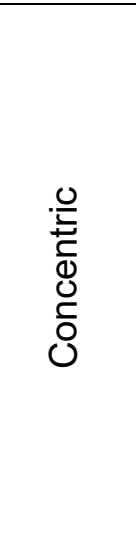 } & 12 & $\mathrm{~F}$ & 23 & 158.5 & 49.3 & 19.6 & 20.5 \\
\hline & 13 & $M$ & 25 & 184 & 79.8 & 23.6 & 11.0 \\
\hline & 14 & $M$ & 22 & 186.5 & 92.1 & 26.5 & 19.0 \\
\hline & 15 & $F$ & 21 & 177 & 111.0 & 35.4 & 48.3 \\
\hline & 16 & $M$ & 21 & 173 & 75.9 & 25.4 & 32.9 \\
\hline & 17 & $M$ & 21 & 169.5 & 81.5 & 28.4 & 41.6 \\
\hline & 18 & $M$ & 27 & 186.5 & 81.6 & 23.5 & 28.9 \\
\hline & 19 & $M$ & 24 & 169 & 70.8 & 24.8 & 30.4 \\
\hline & 20 & $M$ & 23 & 197 & 93.6 & 24.1 & 11.0 \\
\hline & 21 & $M$ & 23 & 172.7 & 66.4 & 22.3 & 12.2 \\
\hline & 22 & $M$ & 32 & 169.0 & 71.0 & 24.9 & 17.0 \\
\hline
\end{tabular}


C.2 Brachial Hemodynamics: Pre-Exercise

\begin{tabular}{|c|c|c|c|c|c|}
\hline Group & Subject & SAP & DAP & MAP & HR \\
\hline \multirow{13}{*}{ 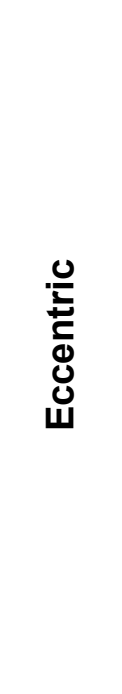 } & 1 & 105 & 56 & 72 & 49 \\
\hline & 2 & 125 & 57 & 80 & 81 \\
\hline & 3 & 94 & 58 & 70 & 57 \\
\hline & 4 & . & . & . & . \\
\hline & 5 & 116 & 58 & 77 & 47 \\
\hline & 6 & 98 & 53 & 68 & 65 \\
\hline & 7 & 113 & 56 & 75 & 66 \\
\hline & 8 & 121 & 75 & 90 & 72 \\
\hline & 9 & 116 & 61 & 79 & 62 \\
\hline & 10 & 106 & 62 & 77 & 79 \\
\hline & 11 & 107 & 55 & 72 & 56 \\
\hline & 12 & 131 & 78 & 96 & 54 \\
\hline & 13 & 99 & 49 & 61 & 64 \\
\hline \multirow{11}{*}{ 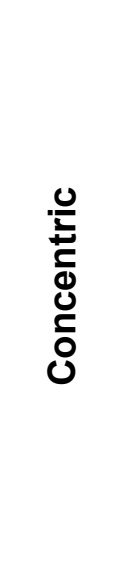 } & 14 & 99 & 54 & 69 & 56 \\
\hline & 15 & 114 & 53 & 73 & 62 \\
\hline & 16 & 128 & 67 & 87 & 42 \\
\hline & 17 & 102 & 61 & 75 & 74 \\
\hline & 18 & 97 & 55 & 69 & 53 \\
\hline & 19 & 114 & 76 & 89 & 70 \\
\hline & 20 & 120 & 60 & 80 & 64 \\
\hline & 21 & 108 & 65 & 79 & 65 \\
\hline & 22 & 118 & 51 & 73 & 59 \\
\hline & 23 & 113.0 & 58.0 & 76 & 60 \\
\hline & 24 & 111.0 & 67.0 & 82 & 56 \\
\hline
\end{tabular}


C.3 Brachial Hemodynamics: 10 min Post-Exercise

\begin{tabular}{|c|c|c|c|c|c|}
\hline Group & Subject & SAP & DAP & MAP & HR \\
\hline \multirow{13}{*}{ 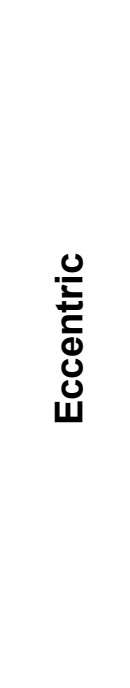 } & 1 & 118 & 62 & 81 & 56 \\
\hline & 2 & 127 & 55 & 79 & 75 \\
\hline & 3 & 99 & 52 & 68 & 68 \\
\hline & 4 & & & & \\
\hline & 5 & 117 & 49 & 72 & 62 \\
\hline & 6 & 107 & 57 & 74 & 75 \\
\hline & 7 & 116 & 54 & 75 & 75 \\
\hline & 8 & 122 & 68 & 86 & 73 \\
\hline & 9 & 114 & 50 & 71 & 59 \\
\hline & 10 & 114 & 56 & 75 & 81 \\
\hline & 11 & 107 & 53 & 71 & 59 \\
\hline & 12 & 129 & 70 & 90 & 50 \\
\hline & 13 & 107 & 49 & 68 & 77 \\
\hline \multirow{11}{*}{ 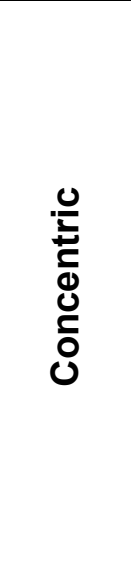 } & 14 & 106 & 48 & 67 & 74 \\
\hline & 15 & 108 & 43 & 65 & 79 \\
\hline & 16 & 119 & 46 & 70 & 45 \\
\hline & 17 & 116 & 62 & 80 & 79 \\
\hline & 18 & 100 & 53 & 69 & 59 \\
\hline & 19 & 114 & 62 & 79 & 74 \\
\hline & 20 & 117 & 52 & 74 & 79 \\
\hline & 21 & 119 & 58 & 78 & 89 \\
\hline & 22 & 112 & 43 & 66 & 69 \\
\hline & 23 & 115.0 & 49.0 & 71 & 67 \\
\hline & 24 & 113.0 & 57.0 & 76 & 72 \\
\hline
\end{tabular}


C.4 Brachial Hemodynamics: 30 min Post-Exercise

\begin{tabular}{|c|c|c|c|c|c|}
\hline Group & Subject & SAP & DAP & MAP & HR \\
\hline \multirow{13}{*}{ 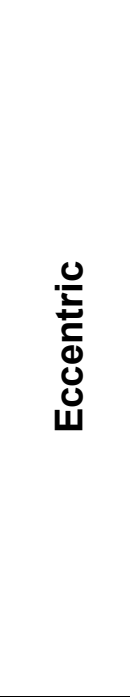 } & 1 & 105 & 55 & 71 & 50 \\
\hline & 2 & 126 & 53 & 77 & 69 \\
\hline & 3 & 102 & 58 & 73 & 60 \\
\hline & 4 & r & . & . & . \\
\hline & 5 & & . & & . \\
\hline & 6 & 109 & 61 & 77 & 63 \\
\hline & 7 & 113 & 52 & 72 & 64 \\
\hline & 8 & 121 & 71 & 88 & 69 \\
\hline & 9 & 109 & 58 & 75 & 54 \\
\hline & 10 & 109 & 57 & 74 & 68 \\
\hline & 11 & 104 & 52 & 69 & 53 \\
\hline & 12 & 129 & 66 & 87 & 51 \\
\hline & 13 & 99 & 48 & 65 & 73 \\
\hline \multirow{11}{*}{ 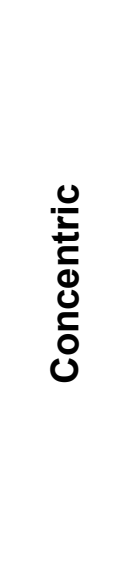 } & 14 & 102 & 52 & 64 & 69 \\
\hline & 15 & 107 & 50 & 69 & 72 \\
\hline & 16 & 123 & 52 & 76 & 45 \\
\hline & 17 & 116 & 60 & 79 & 79 \\
\hline & 18 & 98 & 63 & 75 & 57 \\
\hline & 19 & 113 & 68 & 83 & 67 \\
\hline & 20 & 123 & 53 & 76 & 71 \\
\hline & 21 & 128 & 63 & 85 & 76 \\
\hline & 22 & 116 & 40 & 65 & 65 \\
\hline & 23 & 113.0 & 50.0 & 71 & 61 \\
\hline & 24 & 111.0 & 56.0 & 74 & 65 \\
\hline
\end{tabular}




\section{C.5 Pulse Wave Analysis Trial 1: Pre-Exercise}

\begin{tabular}{|c|c|c|c|c|c|c|c|c|c|}
\hline & & Ol & HR & aSAP & aDAP & aMAP & aPP & Alx & Alx@75 \\
\hline \multirow{13}{*}{ 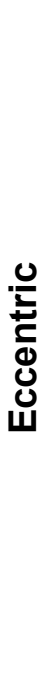 } & 1 & 91 & 52 & 88 & 57 & 72 & 31 & -3 & -14 \\
\hline & 2 & 99 & 79 & 97 & 58 & 74 & 39 & -11 & -9 \\
\hline & 3 & 92 & 59 & 81 & 58 & 68 & 23 & -1 & -8 \\
\hline & 4 & . & . & . & . & . & . & . & . \\
\hline & 5 & 85 & 49 & 90 & 58 & 70 & 32 & -21 & -33 \\
\hline & 6 & 88 & 56 & 82 & 53 & 66 & 29 & -5 & -14 \\
\hline & 7 & 82 & 59 & 93 & 56 & 71 & 37 & 11 & 3 \\
\hline & 8 & 89 & 78 & 103 & 76 & 89 & 27 & 4 & 5 \\
\hline & 9 & 99 & 64 & 96 & 61 & 76 & 35 & -8 & -13 \\
\hline & 10 & 91 & 72 & 87 & 63 & 74 & 24 & 4 & 3 \\
\hline & 11 & 98 & 58 & 86 & 55 & 69 & 31 & -11 & -19 \\
\hline & 12 & 96 & 54 & 109 & 78 & 91 & 31 & -11 & -22 \\
\hline & 13 & 90 & 61 & 79 & 49 & 61 & 30 & -15 & -22 \\
\hline \multirow{11}{*}{ 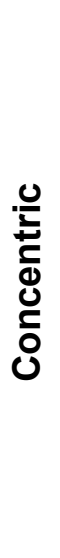 } & 14 & 100 & 57 & 80 & 54 & 67 & 26 & -3 & -11 \\
\hline & 15 & 94 & 60 & 90 & 54 & 66 & 36 & -26 & -33 \\
\hline & 16 & 100 & 40 & 103 & 67 & 81 & 36 & -12 & -29 \\
\hline & 17 & 96 & 72 & 85 & 61 & 70 & 24 & -16 & -18 \\
\hline & 18 & 88 & 56 & 80 & 55 & 66 & 25 & -5 & -14 \\
\hline & 19 & 82 & 70 & 99 & 77 & 87 & 22 & 6 & 4 \\
\hline & 20 & 100 & 63 & 96 & 60 & 74 & 36 & -26 & -31 \\
\hline & 21 & 87 & 70 & 94 & 66 & 80 & 28 & 10 & 8 \\
\hline & 22 & 95 & 61 & 91 & 51 & 65 & 40 & -11 & -17 \\
\hline & 23 & 100 & 54 & 93 & 59 & 75 & 34 & 2 & -8 \\
\hline & 24 & 88 & 56 & 95 & 68 & 82 & 27 & 7 & -2 \\
\hline
\end{tabular}




\section{C.6 Pulse Wave Analysis Trial 1: 10 min Post-Exercise}

\begin{tabular}{|c|c|c|c|c|c|c|c|c|c|}
\hline & & OI & HR & aSAP & aDAP & aMAP & aPP & Alx & Alx@75 \\
\hline \multirow{13}{*}{ 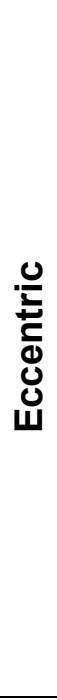 } & 1 & 97 & 65 & 101 & 63 & 81 & 38 & 11 & 6 \\
\hline & 2 & 89 & 83 & 96 & 56 & 75 & 40 & -4 & 0 \\
\hline & 3 & 98 & 67 & 80 & 53 & 66 & 27 & -2 & -6 \\
\hline & 4 & . & . & . & . & . & . & . & . \\
\hline & 5 & 75 & 60 & 90 & 50 & 69 & 40 & 4 & -4 \\
\hline & 6 & 89 & 72 & 91 & 58 & 73 & 33 & 15 & 13 \\
\hline & 7 & 77 & 72 & 98 & 56 & 76 & 42 & 7 & 6 \\
\hline & 8 & 83 & 78 & 104 & 69 & 87 & 35 & 8 & 7 \\
\hline & 9 & 93 & 60 & 92 & 50 & 68 & 42 & -1 & -8 \\
\hline & 10 & 94 & 78 & 94 & 58 & 74 & 36 & 4 & 6 \\
\hline & 11 & 92 & 61 & 88 & 53 & 69 & 35 & 6 & -1 \\
\hline & 12 & 100 & 53 & 106 & 71 & 86 & 35 & -11 & -21 \\
\hline & 13 & 98 & 82 & 86 & 52 & 67 & 61 & -4 & -1 \\
\hline \multirow{11}{*}{$\begin{array}{l}0 \\
\text { 는 } \\
\frac{1}{00} \\
0 \\
0 \\
0\end{array}$} & 14 & 91 & 71 & 81 & 48 & 63 & 33 & -1 & -3 \\
\hline & 15 & 100 & 79 & 81 & 46 & 60 & 35 & -9 & -7 \\
\hline & 16 & 97 & 48 & 89 & 46 & 63 & 43 & -9 & -22 \\
\hline & 17 & 86 & 75 & 94 & 63 & 76 & 31 & -1 & -1 \\
\hline & 18 & 84 & 65 & 80 & 53 & 64 & 27 & -7 & -12 \\
\hline & 19 & 91 & 73 & 92 & 63 & 79 & 29 & 0 & -1 \\
\hline & 20 & 100 & 72 & 90 & 53 & 69 & 37 & -19 & -20 \\
\hline & 21 & 100 & 66 & 94 & 58 & 75 & 36 & 1 & -3 \\
\hline & 22 & 78 & 72 & 89 & 45 & 62 & 44 & -5 & -7 \\
\hline & 23 & 86 & 64 & 93 & 50 & 71 & 43 & 3 & -3 \\
\hline & 24 & 94 & 69 & 93 & 58 & 75 & 35 & 5 & 2 \\
\hline
\end{tabular}




\section{C.7 Pulse Wave Analysis Trial 1: 30 min Post-Exercise}

\begin{tabular}{|c|c|c|c|c|c|c|c|c|c|}
\hline & & OI & HR & aSAP & aDAP & aMAP & aPP & Alx & Alx@75 \\
\hline \multirow{13}{*}{ 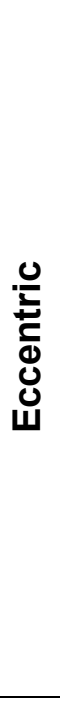 } & 1 & 99 & 56 & 88 & 56 & 71 & 32 & 6 & -3 \\
\hline & 2 & 97 & 75 & 96 & 54 & 73 & 42 & -7 & -7 \\
\hline & 3 & 86 & 56 & 84 & 58 & 70 & 26 & -4 & -13 \\
\hline & 4 & . & . & . & . & . & . & . & . \\
\hline & 5 & . & . & . & . & . & . & . & . \\
\hline & 6 & 95 & 60 & 92 & 61 & 75 & 31 & 14 & 7 \\
\hline & 7 & 77 & 66 & 89 & 52 & 67 & 37 & -4 & -8 \\
\hline & 8 & 92 & 71 & 103 & 72 & 87 & 31 & 8 & 6 \\
\hline & 9 & 92 & 59 & 90 & 58 & 70 & 32 & -8 & -15 \\
\hline & 10 & 89 & 71 & 92 & 58 & 73 & 34 & 8 & 6 \\
\hline & 11 & 95 & 50 & 84 & 53 & 66 & 31 & 1 & -11 \\
\hline & 12 & 96 & 49 & 103 & 67 & 82 & 36 & -11 & -23 \\
\hline & 13 & 98 & 77 & 80 & 50 & 62 & 30 & -7 & -6 \\
\hline \multirow{11}{*}{ 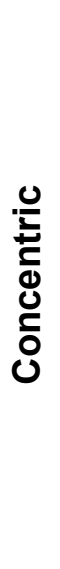 } & 14 & 97 & 65 & 80 & 51 & 64 & 29 & -5 & -10 \\
\hline & 15 & 86 & 67 & 81 & 43 & 58 & 38 & -15 & -18 \\
\hline & 16 & 100 & 44 & 93 & 51 & 67 & 42 & -10 & -25 \\
\hline & 17 & 97 & 83 & 92 & 62 & 76 & 30 & -7 & -2 \\
\hline & 18 & 88 & 54 & 83 & 63 & 71 & 20 & -9 & -19 \\
\hline & 19 & 83 & 59 & 93 & 68 & 80 & 25 & -5 & -12 \\
\hline & 20 & 97 & 76 & 92 & 54 & 70 & 38 & -13 & -12 \\
\hline & 21 & 85 & 72 & 105 & 64 & 83 & 41 & 11 & 9 \\
\hline & 22 & 100 & 57 & 87 & 40 & 57 & 47 & -11 & -20 \\
\hline & 23 & 95 & 54 & 89 & 51 & 69 & 38 & -2 & -12 \\
\hline & 24 & 98 & 62 & 59 & 57 & 71 & 32 & -5 & -11 \\
\hline
\end{tabular}




\section{C.8 Pulse Wave Analysis Trial 2: Pre-Exercise}

\begin{tabular}{|c|c|c|c|c|c|c|c|c|c|}
\hline & & Ol & aSAP & aDAP & aMAP & aPP & aSAP & Alx & Alx@75 \\
\hline \multirow{13}{*}{ 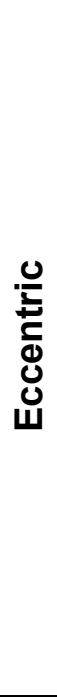 } & 1 & 96 & 52 & 88 & 57 & 71 & 31 & -4 & -15 \\
\hline & 2 & 99 & 76 & 97 & 58 & 76 & 39 & -5 & -5 \\
\hline & 3 & 77 & 57 & 81 & 58 & 68 & 23 & 7 & -1 \\
\hline & 4 & . & . & . & . &. & . & . & . \\
\hline & 5 & 82 & 48 & 91 & 58 & 72 & 33 & -8 & -21 \\
\hline & 6 & 84 & 57 & 82 & 54 & 66 & 28 & -3 & -12 \\
\hline & 7 & 93 & 60 & 94 & 57 & 72 & 37 & 14 & 7 \\
\hline & 8 & 87 & 66 & 105 & 76 & 89 & 29 & 10 & 6 \\
\hline & 9 & 99 & 62 & 94 & 61 & 74 & 33 & -9 & -15 \\
\hline & 10 & 83 & 75 & 88 & 63 & 74 & 25 & 9 & 9 \\
\hline & 11 & 83 & 54 & 86 & 56 & 69 & 30 & -9 & -19 \\
\hline & 12 & 98 & 53 & 108 & 79 & 91 & 29 & -5 & -16 \\
\hline & 13 & 92 & 65 & 80 & 49 & 62 & 31 & -14 & -19 \\
\hline \multirow{11}{*}{ 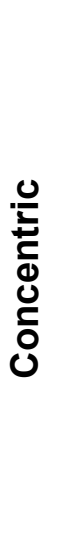 } & 14 & 89 & 55 & 80 & 84 & 67 & 26 & 1 & -9 \\
\hline & 15 & 92 & 60 & 91 & 53 & 66 & 38 & -25 & -32 \\
\hline & 16 & 92 & 44 & 102 & 67 & 80 & 35 & -12 & -26 \\
\hline & 17 & 95 & 69 & 85 & 61 & 70 & 24 & -14 & -17 \\
\hline & 18 & 88 & 57 & 80 & 55 & 67 & 25 & -5 & -13 \\
\hline & 19 & 91 & 66 & 100 & 76 & 88 & 24 & 9 & 4 \\
\hline & 20 & 100 & 63 & 95 & 61 & 73 & 34 & -27 & -33 \\
\hline & 21 & 83 & 68 & 94 & 66 & 79 & 28 & 12 & 9 \\
\hline & 22 & 92 & 59 & 92 & 51 & 67 & 41 & -8 & -15 \\
\hline & 23 & 90 & 58 & 92 & 59 & 76 & 33 & 0 & -9 \\
\hline & 24 & 96 & 57 & 95 & 68 & 82 & 27 & 6 & -2 \\
\hline
\end{tabular}




\section{C.9 Pulse Wave Analysis Trial 2: 10 min Post-Exercise}

\begin{tabular}{|c|c|c|c|c|c|c|c|c|c|}
\hline & & Ol & HR & aSAP & aDAP & aMAP & aPP & Alx & Alx@75 \\
\hline \multirow{13}{*}{ 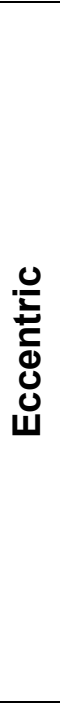 } & 1 & 91 & 63 & 101 & 63 & 82 & 38 & 11 & 6 \\
\hline & 2 & 94 & 80 & 96 & 56 & 74 & 40 & -4 & -2 \\
\hline & 3 & 78 & 69 & 80 & 52 & 67 & 28 & -2 & -5 \\
\hline & 4 & . & . & . & . & . & . & . & . \\
\hline & 5 & 76 & 53 & 94 & 50 & 70 & 44 & 12 & 2 \\
\hline & 6 & 85 & 69 & 90 & 58 & 73 & 32 & 15 & 12 \\
\hline & 7 & 79 & 73 & 98 & 57 & 76 & 41 & 8 & 7 \\
\hline & 8 & 87 & 73 & 103 & 69 & 87 & 34 & 10 & 9 \\
\hline & 9 & 98 & 61 & 92 & 50 & 67 & 42 & -5 & -13 \\
\hline & 10 & 86 & 77 & 94 & 57 & 73 & 37 & -3 & -2 \\
\hline & 11 & 80 & 59 & 88 & 53 & 68 & 35 & 6 & -2 \\
\hline & 12 & 100 & 55 & 105 & 71 & 86 & 34 & -8 & -18 \\
\hline & 13 & 95 & 78 & 87 & 51 & 67 & 36 & -2 & -1 \\
\hline \multirow{11}{*}{ 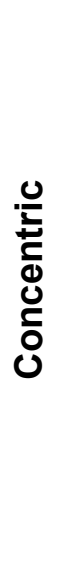 } & 14 & 96 & 66 & 81 & 48 & 64 & 33 & -1 & -3 \\
\hline & 15 & 89 & 73 & 81 & 44 & 59 & 37 & -7 & -8 \\
\hline & 16 & 86 & 51 & 92 & 47 & 66 & 46 & -5 & -17 \\
\hline & 17 & 97 & 83 & 92 & 62 & 76 & 30 & -7 & -2 \\
\hline & 18 & 95 & 59 & 80 & 53 & 65 & 27 & -4 & -12 \\
\hline & 19 & 77 & 72 & 92 & 63 & 79 & 29 & -2 & -3 \\
\hline & 20 & 100 & 75 & 90 & 53 & 69 & 37 & -9 & -9 \\
\hline & 21 & 99 & 69 & 93 & 59 & 74 & 34 & -1 & -4 \\
\hline & 22 & 100 & 72 & 89 & 45 & 62 & 44 & -3 & -4 \\
\hline & 23 & 96 & 64 & 94 & 50 & 70 & 44 & 2 & -3 \\
\hline & 24 & 89 & 69 & 93 & 58 & 75 & 35 & 6 & 4 \\
\hline
\end{tabular}




\section{C.10 Pulse Wave Analysis Trial 2: 30 min Post-Exercise}

\begin{tabular}{|c|c|c|c|c|c|c|c|c|c|}
\hline & & OI & HR & aSAP & aDAP & aMAP & aPP & Alx & Alx@75 \\
\hline \multirow{13}{*}{ 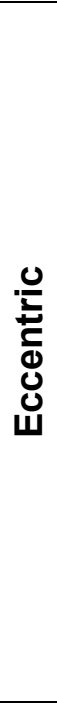 } & 1 & 89 & 59 & 87 & 56 & 70 & 31 & 4 & -4 \\
\hline & 2 & 88 & 70 & 96 & 54 & 71 & 42 & -8 & -10 \\
\hline & 3 & . & . & . & . & . & . & . & . \\
\hline & 4 & . & . & . & . & . & . & . & . \\
\hline & 5 & . & . & . & . & . & . & . & . \\
\hline & 6 & 87 & 63 & 84 & 62 & 78 & 32 & 20 & 14 \\
\hline & 7 & 90 & 61 & 90 & 52 & 67 & 38 & -4 & -11 \\
\hline & 8 & 83 & 66 & 102 & 72 & 87 & 30 & 8 & 4 \\
\hline & 9 & 94 & 58 & 90 & 58 & 70 & 32 & -9 & -17 \\
\hline & 10 & 93 & 68 & 92 & 59 & 74 & 33 & 8 & 5 \\
\hline & 11 & 86 & 59 & 84 & 52 & 65 & 32 & -1 & -9 \\
\hline & 12 & 99 & 53 & 103 & 67 & 83 & 36 & -8 & -19 \\
\hline & 13 & 88 & 72 & 82 & 49 & 64 & 33 & -3 & -4 \\
\hline \multirow{11}{*}{ 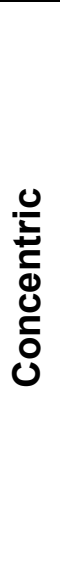 } & 14 & 98 & 65 & 80 & 52 & 64 & 28 & -9 & -13 \\
\hline & 15 & 99 & 67 & 81 & 43 & 58 & 38 & -14 & -18 \\
\hline & 16 & 100 & 46 & 93 & 52 & 68 & 41 & -10 & -24 \\
\hline & 17 & 90 & 76 & 92 & 60 & 73 & 32 & -7 & -7 \\
\hline & 18 & 95 & 56 & 83 & 63 & 72 & 20 & -8 & -18 \\
\hline & 19 & 84 & 62 & 94 & 68 & 80 & 26 & -7 & -14 \\
\hline & 20 & 94 & 69 & 93 & 54 & 71 & 39 & -10 & -13 \\
\hline & 21 & . & . & . & . & . & . & . & . \\
\hline & 22 & 100 & 60 & 86 & 41 & 58 & 45 & -9 & -16 \\
\hline & 23 & 98 & 62 & 88 & 51 & 70 & 37 & -1 & -7 \\
\hline & 24 & 100 & 62 & 59 & 57 & 72 & 32 & -2 & -8 \\
\hline
\end{tabular}




\section{C.11 Pulse Wave Velocity: Pre-Exercise}

\begin{tabular}{|c|c|c|c|c|c|c|c|c|}
\hline & \multicolumn{4}{|c|}{ Peripheral PWV } & \multicolumn{4}{|c|}{ Central PWV } \\
\hline & \multicolumn{2}{|c|}{ Trial 1} & \multicolumn{2}{|c|}{ Trial 2} & \multicolumn{2}{|c|}{ Trial 1} & \multicolumn{2}{|c|}{ Trial 2} \\
\hline & Velocity & SD & Velocity & SD & Velocity & SD & Velocity & SD \\
\hline 1 & 6.3 & 0.3 & 5.7 & 0.4 & 5.3 & 0.2 & 5.5 & 0.3 \\
\hline \multirow{11}{*}{ 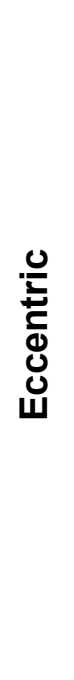 } & 7.6 & 0.6 & 8.2 & 0.6 & 8.1 & 0.6 & 7.7 & 0.6 \\
\hline & 7.6 & 0.5 & 7.2 & 0.7 & 5.6 & 0.2 & 5.1 & 0.3 \\
\hline & . & & & & . & & & 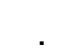 \\
\hline & . & . & 5.8 & 0.6 & 4.9 & 0.5 & 5.4 & 0.6 \\
\hline & 8.4 & 1.2 & 9.7 & 1.4 & 5.7 & 0.6 & 5.0 & 0.3 \\
\hline & 4.9 & 0.4 & 5.9 & 0.3 & 5.1 & 0.3 & 5.8 & 0.4 \\
\hline & 7.4 & 0.6 & 7.7 & 0.8 & 5.6 & 0.3 & 5.9 & 0.4 \\
\hline & 6.7 & 0.5 & 6.5 & 0.6 & 5.9 & 0.5 & 5.3 & 0.4 \\
\hline & 6.4 & 0.4 & 7.3 & 0.4 & 6.3 & 0.6 & 6.1 & 0.3 \\
\hline & 7.5 & 0.2 & 7.2 & 0.3 & 6.9 & 0.3 & 5.8 & 0.2 \\
\hline & 7.5 & 0.5 & 8.1 & 0.3 & 6.8 & 0.3 & 6.8 & 0.6 \\
\hline 13 & 6.1 & 0.6 & 6.8 & 0.6 & 4.7 & 0.5 & 5.2 & 0.5 \\
\hline \multirow{11}{*}{ 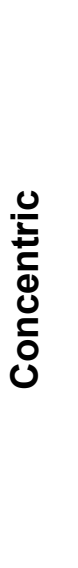 } & 8.0 & 0.7 & 6.5 & 0.4 & 5.0 & 0.3 & 5.1 & 0.4 \\
\hline & 6.0 & 0.3 & 5.5 & 0.3 & 5.5 & 0.6 & 4.9 & 0.1 \\
\hline & 5.9 & 0.4 & 7.2 & 0.2 & 5.3 & 0.3 & 5.0 & 0.4 \\
\hline & 6.9 & 0.3 & 5.6 & 0.2 & 6.3 & 0.5 & . & . \\
\hline & 7.4 & 0.4 & 7.9 & 0.8 & 5.1 & 0.4 & 5.8 & 0.5 \\
\hline & 8.5 & 0.9 & 7.3 & 0.7 & 5.4 & 0.4 & 5.4 & 0.3 \\
\hline & 6.8 & 0.4 & 6.1 & 0.2 & 5.5 & 0.3 & 5.7 & 0.3 \\
\hline & 8.3 & 0.4 & 8.2 & 0.7 & 7.1 & 0.5 & 7.3 & 0.7 \\
\hline & 5.8 & 0.3 & 6.2 & 0.5 & 6.1 & 0.5 & 5.0 & 0.5 \\
\hline & 6.8 & 0.3 & 7.1 & 0.3 & 4.8 & 0.2 & 5.7 & 0.3 \\
\hline & 7.70 & 0.70 & 7.00 & 0.40 & 5.40 & 0.4 & 5.9 & 0.4 \\
\hline
\end{tabular}


C.12 Pulse Wave Velocity: 10 min Post-Exercise

\begin{tabular}{|c|c|c|c|c|c|c|c|c|}
\hline & \multicolumn{4}{|c|}{ Peripheral PWV } & \multicolumn{4}{|c|}{ Central PWV } \\
\hline & \multicolumn{2}{|c|}{ Trial 1} & \multicolumn{2}{|c|}{ Trial 2} & \multicolumn{2}{|c|}{ Trial 1} & \multicolumn{2}{|c|}{ Trial 2} \\
\hline & Velocity & SD & Velocity & SD & Velocity & SD & Velocity & SD \\
\hline \multirow{11}{*}{ 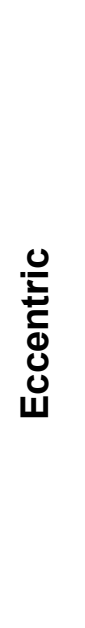 } & 5.8 & 0.3 & 6.7 & 0.5 & 4.9 & 0.2 & 5.8 & 0.4 \\
\hline & 6.5 & 0.2 & 6.5 & 0.4 & 8.3 & 0.7 & 6.5 & 0.4 \\
\hline & 8.2 & 0.3 & 7.4 & 0.4 & . & . & . & . \\
\hline & . & . & . & . & . & . & . & . \\
\hline & 4.5 & 0.2 & 6.4 & 0.6 & . & . & . & . \\
\hline & 7.0 & 0.7 & . & . & 4.8 & 0.4 & 4.6 & 0.3 \\
\hline & 5.4 & 0.3 & 5.9 & 0.4 & 7.5 & 0.6 & . & . \\
\hline & 7.0 & 0.4 & 7.2 & 0.3 & 6.9 & 0.6 & 5.4 & 0.2 \\
\hline & 6.6 & 0.3 & 6.6 & 0.5 & 5.1 & 0.4 & 4.8 & 0.3 \\
\hline & 6.9 & 0.2 & 5.3 & 0.3 & . & . & . & . \\
\hline & 7.1 & 0.4 & 7.3 & 0.3 & 5.9 & 0.2 & 6.5 & 0.3 \\
\hline 12 & 6.1 & 0.2 & 6.4 & 0.2 & 5.8 & 0.4 & . & . \\
\hline \multirow{11}{*}{ 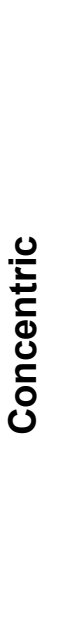 } & 5.6 & 0.3 & 6.0 & 0.3 & 6.5 & 0.4 & 6.3 & 0.4 \\
\hline & 6.5 & 0.2 & 6.1 & 0.3 & 4.8 & 0.3 & 5.5 & 0.4 \\
\hline & 5.4 & 0.2 & 5.3 & 0.1 & 5.4 & 0.3 & 5.8 & 0.3 \\
\hline & 6.7 & 0.4 & . & . & 6.2 & 0.3 & 5.4 & 0.3 \\
\hline & 6.3 & 0.4 & 6.6 & 0.2 & 6.7 & 0.3 & 6.3 & 0.7 \\
\hline & 7.0 & 0.6 & . & . & 6.5 & 0.5 & . & . \\
\hline & 7.8 & 0.5 & 7.3 & 0.4 & 5.9 & 0.3 & 5.4 & 0.3 \\
\hline & 6.5 & 0.5 & 7.0 & 0.5 & 5.2 & 0.2 & 5.3 & 0.2 \\
\hline & 8.2 & 0.3 & 7.4 & 0.4 & . & . & . & . \\
\hline & 5.4 & 0.3 & 5.2 & 0.3 & 6.1 & 0.6 & 6.3 & 0.5 \\
\hline & 6.2 & 0.4 & 6.8 & 0.4 & 5.5 & 0.2 & 4.8 & 0.3 \\
\hline 24 & 6.0 & 0.3 & 6.0 & 0.2 & 5.6 & 0.5 & 5.4 & 0.3 \\
\hline
\end{tabular}




\section{C.13 Pulse Wave Velocity: 30 min Post-Exercise}

\begin{tabular}{|c|c|c|c|c|c|c|c|c|}
\hline & \multicolumn{4}{|c|}{ Peripheral PWV } & \multicolumn{4}{|c|}{ Central PWV } \\
\hline & \multicolumn{2}{|c|}{ Trial 1} & \multicolumn{2}{|c|}{ Trial 2} & \multicolumn{2}{|c|}{ Trial 1} & \multicolumn{2}{|c|}{ Trial 2} \\
\hline & Velocity & SD & Velocity & SD & Velocity & SD & Velocity & SD \\
\hline 1 & 5.8 & 0.3 & 6.7 & 0.5 & 4.9 & 0.2 & 5.8 & 0.4 \\
\hline 2 & 6.5 & 0.2 & 6.5 & 0.4 & 8.3 & 0.7 & 6.5 & 0.4 \\
\hline 3 & 8.2 & 0.3 & 7.4 & 0.4 & . & . & . & . \\
\hline 4 & . & . & . & . & . & . & . & . \\
\hline 5 & 4.5 & 0.2 & 6.4 & 0.6 & . & . & . & . \\
\hline 는 & 7.0 & 0.7 & . & . & 4.8 & 0.4 & 4.6 & 0.3 \\
\hline ఫ్ & 5.4 & 0.3 & 5.9 & 0.4 & 7.5 & 0.6 & . & . \\
\hline س & 7.0 & 0.4 & 7.2 & 0.3 & 6.9 & 0.6 & 5.4 & 0.2 \\
\hline 9 & 6.6 & 0.3 & 6.6 & 0.5 & 5.1 & 0.4 & 4.8 & 0.3 \\
\hline 10 & 6.9 & 0.2 & 5.3 & 0.3 & . & . & . & . \\
\hline 11 & 7.1 & 0.4 & 7.3 & 0.3 & 5.9 & 0.2 & 6.5 & 0.3 \\
\hline 12 & 6.1 & 0.2 & 6.4 & 0.2 & 5.8 & 0.4 & . & . \\
\hline 13 & 5.6 & 0.3 & 6.0 & 0.3 & 6.5 & 0.4 & 6.3 & 0.4 \\
\hline \multirow{11}{*}{ 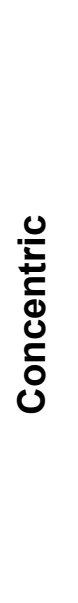 } & 6.5 & 0.2 & 6.1 & 0.3 & 4.8 & 0.3 & 5.5 & 0.4 \\
\hline & 5.4 & 0.2 & 5.3 & 0.1 & 5.4 & 0.3 & 5.8 & 0.3 \\
\hline & 6.7 & 0.4 & . & $\cdot$ & 6.2 & 0.3 & 5.4 & 0.3 \\
\hline & 6.3 & 0.4 & 6.6 & 0.2 & 6.7 & 0.3 & 6.3 & 0.7 \\
\hline & 7.0 & 0.6 & . & . & 6.5 & 0.5 & . & . \\
\hline & 7.8 & 0.5 & 7.3 & 0.4 & 5.9 & 0.3 & 5.4 & 0.3 \\
\hline & 6.5 & 0.5 & 7.0 & 0.5 & 5.2 & 0.2 & 5.3 & 0.2 \\
\hline & 8.2 & 0.3 & 7.4 & 0.4 & . & . & . & . \\
\hline & 5.4 & 0.3 & 5.2 & 0.3 & 6.1 & 0.6 & 6.3 & 0.5 \\
\hline & 6.2 & 0.4 & 6.8 & 0.4 & 5.5 & 0.2 & 4.8 & 0.3 \\
\hline & 6.0 & 0.3 & 6.0 & 0.2 & 5.6 & 0.5 & 5.4 & 0.3 \\
\hline
\end{tabular}




\section{Appendix D. Summary Statistics for Study 2}

\section{D.1 Aortic Pulsatile Load}

\section{Repeated Measures ANOVA}

\begin{tabular}{llllll}
$\begin{array}{l}\text { Within Subjects } \\
\text { Effect }\end{array}$ & $\begin{array}{l}\text { Mauchy's } \\
\text { W }\end{array}$ & $\begin{array}{l}\text { Approx. Chi- } \\
\text { Squate }\end{array}$ & df & Sig. & $\begin{array}{l}\text { Greenhouse- } \\
\text { Geisser }\end{array}$ \\
\hline Condition & 1.000 & 0.000 & 0 &. & 1.000 \\
Time & 0.970 & 0.275 & 2 & 0.871 & 0.971 \\
Condition * Time & 0.809 & 1.912 & 2 & 0.384 & 0.839
\end{tabular}

\begin{tabular}{|c|c|c|c|c|c|c|}
\hline Source & & $\begin{array}{l}\text { Type III Sum } \\
\text { of Squares }\end{array}$ & df & Mean Square & $\mathbf{F}$ & Sig \\
\hline \multirow[t]{2}{*}{ Time } & $\begin{array}{l}\text { Sphericity } \\
\text { Assumed }\end{array}$ & 4992062.394 & 2 & 2496031.197 & 36.026 & 0.000 \\
\hline & $\begin{array}{l}\text { Greenhouse- } \\
\text { Geisser }\end{array}$ & 4992062.394 & 1.942 & 2571221.759 & 36.026 & 0.000 \\
\hline \multirow[t]{2}{*}{$\begin{array}{l}\text { Time } \mathrm{x} \\
\text { Condition }\end{array}$} & $\begin{array}{l}\text { Sphericity } \\
\text { Assumed }\end{array}$ & 223981.121 & 2 & 111990.561 & 2.121 & 0.146 \\
\hline & $\begin{array}{l}\text { Greenhouse- } \\
\text { Geisser }\end{array}$ & 223981.121 & 1.679 & 133423.595 & 2.121 & 0.156 \\
\hline
\end{tabular}

\section{Paired T-Tests}

95\% Confidence Interval

\begin{tabular}{lllllll} 
& Mean & Lower & Upper & T & df & $\begin{array}{l}\text { Sig. } \\
\text { (2-tailed) }\end{array}$ \\
\hline Pre-E - P10-E & -700.455 & -1026.180 & -374.730 & -4.791 & 10 & 0.001 \\
Pre-E - P30-E & -167.636 & -314.030 & -21.243 & -2.551 & 10 & 0.029 \\
P10-E - P30-E & 532.818 & 275.906 & 789.731 & 4.621 & 10 & 0.001 \\
Pre-C - P10-C & -639.273 & -775.377 & -503.169 & -10.465 & 10 & 0.000 \\
Pre-C - P30-C & -378.455 & -618.576 & -138.333 & -3.512 & 10 & 0.006 \\
P10-C - P30-C & 260.819 & 14.095 & 507.541 & 2.355 & 10 & 0.040
\end{tabular}




\section{D.2 Peripheral Pulse Wave Velocity}

\section{Repeated Measures ANOVA}

\begin{tabular}{llllll}
$\begin{array}{l}\text { Within Subjects } \\
\text { Effect }\end{array}$ & $\begin{array}{l}\text { Mauchy's } \\
\text { W }\end{array}$ & $\begin{array}{l}\text { Approx. Chi- } \\
\text { Squate }\end{array}$ & df & Sig. & $\begin{array}{l}\text { Greenhouse- } \\
\text { Geisser }\end{array}$ \\
\hline Condition & 1.000 & 0.000 & 0 &. & 1.000 \\
Time & 0.895 & 0.995 & 2 & 0.608 & 0.905 \\
Condition * Time & 0.949 & 0.475 & 2 & 0.789 & 0951
\end{tabular}

\begin{tabular}{|c|c|c|c|c|c|c|}
\hline Source & & $\begin{array}{l}\text { Type III Sum } \\
\text { of Squares }\end{array}$ & df & $\begin{array}{l}\text { Mean } \\
\text { Square }\end{array}$ & $\mathbf{F}$ & Sig \\
\hline \multirow[t]{2}{*}{ Time } & $\begin{array}{l}\text { Sphericity } \\
\text { Assumed }\end{array}$ & 3.082 & 2 & 1.541 & 8.527 & 0.002 \\
\hline & $\begin{array}{l}\text { Greenhouse- } \\
\text { Geisser }\end{array}$ & 3.082 & 1.810 & 1.702 & 8.527 & 0.003 \\
\hline \multirow[t]{2}{*}{$\begin{array}{l}\text { Time } x \\
\text { Condition }\end{array}$} & $\begin{array}{l}\text { Sphericity } \\
\text { Assumed }\end{array}$ & 0.048 & 2 & 0.024 & 0.107 & 0.899 \\
\hline & $\begin{array}{l}\text { Greenhouse- } \\
\text { Geisser }\end{array}$ & 0.048 & 1.902 & 0.025 & 0.107 & 0.890 \\
\hline
\end{tabular}

\section{$\underline{\text { Paired T-Tests }}$}

\begin{tabular}{lllllll} 
& \multicolumn{7}{c}{$95 \%$ Confidence Interval } \\
& Mean & Lower & Upper & T & df & Sig. (2-tailed) \\
\hline Pre-E - P10-E & 0.564 & 0.006 & 1.121 & 2.253 & 10 & 0.048 \\
Pre-E - P30-E & 0.118 & -0.215 & 0.451 & 0.791 & 10 & 0.447 \\
P10-E - P30-E & -0.446 & -0.905 & 0.015 & -2.158 & 10 & 0.056 \\
Pre-C - P10-C & 0.446 & 0.100 & 0.791 & 2.871 & 10 & 0.017 \\
Pre-C - P30-C & 0.109 & -0.320 & 0.538 & 0.567 & 10 & 0.583 \\
P10-C - P30-C & -0.336 & -0.730 & 0.057 & -1.906 & 10 & 0.086
\end{tabular}




\section{D.3 Central Pulse Wave Velocity}

\section{Repeated Measures ANOVA}

\begin{tabular}{llllll}
$\begin{array}{l}\text { Within Subjects } \\
\text { Effect }\end{array}$ & $\begin{array}{l}\text { Mauchy's } \\
\text { W }\end{array}$ & $\begin{array}{l}\text { Approx. Chi- } \\
\text { Squate }\end{array}$ & df & Sig. & $\begin{array}{l}\text { Greenhouse- } \\
\text { Geisser }\end{array}$ \\
\hline Condition & 1.000 & 0.000 & 0 &. & 1.000 \\
Time & 0.341 & 7.530 & 2 & 0.023 & 0.603 \\
Condition * Time & 0.810 & 1.475 & 2 & 0.478 & 0.840
\end{tabular}

\begin{tabular}{lllllll} 
Source & & $\begin{array}{l}\text { Type III Sum } \\
\text { of Squares }\end{array}$ & df & $\begin{array}{l}\text { Mean } \\
\text { Square }\end{array}$ & F & Sig \\
\hline Time & $\begin{array}{l}\text { Sphericity } \\
\text { Assumed }\end{array}$ & 0.381 & 2 & 0.191 & 0.798 & 0.467 \\
& $\begin{array}{l}\text { Greenhouse- } \\
\text { Geisser }\end{array}$ & 0.381 & 1.206 & 0.316 & 0.798 & 0.417 \\
$\begin{array}{l}\text { Time } \mathrm{x} \\
\text { Condition }\end{array}$ & $\begin{array}{l}\text { Sphericity } \\
\text { Assumed }\end{array}$ & 0.203 & 2 & 0.102 & 0.709 & 0.507 \\
& $\begin{array}{l}\text { Greenhouse- } \\
\text { Geisser }\end{array}$ & 0.203 & 1.681 & 0.121 & 0.709 & 0.486
\end{tabular}

